\title{
Smoking prevention in Dutch adolescents
}

Citation for published version (APA):

de Vries, H. (1989). Smoking prevention in Dutch adolescents. [Doctoral Thesis, Maastricht University]. Rijksuniversiteit Limburg. https://doi.org/10.26481/dis.19891214hd

Document status and date:

Published: 01/01/1989

DOI:

10.26481/dis.19891214hd

Document Version:

Publisher's PDF, also known as Version of record

\section{Please check the document version of this publication:}

- A submitted manuscript is the version of the article upon submission and before peer-review. There can be important differences between the submitted version and the official published version of record.

People interested in the research are advised to contact the author for the final version of the publication, or visit the DOI to the publisher's website.

- The final author version and the galley proof are versions of the publication after peer review.

- The final published version features the final layout of the paper including the volume, issue and page numbers.

Link to publication

\footnotetext{
General rights rights.

- You may freely distribute the URL identifying the publication in the public portal. please follow below link for the End User Agreement:

www.umlib.nl/taverne-license

Take down policy

If you believe that this document breaches copyright please contact us at:

repository@maastrichtuniversity.nl

providing details and we will investigate your claim.
}

Copyright and moral rights for the publications made accessible in the public portal are retained by the authors and/or other copyright owners and it is a condition of accessing publications that users recognise and abide by the legal requirements associated with these

- Users may download and print one copy of any publication from the public portal for the purpose of private study or research.

- You may not further distribute the material or use it for any profit-making activity or commercial gain

If the publication is distributed under the terms of Article $25 \mathrm{fa}$ of the Dutch Copyright Act, indicated by the "Taverne" license above, 


\section{Smoking prevention in Dutch adolescents}




\section{Smoking prevention in Dutch adolescents}

\section{PROEFSCHRIFT}

ter verkrijging van de graad van doctor

aan de Rijksuniversiteit Limburg te Maastricht, op gezag van de Rector Magnificus, Prof. Dr. F.I.M. Bonke, volgens het besluit van het College van Dekanen, in het openbaar te verdedigen op donderdag, 14 december 1989 om 16.00 uur

door

Hein de Vries geboren te Ten Boer in 1956 


\section{Smoking prevention in Dutch adolescents}

\section{PROEFSCHRIFT}

ter verkrijging van de graad van doctor

aan de Rijksuniversiteit Limburg te Maastricht, op gezag van de Rector Magnificus, Prof. Dr. F.I.M. Bonke, volgens het besluit van het College van Dekanen, in het openbaar te verdedigen op donderdag, 14 december 1989 om 16.00 uur

door

Hein de Vries

geboren te Ten Boer in 1956 


\section{Promotores:}

Prof. Dr. G.J, Kok

Prof. Dr. L.W. Green

Beoordelingscomissie:

Prof. Dr. H. Philipsen (voorzitter)

Dr. R. Knibbe

Prof. Dr. R. Maes

Prof. Dr. G. Parcel

Dr. A. Visser

CIP DATA KONINKLIJKE BIBLIOTHEEK, DEN HAAG

Vries, Hein de

Smoking prevention in Dutch adolescents / Hein de Vries.

Maastricht : Datawyse. - Ill.

Thesis Maastricht. - With ref. - With summary in Dutch.

ISBN 90-5291-014-6

SISO 614.71 UDC [659.2:613.84:3-053.6](492)(043.3)

Subject headings: smoking prevention : the Netherlands

Produktie en layout: Datawyse Maastricht, Ruud Leliveld

Omslagontwerp: Hein de Vries

Druk: Krips Repro Meppel

The Dutch Smoking Prevention Project was supported by a grant from the Dutch Cancer Foundation

Financial support by the Catherina Pijls Foundation and the Netherlands Heart Foundation for the publication of this thesis is gratefully acknowledged. 
To Trudy and Rutger 


\section{Content}

\section{Preface 9}

1. General introduction $\quad 1 I$

1.1 Introduction 11

1.2 Health education 12

1.2.1 The PRECEDE model 12

1.2.2 The applied research model 13

1.3 Smoking prevention 13

1.3.1 Smoking prevalence and incidence in the Netherlands 14

1.3.2 Social learning theory 14

1.3.3 Theory of reasoned action 15

1.3.4 The onset of smoking 16

1.3.5 Early smoking prevention programs $\quad 16$

1.3.6 The social influence approach $\quad 17$

1.3.7 Innovations of the social influence approach 17

1.3.8 Didactic components of smoking prevention programs 18

1.3.9 Behavioral impact of smoking prevention programs 20

1.4 The Dutch smoking prevention project 21

1.4.1 Models used in this study 22

2. From determinants of smoking behavior to the implications for a prevention program 29

$2.1 \quad$ Introduction 30

$2.2 \quad$ Method 32

$2.3 \quad$ Results 33

2.3.1 Demographic findings 33

2.3.2 Correlations between variables 34

2.3.3 Attitude towards smoking 34

2.3.4 Subjective norm towards smoking 37

2.3.5 Intentions towards smoking 39

2.4 Discussion 40

2.5 Implications for a smoking prevention program $4 I$ 
3. Self-efficacy: the third factor besides attitude and subjective norm as apredictor of behavioral intentions $\quad 47$

$3.1 \quad$ Introduction 48

3.1.1 Attitudes and subjective norms 48

3.1.2 Self-efficacy 49

$3.2 \quad$ Model for behavioral change 52

3.3 Method 53

3.3.1 Sample 53

3.3.2 Questionnaire 53

3.3.3 Procedure 54

3.4 Results 55

3.4.1 Correlations between attitude, subjective norm and self-efficacy 55

3.4.2 Smokers and non-smokers: attitude and subjective norm 57

3.4.3 Differences in self-efficacy 58

3.5 Summary and conclusions 59

4. The development of a peer-led smoking prevention program on video 65

4.1 Introduction 66

4.2 Planning 67

4.3 Behavioral change and information processing 68

4.4 Method 71

4.4.1 Program preparation: analysis of the smoking problem 71

4.4.2 Program development: behavioral change $\quad 72$

4.4.3 Questionnaire 75

4.4.4 Program implementation 75

4.5 Results 75

4.6 Conclusions and discussion $\quad 79$

5. Results of a video smoking prevention program in Dutch schools 83

$5.1 \quad$ Introduction 84

5.2 Method 87

5.2.1 The program 87

5.2.2 Design and sampling 87

5.2.3 Questionnaire and measures 88

5.2.4 Risk categories 88

5.2.5 Analysis 89

$5.3 \quad$ Results 90

5.3.1 General behavioral effects 91 
5.3.2 Program effects as a function of type of school 92

5.3.3 Program effects as a function of social norm risk 92

5.4 Conclusions and discussion 94

6 Discussion and conclusions 101

6.1 What do we know; a summary of the major findings 101

6.1.1 The determinants study 101

6.1.2 The impact of self-efficacy 103

6.1.3 The development of the program 104

6.1.4 Behavioral effects of the program 106

6.2 Important developments in smoking prevention and health education 109

6.2.1 The target group 109

6.2.2 The impact of peers 111

6.2.3 Information processing 114

6.2.4 Smoking prevention: health education or health promotion 116

6.2.5 Diffusion 119

6.3 Methodological issues 121

6.4 Implications for smoking prevention 124

Summary $\quad 129$

Samenvatting $\quad 133$

Curriculum Vitae $\quad 137$ 


\section{Preface}

Being involved in this smoking prevention project implied more than I could have imagined at its start in September 1984. On the whole I found it a far more interesting experience than I had expected, for instance: learning to understand (not to speak, unfortunately) the local dialect in order to understand the adolescents during the group interviews, learning how to be a producer of the film team during the hectic times of the development of the video, and learning how to cope with the enormous amount of data that had to (and still has to..) be analyzed, and learning how to write papers.

During these periods I have received much help from my research assistants, and I therefore want to thank Resi Borgers, Margo Dijkstra, Ingeborg Hoekstra, Ellen Themmen and Jaap Toet for their support in various stages of the project. I would also like to thank the students, teachers, and staff of the schools, and many others who have been involved in the project. I especially want to thank those who served as contact persons and were responsible for the organization within the schools and the contacts with our project.

As English is not my native language I am glad that the writing of the various chapters of this dissertation was facilitated by detailed corrections from Chris Sion, Tineke van de Noort, and Jan Klerkx.

I should like to thank all my colleagues for their support they have given. In particular, I want to thank Gerjo Kok. Apart from being the initiator of this project, he guided me through the whole process from apprentice to senior researcher, as he now calls me (although I still do not feel old and wise enough to fit this description). Larry Green and Guy Parcel provided much support by their stimulating editorial comments, and our discussions about the project. I would also like to thank Harm Hospers and Paul Geelen for their assistance in working with the computer and for coping with the many irritating problems. The project also benefitted from the secretarial support given by Helene Vermeer and Marja Slangen.

Over the last few months I also received much support from Margo Dijkstra and Resi Borgers with respect to finishing the dissertation and organizing attendant procedures. 
Last, but certainly not least, I want to thank my wife Trudy. Besides correcting and checking all the draft versions and helping me with the organization of procedures, she provided much support and encouragement in writing and finishing this dissertation, which helped me a great deal at the right times. Thank you, Trudy. 


\section{General introduction}

\section{$1.1 \quad$ INTRODUCTION}

Cancer and cardiovascular diseases constitute the two most important health concerns of our society today. It is estimated that regarding cancer 80 percent of cancer cases are linked to lifestyle and environmental factors (Doll \& Peto, 1981; Higginson \& Muir, 1979; Wynder \& Gori, 1977). The most striking example of voluntary high-risk behavior is cigarette smoking, which is directly related to approximately $30 \%$ of all cancer cases (and to $90 \%$ of all lung cancer cases), $75 \%$ of the mortality due to asthma, emphysema and bronchitis (COLD), and $25 \%$ of mortality due to coronary heart diseases. Smoking is thus associated with 350,000 deaths in the United States per year (Janicki \& Braverman, 1986), and with 18,000 deaths in the Netherlands (Dutch Foundation on Smoking and Health, 1988). This makes a strong case for smoking control activities such as smoking cessation and smoking prevention.

This dissertation reflects the process of development and evaluation of a Dutch smoking prevention program, "Non-Smoking, your choice!", from 1984 to 1989. Many issues needed elaboration in this process. The first step was planning the intervention, the second the development of the intervention, and the third was to evaluate the intervention. These steps will be described in the following chapters. A next step will hopefully be the diffusion of the program on a larger scale.

In this introduction we will first start with providing some general background information about health education and planning models for health education. We will then discuss smoking in the Netherlands and theories on smoking onset, followed by a short review on the history of smoking prevention and its innovations. Finally, we will describe the Dutch smoking prevention project. 


\subsection{HEALTH EDUCATION}

Health education may be described as any combination of learning experiences designed to predispose, to enable, and to reinforce voluntary adaptations of individual or collective behavior conducive to health (Green, 1986). The focus of health education is on people and action. In general, its aims are to persuade people to adopt and sustain healthful life practices, to use judiciously and wisely the health services available to them, and to take their own decisions, both individually and collectively, to improve their health status and environment (wHO, 1974). Health education focusses on motivating people to adopt healthful lifestyles (Kok, 1988). Health education often means information and communication, and thus developing programs or campaigns.

One of the most essential elements determining the effect of health education is the quality of planning (Green et al., 1980; Jonkers et al., 1988). Therefore, two planning models are described that had a strong impact on the process of development and evaluation of the Dutch smoking prevention program.

\subsubsection{The PRECEDE model}

One of the most well known planning models in health education is the PRECEDE framework. PRECEDE stands for Predisposing, Reinforcing, and Enabling Causes in Educational Diagnosis and Evaluation (Green et al., 1980). The model is a framework for planning and evaluation of health education activities. Successful application, therefore, depends on the users' ability to utilize and to integrate several relevint theories and empirical findings, and to define the variables in each category of the planning model.

The model distinguishes four basic stages. In the first stage, the epidemiological and social diagnosis, general problems and specific health problems, which effect both health status and "quality of life", are identified in a population. The second stage, the behavioral diagnosis, consists of identifying the specific factors that are linked to the health problem chosen. These factors include those having a behavioral nature (e.g. smoking, consumption patterns), and those having a non-behavioral nature (e.g. genetic, economic, and environmental factors). The third step, the educational diagnosis, is the assessment of predisposing, enabling, and reinforcing factors related to the health behaviors of interest. Predisposing factors include the target population's attitudes, values, knowledge, and perceptions about the behaviors identified in the previous stage. 
Enabling factors include the skills and resources that are necessary for the performance of health-related behaviors. Reinforcing factors include attitudes and behaviors of significant others within the environment that provide support for performance of the specific behaviors. The fourth step is the development and implementation of a program. Evaluation is considered to be an integral and continuous part of working with the entire framework.

\subsubsection{Applied Research Model}

In his model on applied research Kok (1988) distinguishes four steps in the process of problem solving. As it is a general model, it is applicable to a variety of problems such as pollution, use of safety-belts, smoking, excessive alcohol use, etc.. As with the PRECEDE model, the model needs to be specified for the target behavior, and, thus, can be specified for health problems.

The first step is the problem analysis. With regard to health problems, assessments should be made of the importance of the health problems and the relation of a health problem with human behavior. The second step focusses on the analysis of the determinants of the behaviors that are related with the health problem. The Fishbein \& Ajzen (1975) model is used to assess the attitudinal and social determinants of behavior. The third step is on influencing the behaviors by motivating people to behave more healthfully. Social psychological theories of McGuire (1985) and Rogers (1983) are used to formulate clear goals on behavioral change. For instance, an intervention should attract attention, its content needs to be clearly understood by the target group, and the message should focus on the relevant determinants to enhance behavioral change and maintenance (Kok, 1985). The fourth step is the evaluation of the effect of the intervention, and the reasons for its success or failure. In each step contributions of other disciplines, such as sociology, epidemiology, psychology, need to be used. Health education is thus utilizing findings of several disciplines.

\subsection{SMOKING PREVENTION}

The application of planning models in health education research has become more thorough in the last two decades. The early smoking prevention programs assumed that the major determinant of smoking was a lack of knowledge about its dangers. In the seventies smoking prevention programs were better planned: 
the application of, for instance, social leaming theory to smoking behavior resulted in an increased awareness of the major determinants of smoking. Moreover, program evaluations were conducted comparing the results of an experimental group with those who received no program. We will focus on smoking in the Netherlands and the theories on smoking onset in the next section, followed by a discussion about the smoking prevention programs.

\subsubsection{Smoking prevalence and incidence in the Netherlands}

Smoking was very popular among men in 1950 in the U.S. and in the Netherlands. About $90 \%$ of the male population of 15 years and older were smokers in 1958 compared to $29 \%$ of the women (Dutch Foundation on Smoking and Health, 1987). Since then smoking prevalence has dropped significantly during the last decades among men to $42 \%$ in 1986 . Women took up smoking rather vigorously during the sixties. This increase has been described as being the result of the emancipation effect (Van Reek \& Adriaanse, 1987). However, smoking prevalence in women has reduced from $42 \%$ in 1970 to $34 \%$ in 1986 (Dutch Foundation on Smoking and Health, 1988). Corresponding trends can be observed with regard to adolescent smoking.

Although smoking prevalence has declined from $22 \%$ in 1979 to $11 \%$ in 1983 among adolescents until age fifteen, smoking prevention remains necessary (De Vries \& Kok, 1986). Many adolescents still take up smoking between 10 and 15 years in the United States (see e.g. Cleary et al., 1986), and in the Netherlands (Van der Rijt, 1979; Dutch Foundation on Smoking and Health, 1984-1988). Figures from the Dutch Foundation on Smoking and Health show that during the last 6 years smoking incidence for adolescents aged 10 to 14 fluctuates between $19 \%$ and $26 \%$ (table 1.1). Smoking prevention activities are therefore necessary to reduce smoking in youth.

Before developing interventions it is, however, necessary to know the determinants of smoking. Therefore, two major theories applicable for the study of the determinants will be discussed: the social leaming theory of Bandura (1977), and the theory of reasoned action of Fishbein \& Ajzen (1975). Finally, a description of the different stages in smoking onset will be given.

\subsubsection{Social learning theory}

Social learning theory (Bandura, 1977, 1986) stresses the importance of vicarious learning or modeling. This concept refers to the process that an in- 
Table 1.1: smoking incidence from 1983-1988 in adolescence; the figures describe regular smoking, meaning smoking at least one cigarette per year (Data obtained from Dutch Smoking and Health Foundation).

\begin{tabular}{lrrrrrr}
\hline age & 1983 & 1984 & 1985 & 1986 & 1987 & 1988 \\
\hline 10 & $2 \%$ & $1 \%$ & $0 \%$ & $1 \%$ & $0 \%$ & $0 \%$ \\
11 & $1 \%$ & $1 \%$ & $2 \%$ & $1 \%$ & $0 \%$ & $1 \%$ \\
12 & $4 \%$ & $2 \%$ & $6 \%$ & $3 \%$ & $2 \%$ & $2 \%$ \\
13 & $9 \%$ & $9 \%$ & $11 \%$ & $11 \%$ & $6 \%$ & $8 \%$ \\
14 & $21 \%$ & $23 \%$ & $26 \%$ & $20 \%$ & $22 \%$ & $19 \%$ \\
$15,16^{1}$ & $16 \%$ & $13 \%$ & $18 \%$ & $15 \%$ & $12 \%$ & $12 \%$ \\
$17-19^{1}$ & $30 \%$ & $26 \%$ & $24 \%$ & $28 \%$ & $28 \%$ & $24 \%$ \\
$20-24^{1}$ & $43 \%$ & $42 \%$ & $39 \%$ & $42 \%$ & $39 \%$ & $35 \%$
\end{tabular}

${ }^{1}$ smoking behavior has been assessed in a family situation among adolescents older than 14 years, while it has been assessed by interviews on the street among the younger adolescents.

dividual learns by observing others performing a behavior that leads to reinforcement. Observation of reinforcement can provide vicarious reinforcement for the observer. Models can both inform and motivate. According to social learning theory adolescents learn about smoking and the positive and negative consequences of smoking by watching peers and adults smoke. According to social learning theory there are four central processes that determine learning (see also Cleary et al., 1986): 1. attention (e.g. watching friends smoke), 2. retention (e.g. remembering positive outcomes of smoking, such as receiving attention, looking cool), 3. motor reproduction (e.g. experimenting with cigarettes), 4. motivation or incentives (e.g. peer pressure, peer acceptance).

The social learning theory also indicates that self-efficacy expectations are important for a person's decision to perform a specific behavior. Self-efficacy refers to a persons' expectation about his abilities to perform a specific behavior. The role and significance of self-efficacy expectations are discussed in chapter 3.

\subsubsection{Theory of reasoned action}

The theory of Fishbein \& Ajzen (1975) argues that behavior can best be predicted by the behavioral intention, which is determined by the individual's 
attitude and the perceived subjective noms of other people. An attitude represents a person's general feeling of (un)favorableness towards a behavior (e.g. smoking is bad). The attitude is determined by: 1 . the expectation of various beliefs (b) about the consequences of the behavior and 2 . the corresponding evaluations (e) of these effects. It is measured as follows: Attitude $=\Sigma$ b.e.

The subjective norm is the perception of whether the majority of important people thinks that the person should or should not perform the behavior. Subjective norms are formed by: 1 . the expectation of other important persons' opinions, their normative beliefs (nb) about the behavior, and 2 . the degree to which an individual is inclined to agree with these opinions, the motivations to comply (mc). The subjective norm can be determined as follows: Subjective norm $=\Sigma$ nb.mc.

\subsubsection{The onset of smoking}

The process of becoming a smoker can be divided into several stages (Leventhal \& Cleary, 1980; Flay et al., 1983; De Vries \& Kok, 1986). In the first preparatory stage, attitudes towards (initial) smoking are formed by influences from family, friends and the media. The second stage is the initiation of smoking. Initial smoking can lead to regular smoking. Although at least $90 \%$ of the population has ever smoked a cigarette, the likelihood of becoming a regular smoker increases if initial smoking is repeated more than four or five times. Studies suggest that this can cause addiction for 70 to $90 \%$ of the initial smokers. Chances of addiction further increase if the time interval between the first cigarettes is short (Hirschman et al., 1984). The third stage is the experimental stage in which a child learns how to smoke. In this period the negative (physiological) effects disappear while the positive (psychological) experiences are reinforced. The fourth stage concerns regular smoking. The positive consequences of smoking have become part of the personality of the child. At every stage each individual can decide to stop smoking, although this decision will be easier for initial smokers.

\subsubsection{Early smoking prevention programs}

The early smoking programs in both the U.S. and the Netherlands were similar to general health curricula and were based on a simple communication model that stressed the importance of the dangers of smoking. The assumption was that such a message would change children's attitudes towards smoking, and that 
would lead to fewer children who would start smoking (Thompson, 1978). The effects of these programs, however, were rather small and were mostly limited to an increase in knowledge, but had no significant effects on smoking behavior (Leventhal \& Cleary, 1980). One of the reasons for the failure of this approach was that childrens decisions are not based upon their knowledge about the dangers of smoking, but upon a variety of psychological and social motives. As stated before, a careful analysis of the smoking problem and its determinants was lacking in these early smoking programs.

\subsubsection{The social influence approach}

Richard Evans and colleagues (Evans et al., 1978) developed a new approach to smoking prevention in 1976. According to Evans" assumption health, personal and social factors are important to explain the development of smoking behavior in an individual. Smoking prevention programs should focus more on short-term effects of smoking, because the traditional long-term effects such as cancer, are less relevant and salient for adolescents.

Another major contribution is the focus on the impact of direct social pressures. Adolescents, according to Evans, start to smoke due to pressure to smoke exerted by parents, the media and, most important, the smoking peers. Direct pressure refers to a variety of behaviors, such as offering a cigarette, persuasion, challenging, and pestering. This pressure is often stronger than the mostly initial negative attitudes of adolescents towards smoking. Therefore, smoking programs should focus on increasing resistance in non-smoking adolescents towards these pressures. In order to increase resistance, Evans applied McGuire's inoculation theory (McGuire, 1964) by confronting non-smoking students with arguments of smokers to start smoking. This confrontation will activate resistance and counter-arguments in non-smokers which will make them cope more effectively with pressure to smoke. Evans was thus one of the first researchers who explicitly applied principles of social learning theory to the development of smoking prevention programs. He especially stressed the impact of direct social influences.

\subsubsection{Innovations of the social influence approach}

The work of Evans stressed the impact of direct pressures. However, indirect social influences are important as well. They refer to the impact of smoking models on the attitude of a non-smoker. By observing positive outcomes with 
smoking, a non-smoker can start to believe that smoking has some advantages. This process, which is described above as vicarious leaming, can initiate changes within the belief system of non-smokers. The impact of indirect pressure is often hard to demonstrate. Adolescents probably do not feel pressure to smoke by observing smoking people, or by observing cigarette advertisements. However, indirect pressure can result in changing beliefs on smoking in nonsmokers. Some studies support the idea of indirect pressure. When non-smoking adolescents grow older they associate more advantages with smoking (De Vries \& Kok, 1988). Observing a friend smoking without having any obseryable disadvantages, causes a non-smoker to perceive himself as less vulnerable to the negative effects of smoking (Urberg \& Robbins, 1984). Adolescents don't report pressure to smoke, although the onset of smoking does take place within a social context (Friedman et al., 1985). In conclusion, both direct and indirect pressures play an important role in influencing a person's decision (not) to smoke.

Moreover, several researchers stressed the need to focus more thoroughly on skills training, as they felt that increased resistance would not be enough to enhance good behavioral performance of refusal skills.

Many researchers elaborated on Evans' work but have included important innovations that resulted in successful programs (Aarö et al., 1983; Best et al., 1984; Biglan et al, 1983, 1987; Botvin et al., 1983; Flay et al., 1983, 1985; Hurd et al., 1980; McAlister 1979, 1980; Murray et al., 1984; Murray et al., 1987; Perry et al., 1983; Schinke et al., 1985; Telch et al., 1982; Tell et al., 1984; Vartianen et al., 1986). A summary of the major didactic components of these programs will be given in the next section. Overviews have been given by, for instance, Best et al., 1988; Botvin, 1986; Cleary et al., 1986; Flay, 1985; Janicki \& Braverman, 1986; and Tobler, 1986.

\subsubsection{Didactic components of smoking prevention programs}

One of the problems in comparing the programs is that, while studies carefully describe the behavioral effects of interventions, less attention is given to a detailed description of the program, which hinders an accurate reference to the projects using them.

Skills training. Most programs include a training of refusal skills which are practiced by role-playing. The goal is to increase self-efficacy and assertiveness in non-smoking adolescents with regard to their (maintenance) of non-smoking behavior. The so-called social influence programs focus mostly on increasing refusal skills, while more broad-based programs (see e.g. Botvin, 1986) also 
include teaching more generic personal and sociall skills. Some programs include a section on the alternatives a non-smoker has for realizing the positive outcomes of smoking by other behaviors.

Peer leaders. Several studies use a peer-led system in which an adolescent of comparable age introduces the program. The advantages of a peer-led system are increased attractiveness and comprehensibility of the program (De Vries \& Borgers, 1988), and increased chances of imitation of the non-smoking behavior of the peer leader (Klepp et al.,1986). Programs differ with regard to the selection, the utilization and training of peer leaders. With respect to the selection some programs choose older students as peer leaders (Arkin et al., 1981; Botvin \& Eng, 1982; Hurd et al., 1980; Murray et al., 1984; Perry et al., 1980; Telch et al., 1982; Tell et al., 1984; Vartianen et al., 1986), while other programs use same age peer leaders (Evans et al., 1978; Murray et al., 1984; Perry et al., 1987). The latter approach has also been used in our study. With regard to their selection, some programs select the peer leader on natural leadership qualities (Botvin \& Eng, 1982; Puska et al., 1981), while in the program of Arkin et al. (1981) students can choose their own peer leaders. Other studies use peer leaders on video-tapes only (Best et al., 1984; Evans et al., 1978).

Active learning. Some programs include active learning techniques: instead of providing students with information, students are stimulated to search for relevant information. This will stimulate them to discover lacks with respect to their knowledge about smoking, which will make them more open for new information (Flay et al., 1983).

Repetition. Some programs provide booster sessions by which the major issues of the program is repeated several months later (Clarke et al., 1986; Best et al., 1984; Dielman et al., 1985; Flay et al., 1985).

Commitment. Commitment techniques can be used to increase chances of behavior maintenance. Students are asked to commit themselves publicly (Best et al., 1984; Biglan et al., 1987; Hurd et al., 1980; Johnson et al., 1986; Murray et al., 1984) or anonymously to their non-smoking behavior. The preventive impact of commitment is the result of the fact that others are aware of a person's decision and thus may exert control. Moreover, if a person has committed himself to a decision, bolstering will occur. Compared to the disadvantages, the advantages of the chosen behavior will be perceived more strongly by the person (Janis \& Mann, 1977). 


\subsubsection{Behavioral impact of smoking prevention programs}

A crucial factor with regard to correct assessments of a programs' impact constitute the self-reports of adolescents on smoking behavior. To increase self-report validity, smoking prevention studies use biochemical measures, such as saliva thiocyanate, expired carbon monoxide or cotinine samples. Another method is the so-called bogus-pipeline procedure by which students are made to believe that their self-reports will be checked by biochemical validation. Although an actual validation does not occur, this method increases self-report validity (Evans et all, 1978).

Several methods to check the validity of the self-reports are available. Blood or saliva cotinine samples give a accurate indication of smoking status (Luepker et al., 1981), but is a very expensive method, just as blood and saliva thiocyanate samples. Measurement of the amount of carbon-monoxide, although having the shortest half-time, is less expensive, and gives a valid indication of smoking status as well (Pechacek et al., 1984).

During the last five years many thorough reviews have been written about the smoking prevention projects that have been developed since Evans' work (see e.g. Best et al,, 1988; Botvin, 1986; Cleary et al., 1986; Flay et al., 1985; Tobler, 1986). Studies on the effects of smoking prevention programs show a generally consistent pattern: after the experimental group has received the program, smoking incidence is lower compared to the control group. Botvin (1986) concludes that the reported results generally range from reductions of $33 \%$ to $39 \%$ if the effects concern the proportion of new smokers, reductions of $29 \%$ to $67 \%$ if the reductions pertain to experimental smoking (less than one cigarette per week), and reductions of $43 \%$ to $47 \%$ with regard to regular smoking (at least one cigarette per week). The inconsistency in specific program effects is hardly surprising, because the studies vary on at least six major dimensions: the scope of the curriculum, its conceptual underpinnings, teaching/delivery methods, specific parameters such as number and spacing of sessions, the intended target population, and the nature of the control group used to assess treatment impact (Best et al., 1988). One of the major challenges for future projects is to focus more explicitly on the impact of specific program modalities. 
The Dutch smoking prevention project started in September 1984 and ended in December 1989 (see figure 1.1). The ultimate goal of the project was to develop and to evaluate a smoking prevention program to enhance prevention of smoking in adolescents. This process can be divided in the three phases that are described below.

The first phase of the project consisted of determining the most salient beliefs of non-smokers and smokers about smoking and non-smoking. In a pilot study the most salient beliefs about smoking, non-smoking and experimental smoking were analyzed (see also De Vries \& Kok, 1988), as beliefs of these behaviors determine an individual's decision (not) to smoke (Fishbein, 1977). Both openended questionnaires and group interviews indicated that smoking and nonsmoking were associated with the same consequences. Experimental smoking, however, was linked with different consequences. In the study on the determinants of smoking behavior, two behaviors were included: initial smoking and regular smoking. The results of this study are described in chapter 2 .

The second phase had two major goals. The first goal was to develop a smoking prevention program for adolescents aged 13 and 14 . In this process, insights derived from the study on the determinants were utilized together with findings of other smoking prevention studies and models on behavioral change. This process is described in chapter 4 (see also De Vries \& Dijkstra, 1989). The second goal was to test the assumption whether self-efficacy expectations constituted a third factor for predicting smoking behavior, apart from attitudes and subjective norms. The results of this study are described in chapter 3 .

The third phase consisted of implementing the program in the experimental schools in November and December 1986, and the evaluation of the program. The acceptability of the program was assessed by questionnaires and interviews in December 1986 and January 1987. This process is described in chapter 4. Another goal was to assess the behavioral impact of the program. The increase in smoking behavior has been analyzed by comparing smoking behavior of the experimental group with the control group. The pretest was in September 1986, the first posttest was in May 1987, while the second posttest was in September 1987. The behavioral effects are discussed in chapter 5 . 


$\begin{array}{ll}1984-1985 & \text { Study on the determinants of initial and regular smoking } \\ 1985-1986 & \text { Development of a peer-led program on video } \\ \text { Sept } 1986 & \text { Pretest } \\ \text { Nov, Dec 1986 } & \text { Program implementation for the experimental group } \\ \text { Jan 1987 } & \text { Process evaluation } \\ \text { June } 1987 & \text { Posttest 1 } \\ \text { Sept 1987 } & \text { Posttest } 2\end{array}$

Figure 1.1: Overview of activities of the Dutch smoking prevention project

\subsubsection{Models used in this study}

The Fishbein \& Ajzen model, which has been discussed before, was used to assess the determinants of smoking in adolescents. However, the results of the determinants study and the group interviews that preceded this study, indicated that this model did not address the relevant factors on smoking behavior completely. As a consequence, the model on the determinants was revised during the process of the development of the smoking prevention program. The extensions on the model will be described briefly.

The first factor that was added to the model relates to self-efficacy expectations. The group interviews, for assessing the salient beliefs about smoking, indicated that adolescents doubted that they had the capabilities to resist peer pressure. Therefore, a special study was developed to test whether self-efficacy expectations could be considered as a third factor besides attitudes and subjective norms. This study is described in chapter 3 , and its findings strongly suggested the need for extension of the model with the self-efficacy concept.

A second modification involved a refinement with regard to the assessment of the effects of social influences. According to the Fishbein \& Ajzen model the impact of social influences are assessed mainly by measuring the subjective social norms. However, the results from the study on the determinants suggested that adolescents did not feel much social influence of peers against smoking. One explanation of this finding was that the students were not willing to admit that they experienced pressure. Another explanation, which does not preclude the former, is that adolescents did not recognize or label these influences as pressure (see also Friedman et al., 1985, and Newman, 1984). It is also conceivable that adolescents may perceive a neutral norm on smoking from their peers, but experience pressure from a specific small group as well. We 
therefore concluded that measuring the subjective norms may not be the optimal method to assess the impact of social influences. Our assumption was that the impact of social influences can be the result of social norms, direct pressures, and perceived behavior of others (modeling).

Therefore, in concordance with Evans' (1976) conception about the importance of direct pressure, the concept of direct pressure has been added to the model. In the study on the effects of the program, direct pressure was assessed by measuring whether students experienced pressure to smoke from their parents, peers, friends, brothers and sisters, teachers, and relatives.

The impact of modeling in general (Bandura, 1986), and of smoking models on smoking onset in particular is widely recognized and discussed (see e.g. Aarø et al., 1981; Flay et al., 1983; Janicki \& Braverman, 1986; Green et al., 1980; Leventhal \& Cleary, 1980; McCaul et al., 1982; Newman, 1984; Spielberger et al., 1983). In the study measuring the effects of the program, the impact of indirect influences, as perceived by the student, was assessed by measuring smoking behavior of parents, peers, friends, brothers and sisters, teachers, and relatives.

Knowledge beliefs have been measured in the study on the effects of the program as well, as many evaluation studies have included this factor (see e.g. Flay et al., 1983; McCaul \& Glasgow, 1985).

In sum, the following model (abbreviated as ASE model) has been formulated to address attitudes, social influences and self-efficacy expectations to describe smoking intentions and behavior at the pretest and the posttests (see figure 1.2). Attitudes were assessed by measuring knowledge, psychological and health beliefs. Social influences were assessed by measuring subjective social norms, perceived behavior and direct pressure. The predictive value of the factors on the prediction of smoking behavior will be considered in more detail in chapter 6.

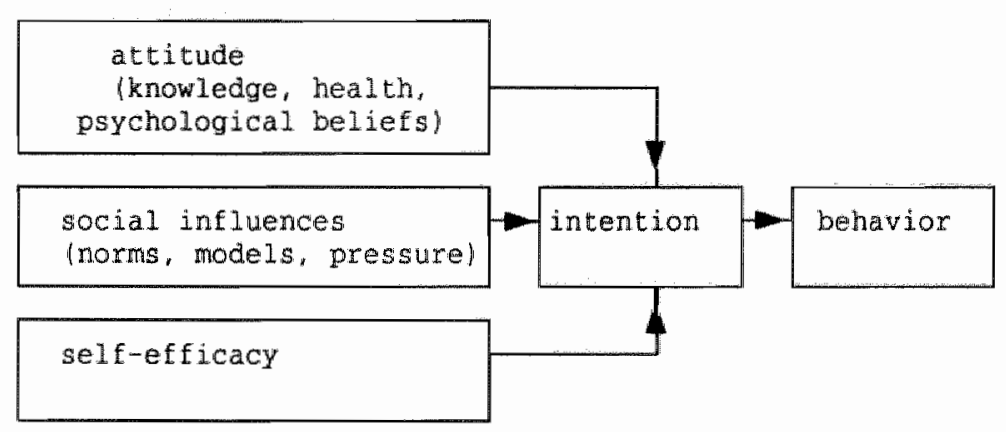

Figure 1.2: Model on explaining behavior 


\section{REFERENCES}

Aaro, L.E., Hauknes, A. and Gerglund, E.L. (1981) Smoking among Norwegian schoolchildren 1975-1980. It. The influence of social environment. Scandirwavian Joumal of Psychology. $22,297-309$.

Aarø, L.E, Bruland, E., Hruiknes, A. \& Lochser, P.M. (1983) Smoking among Norwegian schoolchildren 1975-1980. III. The effect of antismoking campaigns. Scandinavian Journal of Psychology, 24, 277-283.

Arkin, R.M., Roernhild, H.F., Johnson, L.A., Luepker, R.V. \& Murray, D.M. (1981) The Minnesota Smoking Program. The Journal of School Health, November, 61 1-616.

Bandura, A. (1986) Social Foundations of thought and action: a social cognitive theory. New York: Prentice-Hall.

Bandura, A. (1977) Self-efficacy: toward a unifying theory of behavior change. Psychological Review, 84, 191-215.

Best, J.A. Flay, B.R., Towson, S.M.J., Ryan, K.B., Perry, C.L., Brown, K.S., Kersell, M.W. \& D'Avernas, I. (1984) Smoking prevention and the concept of risk. Journal of Applied Social Psychology, 14, 257-273.

Best, J.A., Thomson, S.J., Santi, S.M. 。 Smith, E.A. \& Brown, K.S., (1988) Preventing cigarette smoking among school children. Annual Review of Public Health, 9, 161-201.

Biglan, A., Severson, H. Bavry, J. \& McConnel, S., (1983) Social influence and adolescent smoking: A first look behind the barn. Health Education, 14-18.

Biglan, A., Glasgow, R., Ary, D., Thompson, R., Severson, H., Lichtenstein, E., Weisman, W., Faller, C. \& Gallison, C. (1987) How generalizable are the effects of smoking prevention programs? Refusal skills training and parent messages in a teacher-administered program. Journal of Behavioral Medicine, 10, 613-628.

Botvin, G.J. (1986) Substance abuse prevention research: Recent developments and future directions. Journal of School Health, 9, 369-374.

Botvin, G.J. \& Eng, A. (1982) The efficacy of a multicomponent approach to the prevention of cigarette smoking. Preventive Medicine, 11, 199-211.

Botvin, G.J., Renick, N.L. \& Baker, E. (1983) The effects of scheduling format and booster sessions on a broad-spectrum psychosocial approach to smoking prevention. Journal of Behavioral Medicine, 6, 359-379.

Clarke, J.J., MacPherson, B., Holmes, D.R. \& Jones, R. (1986) Reducing adolescent smoking: Comparison of peer-led, teacher-led, and expert interventions. Journal of School Health, 56, $102-106$.

Cleary, P.D. Hitchcock, J.L., Semmer, N., Flinchbaugh, L.J. \& Pinney, J. (1986) Smoking Behavior and Policy. Discussion Paper Series. Cambridge: Institute for the study of smoking behavior and policy "Harvard University.

De Vries, H., Borgers, R. \& Kok, G.J. (1988) Niet roken; jouw keuze. De ontwikkeling van een rookpreventieprogramma [Non-smoking: your choice. The development of a smoking prevention program]. GVO-Preventie, 9, 169-178.

De Vries, H. \& Dijkstra, M. (1989) Non-smoking: your choice, a Dutch smoking prevention programme-A case study. In C. James, J. Balding \& D. Harris (Eds.), World Yearbook of Education 1989. Health Education (pp. 20-31). London: Kogan Page. 
De Vries, H. \& Kok, G.J., (1986) From deteminants of smoking behaviour to the implications for a prevention programme. Health Education Research, $1,85.94$.

De Vries, H. \& Kok, G.J. (1988) Prevention of Smoking in children. In D. Tamir (Ed.), Health education in schools (pp. 217-235). London: Freund Publishing House Ltd.

Dielman, T.E., Lorenger, A.T., Leech, S.L., Lyons, A.L. \& Klos, D.M. (1985) Fifteen-month follow-up results of an elementary school based smoking prevention project. International Journal of Health Education (Hygie), 4, 28-35.

Doll, R. \& Peto, R. (1981) The causes of cancer: Quantitative estimate of avoidable risks of cancer in the United States today. Journal of the National Cancer Institute, 66, 1191-1308.

Dutch Foundation on Smoking and Health. Annwal Reports 1983-1988, The Hague.

Evans, R.I. (1976) Smoking in children: developing a social psychological strategy of deterrence. Journal of Preventive Medicine, 5, 122-127.

Evans, R.I., Rozelle, R.M., Mittelmark, M.B., Hansen, W.B., Bane, A.L. \& Havis, J. (1978) Deterring the onset of smoking in children: knowledge of immediate physiological effects and coping with peer pressure, media pressure and parent modeling. Joumal of Applied Social Psychology, 8, 126-135.

Fishbein, M. (1977) Consumers beliefs and behavior with respect to cigarette smoking: a critical analysis of the public literature. Report prepared for the staff of the Federal Trade Commission.

Fishbein, M. \& Ajzen, I. (1975) Belief, attitude, intention and behavior: an introduction to theory and research. Reading, Mass.:Addison Wesley.

Flay, B.R. (1985) Psychosocial approaches to smoking prevention: a review of findings. Health Psychology, 4, 449-488.

Flay, B.R., D'Avernas, J.R., Best, J.A., Kersell, M.W., Ryan, K.B. (1983) Cigarette smoking: why young people do it and ways of preventing it. In P.J. Mc Grath \& P. Firestone (Eds.), Pediatric and adolescent behavioral medicine (pp. 132-183). New York: Springer.

Flay, B.R., Ryan, K.B., Best, J.A., Brown, K.S., Kersell, M.W., d'Avernas, J.R. \& Zanna, M.P. (1985) Are social-psychological smoking prewention programs effective? The Waterloo Study. Journal of Behavional Medicine, 8, 37-59.

Fishbein, M. \& Ajzen, I. (1975) Belief, attitude, intention and behavior: an introduction to theory and research. Reading, Mass.: Addison Wesley.

Friedman, L.S., Lichtenstein, E. \& Biglan, A. (1985) Smoking onset among teens: an empirical analysis of initial situations. Addicrive Behaviors, $10,1-13$.

Green, L.W. (1986) Prevention and Health Education. In J.M. Last (Ed.), Prevention and health education (pp. 1089-1108). Norwalk: Appleton-Century-Crofts.

Green, L.W., Kreuter, M.W., Deeds, S.G. \& Partridge, K.B. (1980) Health education planning; a diagnostic approach. Palo Alto: Mayfield.

Higginson, J. \& Muir, C.S. (1979) Environmental carcinogenesis: misconceptions and limitations to cancer control. Journal of the National Cancer Institute, 63, 1291-1299.

Hirschman, R.S., Leventhal, H. \& Glynn, K. (1984) The development of smoking behavior: conceptualization and supportive cross -sectional survey data. Journal of Applied Social Psychology, 14, 184-206.

Hurd, P.D., Johnson, C.A., Pechacek, T., Bast, L.P., Jacobs, P.R. \& Luepker, R.V. (1980) Prevention of cigarette smoking in seventh grade students. Journal of behavioral Medicine, 3, 15-28. 
Janicki, T. \& Braverman, M.T. (1986) The development and evaluation of school smoking prevention programs. Advances in Health Education and Promotion, 1, 307-340.

Janis, L.L. \& Mann, L. (1977) Decision making: a psychological analysis of conflict, choice commitment. New York: Free Press.

Johnson, C.A., Hansen, W.B., Collins, L.M. \& Graham, W. (1986) High-school smoking prevention: results of a three-year longitudinal study. Journal of Behavioral Medicine, 9 , 439-45.4.

Jonkers, R., Liederkerken, P.C., De Haes, W.F.M., Kok, G.J., Saan, J.A.M. (Eds.) (1988), Effectiviteit van GVO. Utrecht: Landelijk Centrum GVO.

Klepp, K.I., Halper, A. \& Perry, C.L. (1986) The efficacy of peer leaders in drug abuse prevention. Journal of School Health, 56, 407-411.

Kok, G.J. (1985) Een model van gedragsverandering via voorlichting. Nederlands Tijdschrift woor de Psychologie, 40, 71-76.

Kok, G.J. (1988) Health motivation: health education from a social psychological point of view. In S. Maes, C.D. Spielberger, P.B. Defares and I.G. Sarason (Eds.), Topics in Health Psychology (pp. 295-300) New York: Wiley \& Sons Ltd.

Leventhal, H. \& Cleary, P.D. (1980) The smoking problem: a review of the research and theory in behavioral risk modification. Psychological Bulletin, 88, 370-405.

Luepker, R.V., Pechacek, T.F., Murray, D.M., Johnson, C.A., Hurd, F. \& Jacobs, D.R. (1981) Saliva thiocyanate: A chemical indicator of cigarette smoking in adolescents. American Journal of Public Health, 71, 1320-1324.

McAlister, A., Perry, C., Maccoby, N. (1979) Adolescent smoking: onset and prevention. Pediatrics, 63, 650-658.

McAlister, A., Perry, C., Killen, J., Slinkard, L. \& Maccoby, N. (1980) Pilot study of smoking, alcohol and drug abuse prevention. American Journal of Public Health, 70, 719-721.

McCaul, K.D. \& Glasgow, R. (1985) Preventing Adolescent smoking: what have we learned about treatment consiruct validity? Health Psychology, 4, 361-387.

McGuire, W.J. (1964) Inducing resistance to persuasion. In L. Berkowitz (Ed), Advances in Experimental Social Psychology, Vol 1. New York: Academic Press.

McGuire, W.J. (1985) Attitudes and attitude change. In G. Lindzey \& E. Aronson (Eds.), Handboak of Social Psychology, Volume II (pp. 233-246). New York: Lawrence Erlbaum Associates.

Murray, D.M., Johnson, C.A., Luepker, R.V. \& Mittelmark, M.B. (1984) The prevention of cigarette smoking in children: a comparison of four strategies. Journal of Applied Social Psychology, 14, 274-288.

Murray, D.M., Richards, P.S. Luepker, R.V. \& Johnson, C.A. (1987) The prevention of cigarette smoking in children: two and three-year follow-up comparisons of four prevention strategies. Journal of Behavioral Medicine, 10, 595-611.

Newman, I.M. (1984) Capturing the energy of peer-pressure: insights from a longitudinal study of adolescent cigarette smoking. Journal of School Health, 54, 146-148.

Pechacek, T.F., Murray, D.M., Luepker, R.V., Mittelmark, M.B., Johnson, C.A. \& Shutz, J.M. (1984) Measurement of adolescent smoking behavior. Rationale and methods. Journal of Behavioral Medicine, 7, 123-140.

Perry, C.L., Killen, J. \& Slinkard, L.A. (1980) Peer teaching and smoking prevention among junior high school students. Adolescence, 15, 277-281. 
Perry, C.L., Telch, M.J., Killen, J., Burke, A., Maccoby, N. (1983). High school smoking prevention: The relative efficacy of varied treatments and instructions. Adolescence, 18 , 561-566.

Perry, C.L., Murray, D.M. \& Klepp, K.I. (1987) Predictors of adolescent smoking and implications for prevention. Morbidity and Mortality Weekly Report, 36, 415 455.

Puska, P., Vartianen, E., Pallonen, U. \& Salonen, J.T. (1981) The North Karelia Youth Project. A community-based intervention study on CVD risk factors among 13 to 15 -year-old children: Study design and preliminary findings. Preventive Medicine, 10, 133-148.

Rogers, E.M. (1983) Difficsion of innovations. New York: The Free Press.

Schinke, S.P., Gilchrist, L.D. \& Snow, W.H., (1985) Skills intervention to prevent cigarette smoking among adolescents. American Jownal of Public Health, 76, 665-667.

Spielberger, C.D, Jacobs, G.A. Crane, R.S. \& Russel, S.F. (1983) On the rellation between family smoking habits and the smoking behaviour of college students. Internationat Review of Applied Psychology, 32, 53-69.

Telch, M.J., Killen, J.D., McAlister, A.L., Perry, C.L. \& Maccoby, N. (1982) Long-term follow-up of a pilot project on smoking prevention with adolescents. Journal of Behavioral Medicine, 5, 1-7.

Tell, G.S., Klepp, K.I., Vellar, O.D. \& McAlister, A.L. (1984) Preventing cigarette smoking in Norwegian adolescents: The Oslo Youth Study. Preventive Medicine, 5, 1-7.

Thompson, E.L. (1978) Smoking Education Programs 1960-1976. American Jourmal Public Health, 68, 250-257.

Tobler, N.S. (1986) Meta-analysis of 143 adolescents drug prevention programs: Quantitative outcome results of program participants compared to a control or comparison group. The Journal of Drug Issues, 16, 537-567.

Urberg, K \& Robbins, R. (1984) Perceived valnerability in adolescents to the health consequences of cigarette smoking. Preventive Smoking, 13, 367-376.

Van der Rijt, B.A.J. (1979) Jeugd en antirookinformatie; een onderzoek naar de invloed van peer groups op roken en op het effect van antirookinformatie bij de jeugd ( $Y$ outh and anti-smoking information. Dissertation. University of Nijmegen.

Van Reek, J. \& Adriaanse, H. (1987) Smoking policy in the Netherlands since the fifties: one factor in the social dynamics of changes in smoking behaviour. Health Policy, 7, 361-368.

Vartianen, E., Puska, P., Koskela, K., Nissinen, A. \& Toumilehto, J. (1986) Ten year results of a community-based anti-smoking program (as part of the North Karelia Project in Finland) Health Education Research, 1, 175-184.

World Health Organization (1974) Health education: a programme review. Geneva: WHO.

Wynder, E.L. \& Gori, G.B. (1977) Contribution of the environment to cancer incidence: an epidemiologic exercise. Journal of the National Cancer Institute, 58, 825-832. 


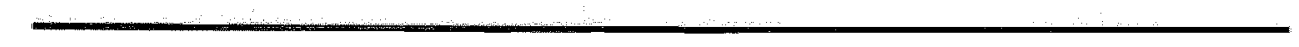




\title{
2 From determinants of smoking behavior to the implications for a prevention program
}

\author{
Hein De Vries \& Gerjo Kok
}

published in Health Education Research, 1986, 1, 85-94

\section{ABSTRACT}

This paper is a report of a study in which motives and factors that predict smoking in Dutch children (10-15 years) are analyzed by applying the Fishbein \& Ajzen model (1975). The results indicate that non-smokers connect smoking more firmly with health hazards, personal hazards and harm to the environment. Smokers recognize these consequences but play down their importance, associating more advantages with smoking. Non-smokers often regard these effects as detrimental. Long-term consequences are more closely associated with regular smoking, while short-term effects are more closely linked with initial smoking. Non-smokers experience more social pressure not to smoke than do smokers. Smokers experience pressure to smoke by friends and classmates. The subjective norm is less negative towards initial smoking than towards regular smoking. Some social situations seem to hold a special attraction for both smokers and non-smokers. The implications of the results for the development of a prevention program are indicated. 


\section{$2.1 \quad$ INTRODUCTION}

Despite the well-known harmful effects of cigarettes, adolescents continue to start smoking. Cessation of this behavior is difficult and only partly successful (Leventhal \& Cleary, 1980). Preventive activities aimed at non-smoking children probably constitute a more successful approach to the smoking problem. In the attempt to solve the problem by prevention, applied behavioral research has to deal with four different questions.

The first concerns the analysis of the problem. Epidemiological evidence shows a clear relationship between human behavior and health. As a result of smoking nearly 17000 people die of lung cancer, coronary heart diseases and asthrna and bronchitis, in The Netherlands annually (Dutch Foundation on Smoking and Health, 1984). The prevention of smoking is thus an important issue.

The second question deals with the determinants of the behavior. Smoking often begins at an early age, and the process can be divided into several stages (Leventhal \& Cleary, 1980; Flay et al., 1983). In the first preparatory stage, attitudes towards (initial) smoking are formed by influences from family, friends and the media. The second stage is the initiation of smoking. Many children (90\%) try to smoke a cigarette and addiction can occur for $60-90 \%$ of those who have smoked only three or four cigarettes (McKennel \& Thomas, 1967; Hirschman et al., 1984; Salber et al., 1968). The role of social influence has been documented extensively (e.g. Aarø et al., 1981; Ashton \& Stepney, 1982; Evans et al., 1978; McCaul et al., 1982; Spielberger et al., 1983). Above all, peer group pressure plays a critical role. In fact, social influences can be divided into overt (or direct) influences such as persuasion, pressure and encouragement, and covert (or indirect) influences such as modeling. The latter are probably harder to recognize but may have a greater impact. Friedman et al. (1985) and Newman (1984) demonstrate that many adolescents deny feeling direct pressures, though their initial smoking is often prompted by peers. According to our definition an initial smoker has tried smoking up to five times.

The third stage is the experimental stage in which a child learns how to smoke. In this period the negative (physiological) effects disappear while the positive (psychological) experiences are reinforced. Major sources of influence are friends and the perceived consequences of smoking. An experimental smoker smokes irregularly and less than one cigarette per week.

The fourth stage is the regular smoking stage in which the positive consequences of smoking have become part of the personality of the child. The main influences are the child's attitude, and the positive social consequences 


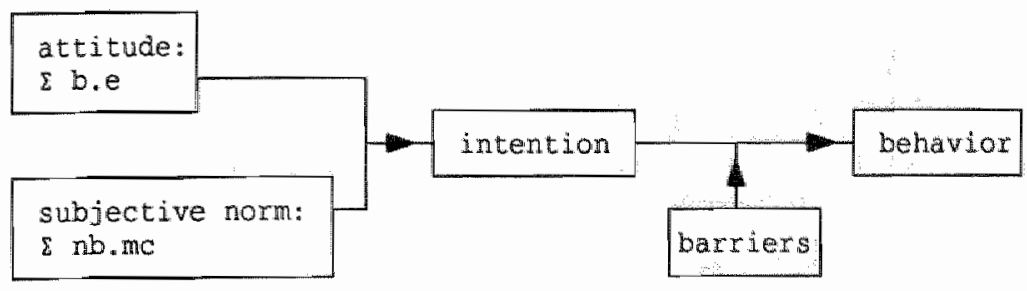

Figure 2.1: The model of Fishbein and Ajzen (1975)

provided by other smokers. The regular smoker smokes at least one cigarette per week. At every stage each individual can decide to stop smoking, though this decision will be easier for initial smokers.

The determinants of smoking behavior can be integrated into the Fishbein \& Ajzen model (1975), which is summarized in figure 2.1. Smoking behavior can be predicted by a person's intention to smoke, though the realization of this intention may not always be possible because of certain barriers (e.g. someone does not want to smoke, but does not know how to refuse a cigarette; someone wants to smoke, but has not enough money to buy cigarettes, etc.). The intention is formed by the attitude and the subjective norm. An attitude represents a person's general feeling of (un)favorableness towards a behavior (e.g. smoking is bad). An attitude consists of several relevant (or salient) beliefs (b) about whether the behavior results in specific consequences (e.g. smoking causes breathing problems) and corresponding evaluations (e) of these consequences (e.g. having breathing problems is bad). The attitude can be measured by multiplying the beliefs with the evaluations, and then adding up the products ( $\Sigma$ b.e).

A person's subjective norm is the perception of whether the majority of important people thinks that the person should or should not perform the behavior in question. The subjective norm is determined by several normative beliefs (nb) which are perceived expectations of specific reference persons (e.g. my father does not want me to smoke) and by the person's motivation to comply $(\mathrm{mc})$ with these expectations (e.g. with regard to smoking, I do what my friends want me to do). It can be measured as follows: $\Sigma$ nb.mc.

This model has already been applied successfully to the study of smoking behavior (Fishbein, 1982; Newman \& Martin, 1982; Page \& Gold, 1983).

The third step for applied research is to discover how to influence smoking behavior. According to social psychological models (Ajzen \& Fishbein, 1980; Kok \& Siero, 1985; McGuire, 1985; Rogers, 1983) a prevention program has to 
attract attention and has to be understandable. The intention not to smoke can be influenced by the person's attitude and the subjective norm, but non-smoking has to be feasible. The behavior will be maintained if it results in the expected effects and if the person feels committed to the behavior.

The final question concerns the evaluation of a prevention program where the measured effects are compared with the results of a control group. The first steps towards establishing a successful prevention program have been taken by Evans et al. (1978) and further elaborated by other investigators (Best et al., 1984; Biglan \& Lichtenstein, 1984; Botvin \& Eng, 1982; Hurd et al., 1980; McAlister et al., 1979; Murray et al., 1984; Schinke et al., 1985), although methodollogical problems have not always been solved (Flay et al., 1983). One of the basic assumptions of this approach is that young children often do not want to smoke regularly, but that they do not possess the necessary abilities to refuse an offer of a cigarette. To prevent (regular) smoking adolescents need to be trained in order to acquire the necessary refusal skills.

The main purpose of this study is to analyze the determinants of both initial and regular smoking behavior in Dutch children. Attitudes and subjective norms concerning both behaviors are compared between smoking and non-smoking children in order to obtain an indication as to why adolescents do or do not smoke. Furthermore, the reasons smokers give for their behavior can indicate which arguments are used in the process of peer pressure. The implications are then discussed using both these results and information from other prevention programs.

\subsection{METHOD}

Of the 231 children aged 10-15 years who participated in the study, 221 completed the questionnaire satisfactorily. The subjects were recruited at random from both primary $(\mathrm{N}=85 ; 38 \%)$ and secondary $(\mathrm{N}=136 ; 62 \%)$ schools.

According to the eliciting procedure of Ajzen \& Fishbein (1980), children were asked about smoking, non-smoking and regular smoking in interviews or in open response questionnaires. The aim was to elicit salient beliefs, salient normative beliefs and intentions corresponding to the three behaviors. The results indicated that non-smoking was associated with the same consequences as was smoking, but that they were evaluated in opposite directions (e.g. smoking is bad, non-smoking is good for my health). Initial smoking was associated with some other consequences. This procedure resulted in 28 beliefs, 
28 evaluations, two questions to measure the (direct) attitude ("smoking is good/bad" and "smoking is pleasant/unpleasant"), 16 normative beliefs, 16 motivations to comply, one question to measure the (direct) subjective norm ("most people who are important to me think that I should/should not smoke"), and 13 intentions which were measured in the final questionnaire for both initial and regular smoking. The beliefs were measured in a slightly different way to the traditional Fishbein \& Ajzen (1975) method (how likely/unlikely is it that smoking causes a specific consequence), since the traditional method may generate some problems in the interpretation of the answer. For example, if someone says that it is unlikely that smoking is sociable, does the person mean that smoking is not really sociable (which answer lies in the middle of the dimension sociable - unsociable), or that smoking is unsociable (which answer refers to the opposite of sociable)? Therefore, for every belief we asked the child to indicate which consequences were associated with smoking [e.g. "If I (should) smoke: it is very sociable $(+3)$, it is sociable $(+2)$, it is rather sociable $(+1)$, it is neither sociable nor unsociable $(0)$, it is rather unsociable $(-1)$, it is unsociable $(-2)$, it is very unsociable $\left.(-3)^{\prime \prime}\right]$.

The questionnaire also covered items about experience of initial smoking, smoking status, smoking consumption, age and sex.

\section{$2.3 \quad$ RESULTS}

\subsubsection{Demographic findings}

In this study $19 \%$ of the children reported smoking $(\mathrm{N}=41)$, while $81 \%$ reported not smoking $(\mathrm{N}=178)$. Forty-nine percent of the non-smokers reported having tried to smoke (initial smoking). Twenty-two percent of the smokers smoked 1-6 cigarettes per week, 17\% smoked 7-29 cigarettes per week, while the rest $(61 \%)$ smoked 30 cigarettes per week. The distribution of smoking children among the age categories (10-15 years) was: $5,0,12,15,26$ and $29 \%$. This was comparable with national findings (10-14 years): 4, 2, 6, 13 and 25\% (Dutch Foundation on Smoking and Health, 1985). There were no differences according to the children's sex. 


\subsubsection{Correlations between variables}

The correlation between the two attitude questions was high $(r=.75 ; \mathrm{p}<.001)$. The two items were summed to form one direct attitude scale. As can be seen from figure 2.2 the correlation ( $r$ ) between the direct and the indirect attitude scale $(\Sigma$ b.e) was relatively high. The correlation between the direct subjective norm and the indirect subjective norm $(\Sigma \mathrm{nb} . \mathrm{mc})$ was less high. The direct attitude scale and the direct subjective norm correlated less highly with the intention (not in figure $2.2: \mathrm{r}=.59$ and $\mathrm{r}=.24 ; \mathrm{p}<.001$, respectively) than did the indirect attitude and the indirect subjective norm. The multiple correlation (R) of these indirect scales with the intention was high. The intention correlated highly with behavior.

The correlations mentioned above refer to regular smoking; the results for initial smoking were comparable. In conclusion, the expected correlations between the variables of the Fishbein \& Ajzen (1975) model were sufficiently high.

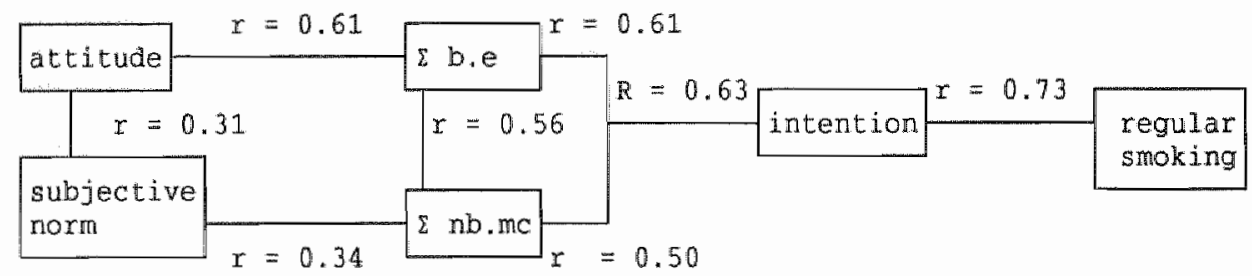

Figure 2.2: The correlations between the attitude, the subjective norm, the intention, and the behavior $(\mathrm{N}=221$; all correlations: $\mathrm{p}<001)$

\subsubsection{Attitude towards smoking}

Smoking children had a positive attitude towards smoking (see table 2.1). They considered smoking to be good and pleasant. Non-smokers had a negative attitude and regarded smoking as having the opposite effects.

Non-smoking children believed more than smoking children (see table 2.2) that smoking has negative health consequences such as bad health, damage to the lungs, increased risk of cancer, bad physical condition, coughing, irritated eyes, nausea and respiratory problems. It appears from table 2.2 that nonsmokers were also more convinced that smoking has negative personal con- 
Table 2.1: Mean scores of attitudes to smoking and the evaluations of conformity consequences for non-smokers (NS) and smokers ( $\mathrm{S})(\mathrm{N}=219)$

Consequences

Smoking is good $(+3)$ or bad $(-3)$ (attitude 1)

Smoking is pleasant or unpleasant (atritude 2 )

Attitude: $1+2$

Indirect attitude $(\Sigma$ b.e)

Subjective norm

Indirect subjective norm ( $\Sigma$ nb.mc)
NS

S

$-1.74$

$0.59 *$

$-1.30$

$0.95 *$

$-3.04$

$1.54 * *$

$-53.48$

$0.54 * *$

$-2.13$

$-1.56^{\text {* }}$

$-38.60$

${ }^{*} \mathrm{p}<.05 ; * * \mathrm{p}<.01$

sequences in terms of unwise behavior, addiction, a bad smell and expense. Furthermore they believed that smoking harms the environment: it is offensive to others, and causes passive smoking. Smoking children were aware of these effects, but minimized their significance.

Table 2.2 shows on the other hand that smoking children believed more than non-smoking children that smoking has personal advantages. For them smoking was sociable, nice to do, showing-off, relaxing, good for the nerves, tasted good and relieved boredom. However, non-smokers appeared to consider smoking to have the opposite, disadvantageous effects. They regarded smoking as unsociable, not nice, not relaxing, bad for the nerves, not a suitable way of showing off and unpleasant-tasting.

Smoking children also appeared to differ from non-smoking children in their less negative evaluations of conformity aspects such as being under pressure to smoke and to do what other people do. Belonging to the group was evaluated more positively by smokers than by non-smokers.

The differences between the two groups are mostly reflected in the product of the beliefs and evaluations. Sometimes the two groups differed only about the belief (expense), or the evaluation (discovering the taste). In one case they differed about both the belief and the evaluation (satisfying curiosity), although the product ( $\Sigma$ b.e) did not show significant differences. These differences can be considered as relatively less important (Fishbein \& Ajzen, 1975).

The differences between smoking and non-smoking children concerning initial smoking are comparable with the reported differences about regular smoking and will not, therefore, be mentioned here. However, some consequences are more closely associated with regular smoking, while other con- 
Table 2.2: Mean scores of non-smokers (NS), and smokers (S) of beliefs (b), evaluations (e) and $\Sigma$ b.e $(N=219)$

\begin{tabular}{|c|c|c|c|c|c|c|}
\hline \multirow[t]{2}{*}{ Consequences } & \multicolumn{2}{|l|}{ Beliefs } & \multicolumn{2}{|c|}{ Evaluations } & \multicolumn{2}{|l|}{$\Sigma$ b.e } \\
\hline & NS & $\mathrm{s}$ & NS & 5 & NS & $\mathrm{S}$ \\
\hline bad health & 2.46 & $1.93 *$ & -2.52 & $-1.46^{* *}$ & -6.40 & $-2.90 * *$ \\
\hline damage to lungs & 2.21 & $1.71 * *$ & -2.76 & $-2.07 *$ & -6.18 & $-3.51 *$ \\
\hline risk of cancer & 1.95 & $1.20 * *$ & -2.77 & -2.80 & -5.44 & $-3.24 * *$ \\
\hline bad physical condition & 1.75 & $1.20^{* * *}$ & -2.26 & -2.07 & -4.04 & $-2.76^{*}$ \\
\hline coughing & 1.69 & $0.44 * *$ & -1.66 & -1.83 & -2.85 & $-0.61 *$ \\
\hline irritated eyes & 1.19 & $0.12 * *$ & -2.01 & -1.78 & -2.54 & $-0.27 * *$ \\
\hline nausea & 1.11 & $0.24 * *$ & -2.09 & -2.20 & -2.35 & $-0.44 * *$ \\
\hline breathing problems & 0.94 & $0.22 * *$ & -2.37 & $-2.05^{*}$ & -2.28 & $-0.59 *$ \\
\hline unwise & 2.39 & $0.63^{*} *$ & -1.94 & $-1.17 * *$ & -4.91 & $-2.15 * *$ \\
\hline addictive & 0.66 & 0.32 & -2.70 & $-2.00 * *$ & -1.92 & $0.29 *$ \\
\hline smells bad & 1.62 & $0.22 * *$ & -1.82 & -2.15 & -3.01 & $-0.10^{* *}$ \\
\hline expensive & 2.29 & $1.49 * *$ & -0.83 & -0.49 & -1.96 & -0.98 \\
\hline passive smoking & 1.93 & $1.44 * *$ & -2.30 & $-1.22 * *$ & -4.49 & $-2.15^{* *}$ \\
\hline offensive to others & 1.64 & $0.80 * *$ & -1.93 & $-0.73 * *$ & -3.28 & $-0.44^{* *}$ \\
\hline sociable & -0.54 & $1.34 * *$ & 2.16 & $2.54^{*}$ & -1.12 & $3.93 * *$ \\
\hline tastes good & -0.98 & $1.32 * *$ & 1.61 & 2.73 & -1.36 & $3.29^{* * *}$ \\
\hline nice to do & -0.56 & $0.95 * *$ & 2.22 & 2.41 & -0.96 & $2.14^{* *}$ \\
\hline relaxing & -0.96 & $0.61 * *$ & 1.74 & 2.00 & -0.67 & $1.59^{* * *}$ \\
\hline good for nerwes & 0.07 & $0.71 * *$ & 0.73 & 1.22 & 0.32 & $2.07 * *$ \\
\hline discovering the laste & 1.18 & 0.83 & 0.50 & $1.54 * *$ & 1.03 & 1.51 \\
\hline relieves boredom & 0.48 & $1.20^{* *}$ & 0.92 & 1.24 & 0.55 & $1.73 * *$ \\
\hline satisfying curiosity & 0.94 & $0.32 * *$ & -0.34 & $0.49 * *$ & 0.14 & 0.61 \\
\hline showing off & 0.48 & 0.29 & -1.17 & $-0.63 * *$ & -0.44 & $0.39 *$ \\
\hline being pressed to smoke & -0.33 & -0.54 & 2.67 & $-1.34 * *$ & 1.03 & 0.63 \\
\hline doing what others do & 1.52 & 1.27 & -0.92 & $-0.05^{* *}$ & -1.08 & -0.05 \\
\hline belonging to the group & 0.25 & 0.44 & 0.56 & $1.24 * *$ & 0.31 & 1.15 \\
\hline being pestered & -0.22 & -0.27 & -2.04 & -1.61 & 0.29 & 0.12 \\
\hline feeling grown-up & 0.20 & 0.07 & 0.21 & 0.59 & 0.15 & 0.98 \\
\hline
\end{tabular}

$* \mathrm{p}<.05 ; * \mathrm{p}<<01$ 
Table 2.3: Mean scores of beliefs about regular (Mr) and initial (Mi) smoking $(+3=$ positive $;-3=$ negative; $N=221 ; p<05)$

More closely associated with regular smoking
More closely associated with initial smoking

\begin{tabular}{llllrr}
\hline a bad health & 2.37 & 1.68 & irritated eyes & 1.15 & 1.00 \\
damage to lungs & 2.12 & 1.39 & nausea & 1.16 & 0.95 \\
cancer & 1.82 & 1.33 & breathing problems & 1.17 & 0.81 \\
bad condition & 1.64 & 1.24 & tastes good & -0.83 & -0.54 \\
unwise & 2.05 & 1.56 & relaxing & -0.24 & 0.20 \\
addictive & 0.57 & 0.13 & discovering taste & 1.51 & 1.10 \\
expensive & 2.14 & 1.41 & satisfying curiosity & 1.25 & -0.83 \\
passive smoking & 1.85 & 1.45 & & & \\
offensive to others & 1.48 & 1.18 & & & \\
\end{tabular}

sequences are more probable in the case of initial smoking (see table 2.3). All children associated long-term health hazards (bad health, damage to the lungs, increased risk of cancer, bad physical condition), long-term personal detriment (doing something unwise, addiction, expense) and harm to the environment (passive smoking, offensiveness to others), more with regular smoking. Shortterm health hazards (irritated eyes, nausea, breathing problems), short-term personal detriment (tastes unpleasant, unrelaxing) and short-term disadvantages (discovering the taste, satisfying curiosity) were associated more with initial smoking. While both behaviors were evaluated as unpleasant, regular smoking was evaluated more negatively than was experimental smoking $(\mathrm{p}<.01)$.

\subsubsection{Subjective norm towards smoking}

Table 2.1 shows that non-smoking children perceived a more negative subjective norm concerning regular smoking. This is due to a more negative subjective norm about regular smoking experienced from their mothers, fathers, relatives, sisters, brothers, doctors, non-smokers, non-smoking friends, the Dutch Foundation on Smoking and Health and the Public Health Department (see table 2.4).

Smoking children appeared to experience a positive subjective norm towards smoking from their friends and classmates, although the impact does not seem to be extremely large. Moreover, the pressure not to smoke exerted by this peer 
Table 2.4: Meam scores of normative beliefs ( $\mathrm{nb}$ ), motivations to comply (mc), and $\Sigma \mathrm{nb}$.mc for nom-smokers (NS) and smokers $(S)(\mathbb{N}=219 ; p<05)$.

\begin{tabular}{|c|c|c|c|c|c|c|}
\hline \multirow[t]{2}{*}{ Person } & \multicolumn{2}{|l|}{$\mathrm{nb}$} & \multicolumn{2}{|l|}{$\mathrm{mc}$} & \multicolumn{2}{|c|}{ Enb.mc } \\
\hline & $\mathrm{NS}$ & $\mathrm{S}$ & NS & $\mathrm{S}$ & NS & $S$ \\
\hline mother & -2.36 & $-0.95 *$ & 2.43 & $1.34 * *$ & -5.99 & $-1.73^{* * *}$ \\
\hline father & -2.25 & $-1.39 * *$ & 2.37 & $1.32 * *$ & -5.79 & $-2.17 * *$ \\
\hline relatives & -1.72 & $-0.85 * *$ & -1.67 & $0.63 * *$ & -3.50 & $-0.85^{*}$ \\
\hline sisters & -1.02 & -0.63 & 0.86 & 0.54 & -1.83 & $-0.44 * *$ \\
\hline brothers & -0.87 & -0.46 & 0.94 & $0.44 *$ & -1.63 & $-0.10 * *$ \\
\hline doctor & -2.05 & $-1.49 *$ & 2.26 & $1.46^{* * *}$ & -5.08 & $-2.32 *$ \\
\hline non-smokers & -1.87 & $-1.20 * *$ & 1.61 & $0.61 * *$ & -3.31 & -0.98 * \\
\hline non-smoking friends & -1.83 & $-0.90 * *$ & 1.49 & $0.73 * *$ & -2.59 & $-1.12 * *$ \\
\hline SHF & -1.78 & -1.39 & 1.42 & $0.76^{* *}$ & -3.17 & $-1.34 * *$ \\
\hline PHD & -1.96 & $-1.34 * *$ & 1.47 & $0.46 * *$ & -3.39 & $-0.71 *$ \\
\hline friends & -0.93 & $0.41 * *$ & 1.11 & $0.63 * *$ & -1.42 & $0.63^{* *}$ \\
\hline classmates & -0.81 & $0.27 * *$ & 0.94 & $0.51 *$ & -1.87 & $0.12 * *$ \\
\hline smokers & 0.34 & 0.20 & 0.68 & 0.44 & 0.07 & 0.10 \\
\hline smoking friends & 0.65 & 0.54 & 0.56 & 0.71 & 0.47 & 0.56 \\
\hline ciggarette industry & 1.34 & 1.39 & 0.29 & 0.27 & 0.31 & 0.59 \\
\hline cigarette adverts & 1.43 & 1.12 & 0.21 & 0.37 & 0.31 & 0.51 \\
\hline
\end{tabular}

group on non-smoking children was less strong than, for example, the effects of parental pressure. Smoking and non-smoking children did not differ on the positive opinions about smoking of other smokers, smoking friends, cigarette manufacturers and advertisements. As a result of little reported motivation to comply with these opinions, the impact ( $\Sigma \mathrm{nb} . \mathrm{mc}$ ) of these groups is rather small $(-.04, .48, .37$, and .35 respectively). However, these pressures to smoke are comparable with the impact of peer group pressure on smoking children (see table 2.4).

The children experienced a less negative subjective norm about initial smoking by parents, relatives and the doctor. Parents and relatives had less negative opinions about initial smoking, while there was less motivation to comply with the doctor's opinion about initial smoking. 
Table 2.5: Mean scores of intention of non-smokers (NS) and smokers (S) to smoke (+3) or not to smoke $(-3)$ regularly. $(\mathrm{N}=219$; all differences: $p<.001)$

\begin{tabular}{llc}
\hline Intention & NS & S \\
\hline outside & -1.44 & 1.27 \\
where nobody sees me & -1.45 & -0.54 \\
in discos or cafés & -1.53 & 1.61 \\
in the street & -1.61 & 0.66 \\
with friends & -1.72 & 1.76 \\
at parties & -1.80 & 1.39 \\
at home & -1.96 & 0.92 \\
in their own room & -1.96 & 0.71 \\
with parents & -2.07 & 0.88 \\
at school & -2.10 & 1.41 \\
with non-smokers & -2.39 & -0.10 \\
to smoke within 2 years & -2.12 & 0.71 \\
to smoke & -2.33 & 1.41 \\
\hline
\end{tabular}

\subsubsection{Intentions towards smoking}

As might be expected, smoking children had positive intentions to smoke while non-smokers had negative intentions (see table 2.5). Non-smokers appeared least negative about their own intentions to smoke outside, in the street and in places where nobody could see them. Furthermore, both non-smokers and smokers were relatively positive about their intentions to smoke in discos or cafes, at parties and with friends.

Differences of intention within the non-smoking population also appeared to exist. Initial smokers (those who had tried smoking up to five times) were less negative $(\mathrm{p}<.05)$ about these intentions towards initial smoking, initial smoking within 2 years, initial smoking at home and where nobody could see them, than non-initial smokers (those who had never tried smoking). Initial smokers also had less negative intentions towards regular smoking, regular smoking within 2 years, regular smoking in the street and with friends $(p<.05)$. Thus, initial smokers had less negative intentions towards both initial and regular smoking. All non-smoking children had less negative intentions towards initial than towards regular smoking $(p<, 05)$. However, they were less likely to reject 
regular smoking in a disco or a cafe and with friends than to reject initial smoking on these occasions. It is possible that regular smoking has a more social function in these situations.

\subsection{DISCUSSION}

Non-smoking children are more likely than smoking children to believe that smoking results in health hazards, personal detriment and harm to the environment. Smoking children appreciate these drawbacks of smoking, but minimize their significance and evaluate conformity aspects less negatively than do non-smokers. Smoking children, on the other hand, associate more personal advantages with smoking. Non-smoking children do not associate smoking with these advantages but consider smoking to have opposite and disadvantageous effects. These discrepancies in opinion between the two populations could have important implications. It is conceivable that smokers can initiate in nonsmokers a redefining of beliefs about the consequences of smoking by direct persuasion or by modeling the advantages of smoking (e.g. by stressing that smoking is relaxing, or creating a relaxed impression). The discrepancy may also constitute an interesting challenge to non-smokers to initiate smoking just to find out which party is right.

Regular smoking is associated more strongly with long-term disadvantages, while initial smoking is more closely connected with short-term effects, both positive and negative.

Smoking children report experiencing less pressure not to smoke from a majority of other people (e.g. parents, siblings, relatives, doctor) than do nonsmoking children. However, smoking children experience pressures to smoke from friends and classmates which non-smokers do not feel. Although both smokers and non-smokers are aware of the smokers' positive opinions of smoking and the cigarette industries, they report little motivation to comply with these opinions. The result is that relatively slight social pressure to smoke is experienced by both smokers and non-smokers. This pressure is comparable to that exerted by the influence of peers on smoking children. It appears that non-smoking children also experience relatively less pressure not to smoke from their peer group than for example from their parents. It is possible that this peer group is less anti-smoking oriented, or that distinct differences about this issue exist within the group. 
Initial smokers are less negative about the intentions towards both initial and to regular smoking than are non-initial smokers. Both non-smokers and smokers are least negative and most positive respectively about smoking in a disco or with friends. Although non-smokers are less negative in general about the intentions as to initial smoking than to regular smoking, they appear to be less negative about regular smoking in a disco and with friends. These findings illustrate the important social function of regular smoking.

Fishbein \& Ajzen's (1975) model, which assesses reasoned behavior, can be applied to investigate and describe differences between children who are (recent) smokers and non-smokers. However, behavior can also be influenced by other factors. One such factor is social influence, which can be exerted both directly and indirectly through modeling. In our study, the influence of peer pressure is not as great as might be expected. This may be due to the fact that these influences are not recognized or labeled as pressure by adolescents. Friedman et al. (1985) and Newman (1984) also reported that adolescents do not always recognize or label the influence of peers as pressure. Therefore, the impact of social influence should also be studied by assessing the direct relationship between smoking and the number of other smokers in the individual's immediate surroundings.

\subsection{IMPLICATIONS FOR A SMOKING PREVENTION PROGRAM}

In order to influence the attitude of non-smokers it is necessary to increase the salience of the advantages of non-smoking and the disadvantages of smoking. As children often consider long-term consequences as being distant in time (the so-called time-perspective trap, Evans et al., 1978), the short-term effects deserve special attention. In order to influence attitudes, a prevention program should:

1. Provide information about general aspects of health, environment and conformity in order to reinforce or increase the knowledge of non-smoking children. Moreover, a program should stress that conformity results not only in advantages but also in detrimental effects, for instance in causing a loss of independence and self-control. Addiction can be discussed within this context.

2. Stress the (short-term) advantages of non-smoking and the (short-term) drawbacks of smoking, while indicating the tendency of smokers to minimize the disadvantages of smoking. 
3. Protect non-smokers from pressures to change their attitudes by demonstrating the inaccuracies of some perceived advantages of smoking (e.g. that it is relaxing), and by indicating that the advantages of smoking can also be realized by other activities (e.g. dancing, discussions and sports) or personal attributes (such as clothes). The challenging effects of the discrepancies between the beliefs non-smokers and smokers have towards the consequences of smoking should be clearly indicated.

4. Stress the long-term and short-term disadvantages of initial smoking.

5. Train non-smokers to obtain skills to cope with the (false) arguments of smokers by giving them effective counter-arguments and by developing their assertiveness.

There are several possible methods which could be employed in influencing the subjective norm of non-smokers. A program could stress that important people are against smoking. However, some people's opinions are not always clear (i.e. the peer group), or may change as children grow older (i.e. parents). Increasing the motivation to comply with non-smokers is inconsistent with the approach suggested for reinforcing the non-smoking attitude in which independence, personal responsibility and assertiveness are central themes. It also conflicts with children's tendency to become more independent of adults. Adolescents do conform with the peer group (Conger, 1977), but this group may not be wholly negative towards smoking. An alternative method is to increase in non-smokers the resistance to pressures to smoke which are exerted by smokers. This approach was initiated by Evans et al. (1978) and has been successfully refined by other investigators (see 2.1.).

Common methods applied by these programs are active participation (e.g. group discussion), the stressing of the short-term effects of smoking and the training of skills to cope with pressures to smoke. Some programs utilize commitment techniques to increase maintenance of non-smoking behavior. To influence the subjective norm, a prevention program should:

1. Indicate that the majority of people do not smoke and are opposed to smoking by other people.

2. Demonstrate the direct and modeling processes by which smokers influence non-smokers.

3. Increase resistance in non-smokers to the pressures to smoke exerted by smokers.

4. Discuss the dangers of challenging situations in which pressures to smoke may be stronger.

5. Develop skills in non-smokers to cope with pressures to smoke and with challenging situations. 
6. Increase chances of maintenance of non-smoking behavior by employing commitment techniques such as presentation of the non-smoking decision in front of an audience, or by drawing up and concluding non-smoking contracts. In conclusion, in the successful prevention of smoking, a multicomponent approach must be used (see figure 2.3). This should stress not only short-term effects of smoking and skills which may be used to cope with pressure, but also indicate how these pressures are being exerted.

Since attention is always selective, a prevention program should employ attractive methods such as video films, booklets, posters, and active participation. Schools are convenient to use in that they involve a great number of children. The messages on video and in the classroom should be presented by peers to increase comprehension and understanding. The demonstration of and discussion of the negative effects of smoking and the positive effects of nonsmoking, the alternatives for achieving the positive outcomes of smoking by non-smoking behaviors, and the trap of experimental smoking, should all

$\begin{array}{lll}\text { Levels } & \text { Factors } & \text { Methods }\end{array}$

\begin{tabular}{|c|c|c|}
\hline attention & selectivity & $\begin{array}{l}\text { prevention at schools } \\
\text { video, booklets, posters } \\
\text { active participation }\end{array}$ \\
\hline comprehension & understandability & presentation by youngsters \\
\hline attitude & $\begin{array}{l}\text { (short-term) } \\
\text { consequences }\end{array}$ & $\begin{array}{l}\text { demonstrating effects } \\
\text { discussion of alternatives } \\
\text { experimental smoking }\end{array}$ \\
\hline intention & social influence & indicating (in)direct persuasion \\
\hline behavior & possibilities & $\begin{array}{l}\text { skills, assertiveness } \\
\text { role-plays }\end{array}$ \\
\hline $\begin{array}{l}\text { behavior } \\
\text { maintenance }\end{array}$ & commitment & $\begin{array}{l}\text { contracts } \\
\text { presentation of decision in public }\end{array}$ \\
\hline
\end{tabular}

Figure 2.3: Elements of a prevention program 
reinforce the non-smoking attitude. Apart from the non-smoking attitude the social influence process should be illustrated to ensure a non-smoking intention. To assure that the non-smoking intention is feasible, adolescents should possess the necessary skills to cope with pressures to smoke. To increase the maintenance of the behavior, adolescents should feel committed to their non-smoking decision.

\section{Acknowledgements}

We would like to thank Resi Borgers and Jaap Toet for helping to collect and analyze the data. This research was supported by a grant from the Dutch Cancer Foundation.

\section{REFERENCES}

Aaro, L.E., Hauknes, A., Berglund, E.L. (1981) Smoking among Norwegian schoolchildren 1975-1980. II. The influence of the social environment. Scandinavian Journal of Psychology, 22, 297-309.

Ajzen, I. \& Fishbein, M. (1980) Understanding attitudes and predicting social behavior. Englewood Cliffs: Prentice Hall.

Ashton, H. \& Stepney, R. (1982) Smoking psychology and pharmacology. London: Tavistock. Best, J.A., Flay, B.R., Towson, S.M.J., Ryan, K.B., Perry, C.L., Brown, K.S., Kersell, M.W.,

D'Avernas, J. (1984) Smoking prevention and the concept of risk. Journal of Applied Social Psychology, 14, 257-273.

Biglan, A. \&ichtenstein, E.A. (1984) A behavior-analytic approach to smoking acquisition: some recent findings. Journal of Applied Social Psychology, 14, 207-223.

Botvin, G.J. \& Eng, A. (1982) The efficacy of a multicomponent approach to the prevention of cigarette smoking. Preventive Medicine, 11, 199-211.

Conger, J.J. (1977) Adolescence and youth: psychological development in a changing world. New York; Harper \& Row.

Dutch Foundation on Smoking and Health (SHF) (1985) Annual report, Den Haag.

Evans, R.I., Rozelle, R.M., Mittelmark, M.B., Hansen, W.B., Bane, A.L., Havis, J. (1978) Deterring the onset of smoking in children: knowledge of immediate physiological effects and coping with peer pressure, media pressure and parental modeling. Journal of Applied Social Psychology, 8, 126-135.

Fishbein, M. (1982) Social psychological analysis of smoking behavior. In Eiser, J.R. (Ed.), Social psychology and behavioral medicine (pp. 179-197). New York: Wiley.

Fishbein, M. \& Ajzen, I. (1975) Belief, attitude, intention and behavior: an introduction to theory and research. Reading, Mass.: Addison Wesley. 
Flay, B.R., D'Avernas, J.R., Best, J.A., Kersell, M. W., Ryan, K B. (1983) Cigarette smoking: why young people do it and ways of preventing it. In McGrath, P.J. \& Firestone, P. (Eds.). Pediatric and Adolescent Behavioral Medicine (pp. 132-183). New York: Springer.

Friedman ${ }_{*}$ L.S., Lichtenstein, E., Biglan, A. (1985) Smoking onset among teens: an empirical analysis of initial situations. Addictive Behaviors, 10, 1-13.

Hirschman, R.S., Leventhal, H., Glynn, K. (1984) The development of smoking behavior: conceptualization and supportive cross-sectional survey data. Jourmal of Applied Social Psychology, 14, 184-206.

Hurd, P.D., Johnson, C.A., Pechacek, T., Bast, L.P., Jacobs, P.R., Luepker, R. V. (1980) Prevention of cigarette smoking in seventh grade students. Journal of Behavioral Medicine, 3, 15-28.

Kok, G.J. \& Siero, S. (1985) Tin recycling: awareness, comprehension, attitude,intention and. behawior. Journal of Economic Psychology, 6, 157-173.

Leventhal, H. \& Cleary, P.D. (1980) The smoking problem: a review of the research and theory in behavioral risk modification. Psychological Bulletin, 88, 370-405.

McAlister, A., Perry, C., Maccoby, N. (1979). Adolescent smoking: onset and prevention. Pediatrics, 63, 650-658.

McCaul, K.D., Glasgow, R., O’Neil, K.H., Freeborn, Y., Rump, B.S. (1982). Predicting adolescent smoking. Journal of School Health, 52, 342-346.

McGuire, W.J. (1985) Attitudes and attitude change. In Lindzey, G. \& Aronson, E. (Eds.), Handbook of Social Psychology, Volume II. New York: Random House.

McKennel, A.C.\& Thomas, R.K. (1967) Adults and adolescents' smoking habits and attitudes. London: Government Social Survey, Ministry of Health.

Murray, D.M., Johnson, C.A., Luepker, R.V., Mittelmark, M.B. (1984) The prevention of cigarette smoking in children: a comparison of four strategies. Journal of Applied Social Psychology, 14, 274-288.

Newman, I.M. (1984) Capturing the energy of peer pressure: insights from a longitudinal study of adolescent cigarette smoking. Journal of School Health, 54, 146-148.

Newman, I.M.\& Martin, G.L. (1982) Attitudinal and normative factors associated with adolescent cigarette smoking in Australia and the United States of America: a methodology to assist health education planning. Community Health Studies, 6, 47-56.

Page, R.M. \& Gold, R.S. (1983) Assessing gender differences in college cigarette smoking intenders and non-intenders. Journal of School Health, 53, 531-535.

Rogers, E.M. (1983) Diffusion of innovations. New York: The Free Press.

Salber, E.J., Freeman, H.E., Abelin, T. (1968)Needed research on smoking: lessons from the Newton study. In E.F. Borgatta and R.R. Evans (Eds.), Smoking, health and behavior. Chicago: Aldine.

Schinke, S.P., Gilchrist, L.D. \& Snow, W.H. (1985) Skills intervention to prevent cigarette smoking among adolescents. American Journal of Public Health, 76, 665-667.

Spielberger, C.D., Jacobs, G.A. Crane, R.S. \& Russel, S.F. (1983) On the relation between family smoking habits and the smoking behawiour of college students. International Review of Applied Psychology, 32, 53-69. 


\title{
Self-efficacy: the third factor besides attitude and subjective norm as a predictor of behavioral intentions
}

\author{
Hein De Vries, Margo Dijkstra \& Piet Kuhlman \\ published in Health Education Research, 1988, 3, 273-282
}

\section{ABSTRACT}

When explaining (health) behavior much attention is paid to attitudes and subjective norms. It is assumed that self-efficacy expectations will significantly increase the prediction of behavioral intentions. Therefore, the self-efficacy concept from Bandura's social learning theory has been integrated together with the two factors of the Fishbein \& Ajzen model within one model to explain behavioral intentions. Results of a hierarchical regression analysis support the abovementioned hypothesis: attitudes and subjective norms are significant predictors of the intention (not) to smoke, but self-efficacy expectations add significantly to the prediction of the intention. Self-efficacy has also a direct effect on behavior, after controlling for intention. Our interpreta tion is that in this study self-efficacy probably highly reflects the actual control or the skills of the adolescents. This study also supports the results of Ajzen \& Madden (1986) who indicated that perceived behavioral control expectations increased the predictions of behavioral intentions. Furthermore, it appears that non-smoking adolescents have higher self-efficacy expecta* tions towards non-smoking than smokers. 


\section{$3.1 \quad$ INTRODUCTION}

When explaining (health) behavior much attention is paid to attitudes and social influences regarding an individual's behavior. This study shows that a third cognitive factor, personal efficacy expectations or self-efficacy is also a relevant variable in explaining behavior. Firstly, for the explanation of attitudes and social influences the Fishbein \& Ajzen model (1975) will be used. Secondly, self-efficacy, a concept from the social leaming theory (Bandura, 1977, 1986) is described. Finally, a model about behavior is explained, based on the hypothesis that behavioral intentions can best be predicted by the individual's attitude, subjective norms and self-efficacy expectations. This study thus integrates elements of the social learning theory with the Fishbein \& Ajzen model.

\subsubsection{Attitudes and subjective norms}

Attitudes and social influences are two factors which have been extensively used to explain (health) behavior. The theory of Fishbein \& Ajzen (1975) constitutes an example by assuming that behavior can best be predicted by the behavioral intention, which is determined by the individual's attitude and the perceived subjective norms from other people. Attitude is determined by: 1 . the expectation of various consequences, beliefs (b) about the behavior and 2 . the corresponding evaluations (e) of these consequences. It is measured as follows: Attitude $=\Sigma$ b.e. Subjective norms consist of: 1 . the expectation of other important persons' opinions, normative beliefs (nb) and 2. the degree to which an individual is inclined to agree with these opinions, the motivations to comply (mc). The subjective norm can be determined as follows: Subjective norm $=\Sigma$ nb.mc. The Fishbein \& Ajzen model (1975) has been successfully applied for the explanation of several behaviors (see, for example, Ajzen \& Fishbein, 1980), such as alcohol (London, 1982; McCarty et al., 1983), drugs (Lacy, 1981), marijuana (Budd et al., 1983), seat-belt use (Budd et al., 1984), tin-recycling (Kok \& Siero, 1985), and smoking (Bauman \& Chenoweth, 1984; Chassin et al., 1984; De Vries \& Kok, 1986; Newman \& Martin, 1982; Page \& Gold, 1983). 


\subsubsection{Self-efficacy}

An important question, however, is whether attitudes and subjective norms are indeed the only significant factors that play a role when explaining behavior. Bandura $(1977,1986)$ indicates the importance of personal mastery expectations of an individual regarding a desired behavior. According to Bandura, behavior and behavioral change depend on both outcome expectations and personal efficacy expectations. Outcome expectations consist of beliefs about whether a particular behavior will lead to particular consequences. They are beliefs about consequences of an act and correspond highly with Fishbein's and Ajzen's conception of beliefs. Self-efficacy refers to a person's expectation regarding his capability to realize a (desired) behavior. It does not reflect a person's skills but rather one's judgments of what one can do with whatever skills one possesses. Therefore, self-efficacy relates to beliefs about capabilities of performing specific behaviors in specific situations.

Bandura indicates that self-efficacy expectations can vary along three dimensions: magnitude, generality and strength. Magnitude refers to level of task difficulty. Self-efficacy expectations may be limited to simple tasks (low magnitude), or can include difficult tasks as well (high magnitude). Generality refers to the generalization of efficacy expectations to other behaviors. Efficacy expectations may be limited to one particular domain of behaviors (low generality) or can be extended to other and different behaviors (high generality). Strength refers to the judgement of how certain a person is about the ability to perform a behavior. Weak expectations will be changed more easily by disconfirming experiences than strong expectations. In the latter case, a person will persevere more strongly in his coping efforts to master a particular behavior.

How do self-efficacy expectations develop? Bandura describes that efficacy expectations are based upon four principal sources.

1. People learn through experience. Performance accomplishments or enactive attainments constitute the most influential source of efficacy information. Self-efficacy expectations increase through successive mastery of behavior while repeated failures lower them.

2. Vicarious learning can also contribute to the development of efficacy expectations. Other people serve as a frame of reference. Self-efficacy appraisals are especially sensitive to vicarious information if people have little prior experience with certain behaviors and if the criteria for evaluating performances are diverse or vague. Vicarious experiences are generally weaker than direct ones but can produce persisting changes as well. 
3. Verbal persuasion is another means to insert or to increase efficacy expectations in individuals. People who are persuaded verbally are more likely to mobilize more effort than if they remain convinced of their incapabilities. Persuasion has the greatest impact on efficacy expectations of people who have some reason to believe that they can perform the desired behavior effectively.

4. Physiological information can influence self-efficacy as well. If people have too much arousal, they are less inclined to expect success than if they have moderate levels of arousal. For example, having trembling hands during a driving test might cause a person to think that he is very nervous and unable to drive well.

Although these sources can provide efficacy information, more important is how this information will be appraised cognitively by the individual. Appraisal is an inferential process. Therefore, self-efficacy expectations are not only dependent on information by the above-mentioned sources, but also and perhaps mostly on how a person integrates this information in his cognitive system. For example, people infer high self-efficacy from success achieved through minimal effort on difficult tasks, but they infer low self-efficacy if they had to work hard to master easy tasks.

Self-efficacy seems related to other concepts regarding self-appraisal and coping behavior (see also Strecher et al., 1986). As Bandura (1986) indicates self-efficacy differs from self-concept theories. Self-concept theories are more involved with global self-images, whereas self-efficacy is more concerned with judgments of personal abilities. Self-efficacy differs also from locus of control. A person's belief that behavior is internally controlled does not imply that one is able to carry out the desired behavior. Anxiety is also a different concept. Self-efficacy scales measure whether a person can perform a specific behavior, independent of the fact whether the behavior will be performed with or without anxiety. In the description of coping Seligman (1975) makes a distinction between personal and universal helplessness. Personal helplessness refers to an inidvidual's loss of control of a particular situation and is comparable to low efficacy. Universal helplessness arises when certain consequences take place, independent of an individual's behavior. Self-efficacy is related to the coping process described by Lazarus \& Folkman (1984). Their definition of secondary appraisal concerns the evaluation of how a person can cope with a threat. During this coping process, a person considers 1 . which coping strategies are available, 2. the likelihood that some strategy will result in the expected outcome and 3. whether he can use the coping strategy effectively. It is evident that the second part of the process refers to outcome expectancies while the third part describes self-efficacy. Rogers (1983) subdivides the concept of efficacy into self-efficacy and response-efficacy. While the former is similar to Ban- 
dura's definition, the latter refers to an individual's adequate behavioral response to an undesired behavior. For example, an effective behavioral response in preventing lung cancer is to stop smoking. Response-efficacy can also be defined in terms of the Fishbein \& Ajzen model as beliefs towards an attitude object.

The Fishbein \& Ajzen model has often been the subject of further exploration (see, for instance, Miniard \& Cohen, 1981; Budd et al., 1983; Fredericks \& Dosset, 1983; Wittenbraker et al., 1983; Liska, 1984; Schifter \& Ajzen, 1985; Bagozzi et al., 1986; Budd \& Spencer, 1986; Grube et al., 1986; Sutton, 1987). Recently, Ajzen \& Madden (1986) have added perceived behavioral control as a third factor. This factor contributed significantly to the prediction of the intention besides attitude and subjective norm. Although the description and operationalization resemble self-efficacy (they also refer to Bandura's concept of self-efficacy), their notion covers both perceived and actual control of behavior. However, Bandura (1986) indicates that self-efficacy and actual control are different concepts. Although self-efficacy will be influenced by actual control, the surplus value of self-efficacy expectations concerns the cognitive appraisal of actual control. Bandura cites a study of Collins (Bandura, 1986, p. 424) which demonstrates that subjects with an equal ability to solve mathematical problems, differed in solving a mathematical task because of (manipulated) differences in their self-efficacy.

Therefore, a clear conceptual distinction has to be made between self-efficacy expectations (or perceived behavioral control) and the abilities or skills (or actual control) of a person. When one assesses skills just before the assessment of behavior, there will probably be a close correspondence between self-efficacy and actual control in a relatively simple task. This may be the case in the Ajzen \& Madden experiment. Students had to estimate their chances of getting an " $A$ " just before their final exams. Their success will mostly be dependent on the acquired knowledge of the past weeks. Consequently self-efficacy expectations will correspond closely with actual control. However, this correspondence may be less clear as estimates about simple tasks will be difficult (e.g. because one is not familiar with the requirements of the task) or when behavior is complex and dependent on several variables. Thus, self-efficacy and actual control are related, but are different concepts. 


\subsection{MODEL FOR BEHAVIORAL CHANGE}

From the foregoing, the following model to explain behavioral intentions and behavior can be deduced. Whether someone intends to perform a particular behavior is determined by personal conceptions concerning this behavior (the attitude), the sociall pressures experienced from other important persons (the subjective norms) and personal expectations about the skills needed to realize the behavior (self-efficacy). It is possible that a positive attitude towards, for example, living on a diet, and positive influences from the social environment go together with negative expectations concerning the skills needed to live on a diet (e.g. my cooking does not suffice to prepare complicated dishes). On the other hand, a person having positive expectations about the necessary skills may have a negative attitude towards dieting behavior. Hence, models for change of behavior and health education programs have to pay attention to increasing personal efficacy expectations as well. According to our conception attitudes, subjective norms and self-efficacy are cognitive factors. Together they result in the intention to perform the behavior. A further elaboration of this model. suggests that the relation between the three factors could be interactive instead of linear. In this case intentions will be positive if self-efficacy is high and either or both attitude and social norms are positive as well. However, Ajzen \& Madden (1986) found no evidence for significant interactions between perceived behavioral control and attitude or subjective norms. The realization of the behavior is not only dependent on a positive intention, but also on the skills or actual control a person has to realize the behavior. The above-mentioned is summarized in the following model to explain behavioral intentions and behavior (see figure 3.1) in which elements of Bandura's social leaming theory and the Fishbein \& Ajzen model are integrated.

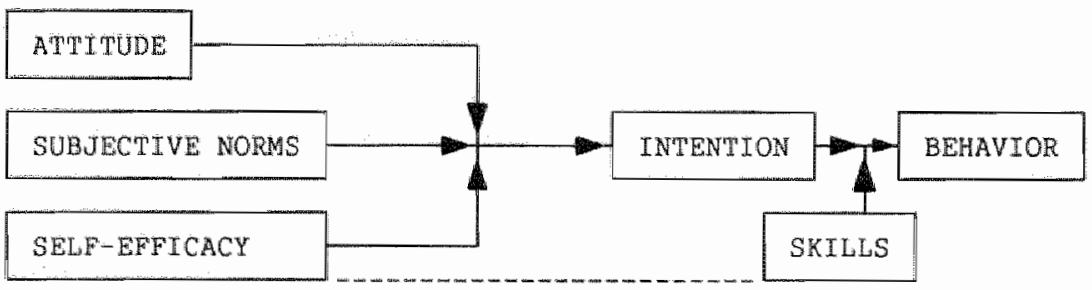

Figure 3.1: Model to explain behavioral intention and behavior 
This study aims at proving the predictive value of self-efficacy when explaining (health) behavior and is based on the assumption that, besides the attitude and the subjective norm, personal efficacy expectations may have an unique contribution in predicting behavioral intentions. Ajzen \& Madden (1986) also found a direct relationship between self-efficacy and behavior, which can be expected: 1 . if the behavior is not under complete volitional control, and 2. if self-efficacy reflects actual control in a situation with some accuracy. As smoking is a behavior which satisfies these conditions, we could expect a direct effect of self-efficacy on behavior. Furthermore, the possibility for interactions between attitude, subjective norms and efficacy will be analyzed. A second objective is to examine the possible differences between smokers and non-smokers with regard to their personal efficacy expectations. The assumption is that non-smokers will have higher self-efficacy about nonsmoking than smokers.

\subsection{METHOD}

\subsubsection{Sample}

In this study, carried out in 1986,85 third-grade Dutch pupils of various secondary schools participated. Forty percent of them were male $(\mathrm{N}=34)$ and $60 \%$ of them female $(\mathrm{N}=51)$. Although an attempt was made to involve a secondary technical school this did not succeed; therefore females are slightly over-represented in the sample. Age of the adolescents varied between 14 and 17 years $(16,59,21$ and $4 \%$ respectively).

\subsubsection{Questionnaire}

Questions to assess attitudes, subjective norms and intentions were based on the questionnaire used by De Vries \& Kok (1986). With the aid of, among others, a factor analysis with respect to attitude and subjective norms, those questions were selected which were thought to be the most relevant. This resulted in 16 questions on the evaluations and the beliefs of the following consequences of smoking: a bad physical condition, expense, coughing, cancer, damaged lungs, showing off, it causes passive smoking for others, nausea, irritated eyes, com- 
bating boredom, a bad health, a nice taste, smelling badly, sociability, irritating other people, getting wrinkles. Evaluations and beliefs were measured on a seven point scale.

Eight questions on the normative beliefs and the motivations to comply also used seven-point scales, and assessed the subjective norms of: mother, father, brother, sister, friends, classmates, teachers and the physician.

Although the questionnaire also used direct measures of attitudes and subjective norms, these are not used in this study because of lower predictive value for the intention than the indirect measures of attitudes and subjective norms. The nine questions on self-efficacy had never been used before. They comprised: finding it difficult/easy when friends smoke; being able to stop smoking when wanting to; knowing a reason to refuse a cigarette offered; being able to refuse a cigarette offered by parents; being able to refuse an offer; succeeding in staying/becoming a non-smoker; being able to refuse a cigarette offered by friends; being able to maintain to refuse smoking in spite of being called a coward. These questions were measured on a seven-point scale where +3 means high efficacy and -3 means low efficacy. One item measured the intention to smoke: "I intend to smoke $(+3)$, not to smoke $(-3)$ ". Behavior was assessed by one question. Pupils were asked to indicate whether they: 1 . had never smoked, not even one cigarette, 2 . had experimented with smoking (having smoked up to five cigarettes) but were not regular or occasional smokers, 3. were exsmokers, 4. smoked occasionally, 5. smoked at least once a week or 6 . smoked every day. To check their statements the number of cigarettes smoked per week and per month were asked as well.

\subsubsection{Procedure}

The pupils were requested to complete the questionnaire. A brief explanatory introduction provided them with information on how to answer the questions. This explanation was repeated regularly. The complete study further included the film "The Feminine Mistake" and a final assessment to determine the effects of the film. This study only describes the results of the pretest. 


\section{$3.4 \quad$ RESULTS}

\subsubsection{Correlations between attitude, subjective norm and self-efficacy}

A factor analysis on the self-efficacy items resulted in one factor. The nine questions regarding self-efficacy formed a reliable scale $(\alpha=.80)$. For the analysis these questions have been summed to form one self-efficacy scale. Figure 3.2 shows that the correlations of the attitude and the subjective norm with the intention were respectively .66 and .47 . These correlations are comparable to the correlations found by De Vries \& Kok (1986) in a similar study: these were respectively .61 and .50 . Self-efficacy had the same predictive value as the attitude: the correlation with intention was also .66. The correlations of attitude and subjective norms with behavior were respectively .55 and .48 . The correlation between self-efficacy and behavior was .71 which is higher than the correlation between self-efficacy and intention, and only slightly lower than between intention and behavior $(r=.74)$. One explanation of this high correlation is that self-efficacy reflects actual control (or skills) to a high degree and thus has a high direct effect on behavior.

The multiple correlation (R) of the attitude, the subjective norm and self-efficacy with the intention was .79 . This means that the three variables together explained $63 \%$ of the variance for the behavioral intention. Figure 3.2 also shows the intercorrelations between the three variables. It appears that all three

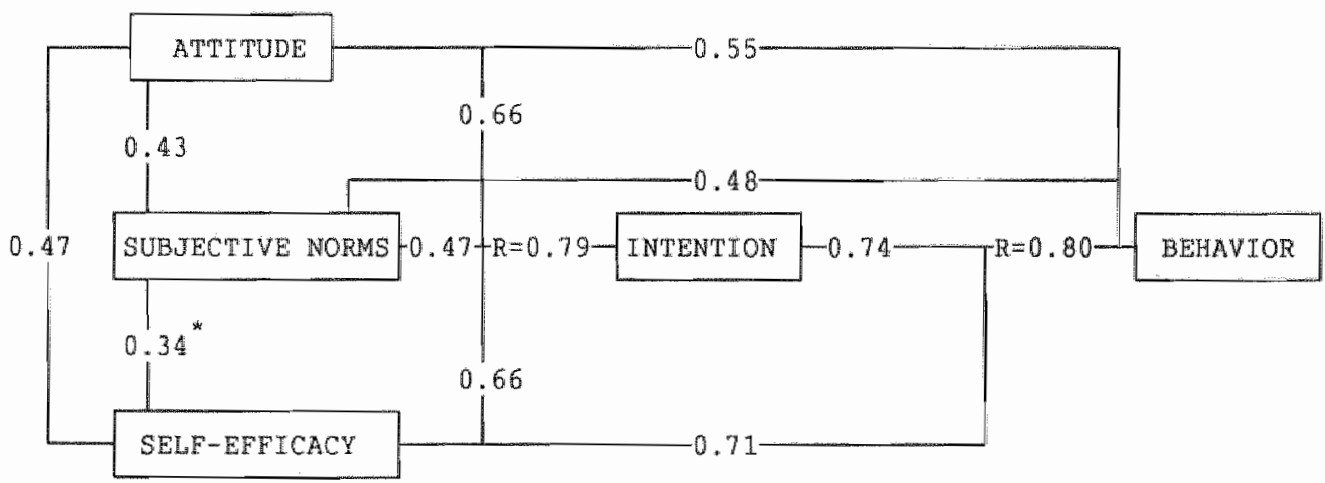

Figure 3.2: Correlation of attitude, subjective norms and self-efficacy with behavioral intention and behavior $(\mathrm{N}=68 ; \mathrm{p}<.001 ; * \mathrm{p}<.005)$. 
factors correlated moderately. Self-efficacy correlated .47 with the attitude and .34 with the subjective norm. The attitude correlated .43 with the subjective norm.

It is possible that self-efficacy is not a different factor but merely a result of attitude and subjective norm. To determine whether self-efficacy had a unique contribution to the prediction of the behavioral intention apart from the contribution of attitude and subjective norm, a hierarchical regression analysis was conducted. For the prediction of the interition, attitude and subjective norm were entered first, and self-efficacy second.

Table 3.1 shows the results of the hierarchical regression analysis. It appears that the attitude explained $44 \%$ of the variance in behavioral intention $(p<.001)$, and that the subjective norm added $4 \%(\mathrm{p}<.05)$. The personal efficacy expectations, however, added afterwards $15 \%(\mathrm{p}<.001)$. It is evident that, besides attitude and subjective norm, self-efficacy had a significant and unique contribution to the prediction of the behavioral intention. Table 3.1 furthermore shows the results of the hierarchical regression analysis for the prediction of behavior. In this analysis, the intention was entered on the first step while attitude, subjective norms and self-efficacy were entered stepwise on the second step. The results of the analysis show that self-efficacy had a significant unique contribution of $9 \%(\mathrm{p}<.001)$ in the prediction of behavior. The intention and self-efficacy explained $63 \%$ of the variance of behavior. Our interpretation is that the self-efficacy scale corresponded highly with the actual control or the skills of the adolescents, and therefore could have a direct effect on behavior apart from intention.

Table 3.1: Hierarchical multiple regression analysis $(\mathrm{N}=68)^{1}$

\begin{tabular}{llllllllll}
\hline Step & Variable & $R$ & $R^{2}$ & $R^{2}$ change & $F$ & $\beta$ & $p<$ & $r$
\end{tabular}

\section{Prediction of intention:}

$\begin{array}{lllllrlll}1 & \text { Attitude } & 0.66 & 0.44 & 0.44 & 51.00 & 0.66 & 0.001 & 0.66 \\ 2 & \text { Subjective Norm } & 0.69 & 0.48 & 0.04 & 5.09 & 0.22 & 0.027 & 0.47 \\ 3 & \text { Self-efficacy } & 0.79 & 0.63 & 0.15 & 25.44 & 0.43 & 0.001 & 0.66\end{array}$

\section{Prediction of behavior:}

$\begin{array}{lllllllll}1 & \text { Intention } & 0.74 & 0.55 & 0.55 & 79.20 & 0.74 & 0.001 & 0.74 \\ 2 & \text { Self-efficacy } & 0.80 & 0.63 & 0.09 & 15.86 & 0.40 & 0.001 & 0.71\end{array}$

${ }^{1}$ due to missing values on the five factors, the population was reduced to 68 
To test the assumption whether the relationship between altitude, subjective norms and efficacy was interactive, self-efficacy was multiplied with attitude and with subjective norms. (Note: as the attitude and subjective norm scores initially varied from -3 to +3 , the scores were transformed to positive scores to avoid artificial effects for the multiplicative variables.) The resulting product scores were entered into the hierarchical regression analysis after the basic variables (see also Cohen, 1978). The interactions did not show a significant effect on the predictions of intention, nor on behavior. Therefore we did not find any support for an interactive nature of the model.

\subsubsection{Smokers and non-smokers: attitude and subjective norm}

The differences between smokers and non-smokers were mostly similar to those found by De Vries \& Kok (1986). The present study also revealed that nonsmokers more than smokers ( $\mathrm{p}<.05$ ) believed that smoking causes bad health, a bad physical condition, damages the lungs, forces others into passive smoking, and causes a bad smell and irritated eyes. Smokers did recognize these negative consequences, but minimized their importance. Smokers more strongly believed $(p<.05)$ than non-smokers that smoking has several advantages, like sociability, good taste and relief of boredom. Both groups did not differ significantly about opinions on smoking being expensive and offensive to others, causing coughing, nausea, wrinkles, and increasing the chances of cancer and the incidence of showing off.

Non-smokers experienced a stronger sociall pressure against smoking from their parents, brothers and sisters, friends, classmates and the physician ( $\mathrm{p}<.05)$. They did not differ on the slight negative social influence about smoking coming from the teachers.

\subsubsection{Differences in self-efficacy}

Multivariate analysis showed that smokers and non-smokers had different opinions about their personal efficacy expectations $(F=71,15 ; \mathrm{df}=1,83 ; \mathrm{p}<.001$ ). The results of the univariate analysis are depicted in table 3.2 .

Table 3.2 shows that smokers perceived greater difficulties than non-smokers: not to smoke when friends are smoking, in thinking of a reason to refuse a cigarette, to refuse an offer of a cigarette, to refuse cigarettes offered by 
Table 3.2. Reponted mean scores of self-efficacy; comparison of smokers (S) with nonsmokers (NS).

\begin{tabular}{lll}
\hline item & $S$ & $N S$ \\
& $(N=21)$ & $(\mathrm{N}=63)$ \\
&
\end{tabular}

When my friends smoke I find it very hard/easy

$\begin{array}{lll}\text { not to smoke } & -0.76 & 2.21^{*}\end{array}$

When I should wish to stop smoking, I shall certainly/

certainly not be able to do so

$0.30 \quad 1.31 *$

When someone offers me a cigarette, I certainly do/ $\begin{array}{lll}\text { certainly do not know a reason to refuse that cigarette } & -1.23 & 2.19 *\end{array}$

When my parents offer me a cigarette, I certainly do/do not dare say no

When I am offered a cigarette, If find it very difficult/ easy to refuse

For me it is very difficult/easy to stay (become) a non-smoker

When my friends offer me a cigarette, I certainly do/do not dare say no

When people call me a coward because I do not want to smoke, I certainly do/do not know what to say

I find it very difficult/easy to explain to other people that $I$ do not want to smoke

0.68 $1.86^{*}$

$+3=$ high self-efficacy towards non-smoking; $-3=$ low self-efficacy; $\alpha=.80 ; * p<.05$

parents and to explain to other people that they do not want to smoke. Smokers also perceived greater difficulties in being able to stop smoking, and to become a non-smoker. The latter is of course quite understandable.

Although non-smokers had higher self-efficacy expectations about nonsmoking in several situations, they did not differ from smokers on all situations. Smokers as well as non-smokers perceived themselves as being capable of refusing a cigarette offered by friends, and of knowing how to respond when called a coward because of not wanting to smoke. 


\subsection{SUMMARY AND CONCLUSIONS}

The most important goal of this study was to support the assumption that self-efficacy, apart from attitude and subjective norms, has a significant unique contribution to the prediction of the behavioral intention. It appeared that attitude and self-efficacy each explained $44 \%$ of the variance of intention with regard to smoking. The subjective norm explained $22 \%$. Together, after correction for overlap, the three variables explained $63 \%$ of the variance of the behavioral intention.

Theoretically it is possible that personal efficacy expectations can be derived from, or are based upon attitude and subjective norm. In that case, self-efficacy cannot be considered as a separate factor or concept. However, the results of a hierarchical regression analysis indicated that personal efficacy expectations, besides the attitude and the subjective norms, had a unique contribution. After attitude and subjective norms, together explaining $48 \%$ of the variance, self-efficacy added an additional $15 \%$. Together with attitude and subjective norm, self-efficacy thus appeared to be a significant factor when predicting the behavioral intention. This study also supports the results of a study by Ajzen \& Madden (1986) which indicated that perceived behavioral control expectations increase significantly the predictions of behavioral intentions.

After controlling for the intention, which explained $55 \%$ of the variance, self-efficacy also had a direct effect on behavior and added $9 \%$. Our interpretation is that this direct effect of self-efficacy on behavior reflects the impact of skills or actual control. Ajzen \& Madden (1986) reported a similar result and stated that this effect is likely to be the case under two conditions. First, the behavior must at least be determined by factors beyond a person's control. If the behavior was under the complete control of an individual, self-efficacy expectations would not be relevant. Second, self-efficacy expectations should reflect actual control with some degree of accuracy. It appeared that the correspondence between self-efficacy and actual control can also be high for more complex behaviors which require, for example, refusal skills, such as smoking. However, one might expect the direct effect of self-efficacy to disappear in future studies, if actual control could be assessed as well. In such a case we assume that it would be highly unlikely that self-efficacy would still have a direct effect on behavior if it is controlled for intentions and actual control. On the other hand, if future research does indicate that there is often a high correspondence between self-efficacy and actual control, there may be less need to include the difficult assessments of skills. 
Non-smokers appeared to have higher self-efficacy than smokers. This might possibly be explained by the fact that in a number of situations smokers are likely to be less motivated to refuse a cigarette because they (want to) smoke. However, smokers and non-smokers did not differ from each other on all items. Therefore, the difference between smokers and non-smokers cannot be completely ascribed to differences of motivation. Moreover, in order to support this assumption, differences within non-smokers (intenders versus nonintenders) have been analyzed as well. A similar pattern for self-efficacy was found as the one characteristic for smokers and non-smokers.

At present, it is not yet clear for which behavior self-efficacy or attitude or subjective norms will be the most important predictor. From a health educational point of view it might be interesting to know which factor has the greatest impact on an individual's behavior. If a decision for a behavior is mostly dependent on, for example, self-efficacy expectations, health educational activities might focus only or mostly on influencing this factor. Personal efficacy expectations of skills may play a significant role when an individual needs to have specific skills in order to perform a particular behavior (e.g. refusing to smoke cigarettes, to drink alcohol at a party, proposing to use condoms). Attitude may play an important role when realization of behavior is relatively easy (e.g. giving up excessive sunbathing), but when expectation of advantages and disadvantages is more decisive. Subjective norm is expected to be an important predictor in case of behavior that is closely related to other people (e.g. in the decision to become a vegetarian). Den Bandt (1982) supports this assumption. In her study on voluntary childlessness the subjective norm was as important a predictor as the attitude $(r=.62)$. However, more research is needed in order to obtain insight into the relative importance of these three factors for various behaviors. From the longitudinal point of view it would also be interesting to determine which of the three factors will be the best predictor of future behavior.

One of the implications of the above findings is that smoking prevention programs should increase perceptions of self-efficacy in non-smokers in order to enhance their chances of behavior maintenance. However, behavior change and behavior maintenance are not only dependent upon attitude, subjective norms and efficacy expectations (see figure 3.3). Prevention research indicates that several factors are relevant (see e.g. Flay et al., 1983), and which will have to be taken into consideration if we want to influence health behaviors. Skills are needed for the realization of the desired behavior. For instance, if someone wants to live on a diet he or she has to know how to prepare low-calory dishes. Barriers, such as the unavailability of certain ingredients and the inability to buy them, may hamper realization of behavior. Outcome expectations should corre- 


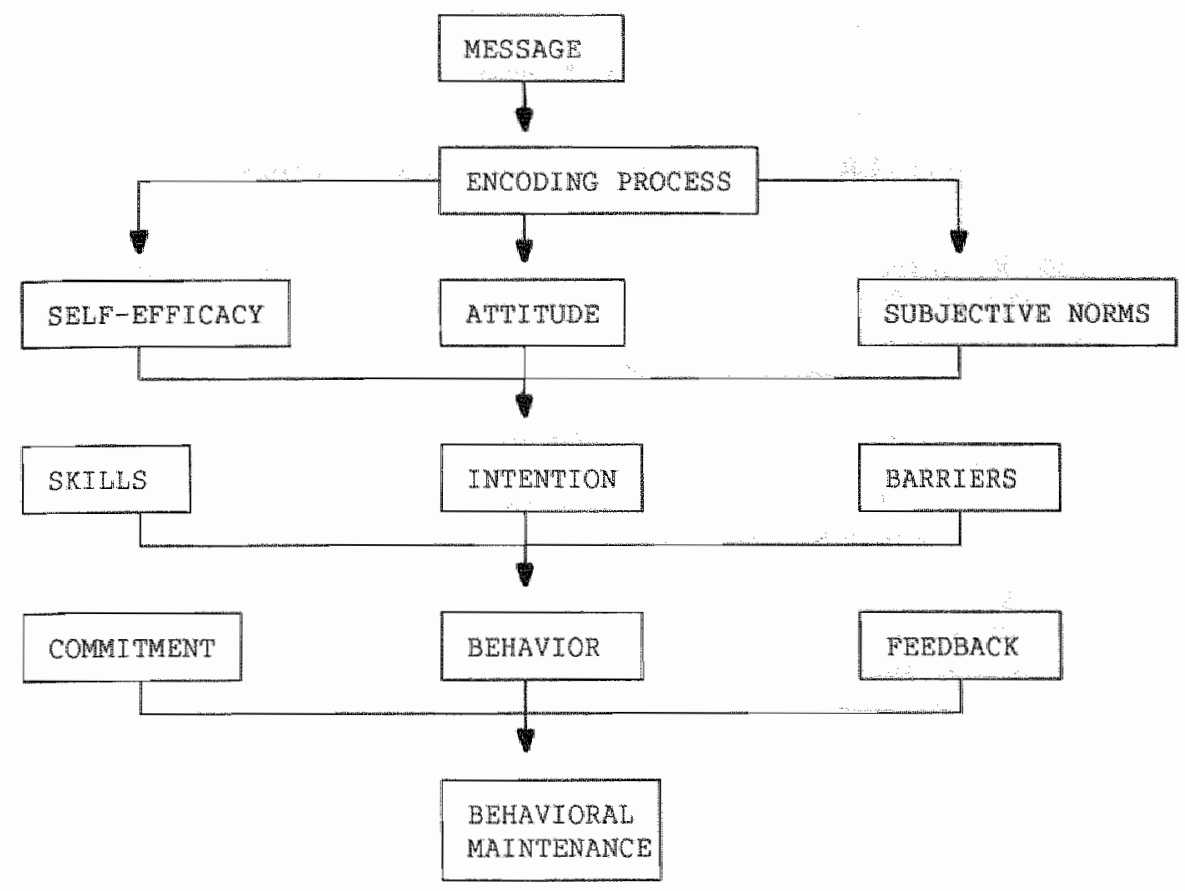

Figure 3.3: Model of information processing and behavioral change and behavioral maintenance

spond with a person's expectations about the behavior. Thus feedback of the new behavior should correspond with expected effects. The likelihood of maintenance of behavior will increase when a person shows commitment. When publicly shown, this commitment will be stronger than when expressed anonymously (Kiesler, 1971; Janis \& Mann, 1977).

Furthermore, Petty \& Cacioppo (1986) indicate that attitude and behavior change do not always occur by extensive cognitive processing of information by the individual, but may be caused by simple affective mechanisms as well. After having received a message, the individual can encode it in two different ways. On the one hand, a person may start extensive cognitive processing by paying much attention to the attitude, the subjective norms, and self-efficacy expectations. On the other side, a person may process the message using more simple decision rules and will focus, for example, on only some consequences. The impact of self-efficacy expectations are thus also dependent on the way an individual processes information. Chances for using the cognitive route increase if, for example, the individual is involved in the subject. Therefore, heallth education should take into account the characteristics of the target group. 
If the target group is not really motivated, the chances of extensive cognitive processing of information by this group will be rather low. In such a case campaigns utilizing a more affective approach may be more successful. However, Petty \& Caccioppo (1986) also state that chances of long-term behavioral change will be higher if it is induced by the cognitive route.

In conclusion, there is evidence that supports the assumption that self-efficacy is an important factor besides attitudes and subjective norms in determining the intention. However, behavioral change and its maintenance is also dependent on other factors, and on the way an individual processes information regarding these factors. Further research is needed to enhance insights in processes which are relevant for information processing, health education and prevention of unhealthy behaviors.

\section{Acknowledgements}

We would like to thank Dirk-Jan Den Boer, Harm Hospers and Ree Meertens for their assistance. This study was supported by a grant from the Dutch Cancer Foundation.

\section{REFERENCES}

Ajzen, I. \& Madden, J.T. (1986) Prediction of goal-directed behavior: attitudes, intentions, and perceived behavioral control. Journal of Experimental Social Psychology, 22, 453-474.

Ajzen, L, \& Fishbein, M. (1980) Understanding attitudes and predicting social behavior. Englewood Cliffs: Prentice Hall.

Bagozzi, R.P. (1986) Attitude formation under the theory of reasoned action and a purposeful behaviour reformulation. British Journal of Social Psychology, 25, 95-107.

Bandura, A. (1977) Self-efficacy: toward a unifying theory of behavior change. Psychological Review, 84, 191-215.

Bandura, A. (1986) Social Foundations of thought and action: a social cognitive theory. New York: Prentice-Hall.

Bauman, K.E. \& Chenoweth, R.L. (1984) The relationship between the consequences adolescents expect from smoking and their behavior: a factor analysis with panel data. Journal of Social Psychology, 14, 28- 41 .

Budd, R., Bleiner, S. \& Spencer, C. (1983) Exploring the use and non-use of marijuana as reasoned actions: an application of Fishbein and Ajzen's methodology. Drug and Alcohol Dependence, 11, 217-224.

Budd, R., North, D. \& Spencer, C. (1984) Understanding seat-belt use: a test of Bentler and Speckart's extension of the 'theory of reasoned action". European Journal of Social Psychology, 14, 69-78. 
Budd, R.J. \& Spencer, C.P. (1986) Lay theories of behavioral intention: A source of response bias in the theory of neasoned action? British Journal of Social Psychology, 25, 109-117.

Cohen, J. (1987) Partialed products are interactions: partialed powers are curve components. Psychological Bulletin, 85, 858-866.

Chassin, L., Presson, C.C., Bensenberg, M., Corty, E., Olshavsky, R.W. \& Sherman, S.J. (1984) Predicting adolescents' intentions to smoking cigarettes. Jownal of Health and Social Behavior, 22, 445-455.

Den Bandt, M.L. (1982) Voluntary childess women" explorations of choice. Thesis. Deventer: Van Loghum Slaterus.

De Vries, H. \& Kok, G.J. (1986) From determinants of smoking behaviour to the implications for a prevention programme. Health Education Research, 1, 85-94.

Fishbein, M. \& Ajzen, I. (1975) Belief, attitude, intention and behavior: an introduction to theory and research. Reading, Mass.: Addision Wesley.

Flay, B.R., D'A vernas, J.R., Best, J.A., Kersell, M. W., Ryan, K.B. (1983)Cigarette smoking: why young people do it and ways of preventing it. In P.J. Mc Grath \& P. Firestone (Eds.), Pediatric and adolescent behavioral medicine (pp. 132-183). New York: Springer.

Fredricks, A.R., \& Dossett, D.L. (1983) Attitude-behavior relations: A comparison of the Fishbein-Ajzen and Bentler-Speckart models. Journal of Personality and Social Psychology, 40, 226-238.

Grube, J.W., Morgan, M. \& McGee, S.T. (1986) Attitudes and nomative beliefs as predictors of smoking intentions and behaviours: A test of three models. British Journal of Social Psychology, 25, 81-93.

Janis, I.L. \& Mann, L. (1977) Decision making: a psychological analysis of conflict, choice commitment. New York: Free Press.

Kiesler, C.A. (1971) The psychology of commitment: Experiments linking behavior to bellefs. New York: Academic Press.

Kok, G.J. \& Siero, S. (1985) Tin recycling: awareness, comprehension, attitude, intention and behavior. Joumal of Economic Psychology, 6, 157-173.

Lacy, W.B. (1981) The influence of attitudes and current friends on drug use intentions. The Journal of Social Psychology, 113,65-76.

Lazarus, R.S. \& Folkman, S. (1984) Stress, appraisal and coping. New York: Springer publications.

Liska, A.E. (1984) A critical examination of the causal structure of the Fislabein/Ajzen attitude-behavior model. Social Psychology Quarterly, 47, 61-74.

London, F.B. (1982) Attitudinal and social normative factors as predictors of intended alcohol abuse among firth- and seventh-grade students. Journal of School Health, 52, 244-249.

McCarty, D., Morrison, S., Mills, K.C. (1983) Attitudes beliefs and alcohol use; an analyses of relationships. Journal of Studies on Alcohol, 2, 328-341.

Miniard, P.W. \& Cohen, J.B. (1981) An examination of the Fishbein-Ajzen behavioral-intentions model's concepts and measures. Journal of Experimental Social Psychology, 17. 309-331.

Newman, I.M. \& Martin, G.L. (1982) Attitudinal and normative factors associated with adolescent cigarette smoking in Australia and the United States of America: A methodology to assist health education planning. Community Health Studies, 6, 47-56.

Page, R.M. \& Gold, R.S. (1983) Assessing gender differences in college cigarette smoking: intenders and non-intenders. Journal of School Health, 53,531-535. 
Petty, R.E., Cacioppo, J.T. (1986) The elaboration likelihood model of persuasion. In: Berkowitz, L. (Ed.), Advances in experimental Sacial Psychology, Vol. 19. London: Academic Press.

Rogers, R. (1983) Cogmitive and physiological processes in fear appeals and attitude change: a revised theory of protection motivation. In J.T. Cacioppo \& R.E. Petry (Eds.), Social Psychophysiology - A source book (pp. 153 176). New York: Guilford Press.

Schifter, D.E. \& Ajzen, I. (1985) Intention, perceived control, and weight loss: An application of the theory of planned behavior. Jownd of Personality and Social Psychology, 49, 843.851 .

Seligman, M.E.P. (1975) Helplessness. San Francisco: Freeman.

Strecher, V.J., McEvoy De Vellis, B., Brecker, M.H. \& Rosenstock, I.M. (1986) The role of self-efficacy in achieving health behavior change. Health Education Quarterly, 13, 73-91.

Sutton, S. (1987) Social-psychological approaches to understanding addictive behaviours: attitude-behaviour and decision-making models. British Journal of Addiction, 82,355 370.

Wittenbraker, J., Gibbs, B.L. \& Kahle, L.R. (1983) Seat belt attitudes, habits, and behaviors: An adaptive amendment to the Fishbein model. Journal of Applied Social Psychology, 13, 406-421. 


\title{
4 The development of a peer-led smoking prevention program on video
}

\author{
Hein De Vries, Margo Dijkstra, Resi Borgers \& Gerjo Kok
}

\section{ABSTRACT}

In this study the development of a peer-led smoking prevention program on video and the program ratings by teachers and students are described. The results of group interviews and questionnaires indicated that teachers and students liked the program, because of the alternation of the video with activities. The peer-led approach on video was easy to employ and facilitated utilization of the program in schools. Program ratings were best predicted by students' evaluation of the assistance by their teacher during the program, followed by the evaluation of the assistance by their peer leader, students' smoking status, and type of school. The program successfully delayed smoking onset in vocational school students, and experimental smoking in high school students.

It is concluded that program development needs to receive more attention as it is a crucial factor determining program impact. Therefore, program development needs to incorporate the following aspects. First, program development needs to be planned carefully, which will be enhanced by imbedding it in a health promotion framework focusing on the analysis of the problem, behavioral change, and continuity of prevention activities. In this study an $A B C$ framework was formulated. Second, theories on behavioral change need to be applied. Utilization of these theories was enhanced in this study by using an adapted version of the matrix of McGuire as a program matrix. Third, evaluation studies need to assess program ratings and behavioral effects. 


\section{$4.1 \quad$ INTRODUCTION}

From 1984 to 1989 the Dutch Smoking Prevention Project was involved in developing a Dutch social influence approach to deter adolescents from smoking. Results of a one year follow-up study indicated that the program had a preventive impact on smoking. Regular smoking was delayed in vocational school students', while experimental smoking was delayed in high school students (De Vries et al., in preparation).

Many smoking prevention programs have been developed and evaluated on their behavioral effects (see for an overview e.g. Best et al., 1988). In addition, several smoking prevention programs have been developed that have not been evaluated. Although program development does receive a lot of attention from practitioners in the field, it receives limited attention in the published literature of health education. Emphasis in program evaluation studies has often been placed on attempts to judge the worth of programs by assessing the behavioral impact using (quasi)-experimental designs. However, this impact is dependent on the planning and development of the program, and its utilization and implementation by the users in the field (Basch, 1984, 1987). Consequently, formative evaluation of a new program including: program implementation, site response, recipient response, practitioner response and the competencies of the personnel, is important (Green \& Lewis, 1986). The aim of this paper is, therefore, to focus more explicitly on discussing program planning, development, and acceptability.

In outlining the process of program development, the most important features will be described. First, program development needs to include problem analysis, application of behavioral change theories, program acceptance, and implementation of successful programs on larger scale. Second, it should pay attention to the relation between information processing and behavioral change. Third, program developers need to plan and evaluate programs carefully. The last section shows the program ratings, and describes whether program ratings were dependent on the quality of the videos, the activities, working in groups, the peer leader, and the teacher.

1 In the Netherlands several types of secondary schools are prevalent. Two main types can be distuinguished: vocational schools preparing students for vocational and domestic jobs like electrician, carpenter, cashier, housewife, and high schools preparing students for continued specialized education (sometimes university) 


\subsection{PLANNING}

In developing the Dutch Smoking Prevention Program we used a health promotion framework that deals with many of the above-mentioned issues. It is called the ABC health promotion framework (De Vries, 1989), and is strongly influenced by health education planning models developed by Green et al. (1980) and by Kok (1988). It distinguishes three important phases: A: Analysis of health problems, B. Behavioral interventions, C. Continued prevention. Each phase will need careful attention before we can move to the next (see figure 4.1).

Relevant issues for the Analysis phase are: the severity of the health problem, its relation with different behaviors, the preventability of these behaviors, and the target groups.

Four sub-phases are relevant for developing interventions. First, one needs to know the determinants of unhealthful behavior. Programs focusing on the wrong determinants will probably have little impact (Fishbein \& Ajzen, 1975).

\section{A: ANALYSIS OF THE PROBLEM}

1. Is the problem serious

2. Which behaviors are related to the problem

3. Which risky behaviors can be altered

4. Which target group

B: BEHAVIORAL CHANGE

1. Why behave people unhealthy $\rightarrow$ determinants

2. How to change behavior $\rightarrow$ small scale interventions

3. Which type of intervention

4. Evaluation of program: process \& effect

\section{C: CONTINUED PREVENTION}

1. Strategies for implementation on large scale

2. Usage of health projects by several sectors

3. Health promoting policies 
Second, we have to understand how behavioral change can be achieved (McGuire, 1985). Third, a choice for the type of intervention has to be made. Three types can be considered: health education (often only one or few sources, and only one sector is involved), a community approach (education is provided by more sources and often focusses on several health behaviors), and an intervention mix using a health promotion approach (De Leeuw, 1988; Green \& Lewis, 1986). In this paper we will only concentrate on program development for health education. Finally, small scale interventions are needed to assess program's ratings by their users, whether behavioral determinants have been changed (McCaul \& Glasgow, 1985), and the behavioral effects of the program.

To enhance continuation of preventive activities, diffusion of successful programs is necessary. Therefore, we need diffusion strategies, health promoting policies, and usage of health projects by several sectors. Theories on diffusion have been described by Basch (1984), Bandura (1986), Green \& McAlister (1984), and Rogers (1983). Recently in Texas a project has started to study the process of diffusion of smoking prevention programs utilizing these theoretical conceptions (Parcel et al., 1989). In studying this process four phases are distinguished: dissemination, adoption, implementation and maintenance. With respect to smoking, Best et al. (1988) indicated that planned diffusion, program packaging, provider training, implementation monitoring, and costing constitute important considerations in the diffusion process. Health promoting policies refer to a variety of policies, for instance structural measures enhancing use of the program, smoke free areas, etc.. If more sectors are involved in a health project, this will enhance impact on health (e.g. not only smoking prevention in schools but also a healthful life style program for the community).

\subsection{BEHAVIORAL CHANGE AND INFORMATION PROCESSING}

Before developing interventions we should know how behavioral change can be achieved, and which phases and factors are relevant. This will enable us to formulate clear goals that can be elaborated in more detail. The following model on behavioral change and information processing leans heavily on findings formulated by McGuire (1985), although insights from other theories have been used as well (Bandura, 1986; Fishbein \& Ajzen, 1975; Janis \& Mann, 1977; Kok, 1988; Rogers, 1983; Petty \& Cacioppo, 1986). Information is conceptualized in a broad sense, varying from factorial to behavioral information like behavioral feedback and skills training. 
Behavioral change can result from processing information in four phases: information, reception, encoding, and behavioral impact (see figure 4.2).

Information. The first step for realizing behavioral change by health education is providing information that motivates individuals to change. Its persuasive impact is determined by four types of information variables: receiver, message, channel, and source variables.

Receiver variables refer to the characteristics of the target group that influence information processing. For instance, an individual should have a certain amount of motivation for the subject to pay attention to a message. However, when an individual is very much involved in, and feels highly committed to a subject, it is hard to change his behavior. Furthermore, age, gender and educational level are important as well. Message variables concentrate on the persuasive effects of messages. To increase persuasiveness it is often important to formulate explicit conclusions. Repetition of the message is useful, but should not be exaggerated (e.g. not more than three repetitions) as too much repetition decreases persuasiveness. The discrepancy between the message and the opinion of the target group should not be too great. Channel variables refer to the means by which messages are delivered, for instance via booklets, posters, television etc.. Source variables focus on who is going to deliver a message to the target group. A source has to be attractive, competent and reliable (McGuire, 1985).

The strategic planning of information variables is important to enhance reception, encoding and behavioral change. Each phase may need different operationalizations of these variables (e.g. an adolescent as a source to attract attention, a doctor to enhance encoding on the physical effects of smoking; see figure 4.2).

Reception. A prerequisite for a persuasive impact of the message is that the target group receives the message. As attention is selective a message should be attractive. Furthermore, it has to be adapted to the level of the target group to enhance comprehension. Therefore, pretesting materials is essential to check whether these two conditions have been met. Clear reception of information is crucial for good processing (Kok \& Siero, 1985).

Petty \& Cacioppo (1986) indicate that persons may have two distinct ways of processing information. The first is called the central route and is characterized by extensive cognitive processing of the information in which all pros and cons are considered. In the second way, a more perifere route, less elaboration of consequences takes place, while more attention is paid to affective cues, such as the impact of attractive sources and nice materials. Chances for enduring behavioral change are greater if this is reached by the cognitive way. The variables that determine the amount of elaborate processing can be categorized 
as information variables. Examples are: a person's need for cognitive structures, level of inwolvement, educational level, prior knowledge (all receiver variables), clarity of the message (a message variable and/or channel variable), expertise of the source, etc.

Encoding. A message should result in a positive intention towards the desired behavior. The model of Fishbein \& Ajzen (1975) suggests that behavioral intentions are predicted by a person's attitude towards the behavior and the perceived social norms of others about the behavior. Recently the model has been extended with self-efficacy expectations (Ajzen \& Madden, 1986; De Vries et al., 1988). With regard to smoking, Evans and colleagues (Evans et al., 1978) emphasized the impact of direct pressure to smoke exerted by parents, media and especially peers. Indirect social influences are important as well (Friedman et al., 1985; Urberg \& Robbins, 1984).

Behavior. A positive intention towards a behavior does not necessarily imply behavioral change. Individuals also need skills to be able to perform a desired behavior (Bandura, 1986; Botvin, 1986). Moreover, adolescence is a period that is characterized by experimentation with several behaviors, and by

\begin{tabular}{|c|c|}
\hline INFORMATION & $\begin{array}{l}\text { source } \\
\text { message } \\
\text { channel } \\
\text { receiver }\end{array}$ \\
\hline RECEPTION & $\begin{array}{l}\text { attention } \\
\text { comprehension }\end{array}$ \\
\hline ENCODING & $\begin{array}{l}\text { attitude } \\
\text { social influences } \\
\text { self-efficacy }\end{array}$ \\
\hline $\begin{array}{l}\text { BEHAVIOR } \\
\text { change } \\
\text { maintenance }\end{array}$ & $\begin{array}{l}\text { skills } \\
\text { barriers } \\
\text { commitment } \\
\text { feedback }\end{array}$ \\
\hline
\end{tabular}

Figure 4.2: A model on Behavioral change and Information Processing 
decision making for an own individual life style (Conger, 1977). Therefore, adolescents have to feel responsible for their own behavior, and must understand the potential consequences and risks associated with their behavior.

Behavior maintenance can be enhanced by, for instance, increasing commitment (both anonymously and publicly) of adolescents towards their behavior (Kiesler, 1971). Furthermore, reinforcement of behavior should be positive (Bandura, 1986; Janis \& Mann, 1977; Rogers, 1983). Enhancing the impact of the program may be achieved by repetition of the message (McGuire, 1985).

In sum, program development can be enhanced when it is carefully planned. The development should address a variety of variables that are important in the process of behavioral change, ranging from information processing, reception, encoding to behavioral change and maintenance. Actual program development and program ratings will be described below.

\subsection{METHOD}

\subsubsection{Program preparation: Analysis of the smoking problem}

Before developing a prevention program, the Dutch Smoking Prevention Project started with a problem analysis. Dutch figures show that smoking is related to 18,000 mortality cases each year. A study on the determinants of initial and regular smoking in 10-15 year old students indicated the relevant determinants, and indicated that smoking increased rapidly between age 13 and 14. This category became the target group (for more details see: De Vries \& Kok, 1986). Based on the results of this study, a video peer-led program was developed for adolescents aged 13 and 14 (2nd grade of secondary school) during the second year of the project.

Preventing initial and experimental smoking is probably futile and counterproductive. Many youngsters try smoking ( $90 \%)$, but this does not necessarily lead to regular smoking (Hirschman et all, 1984). The goal of the Dutch program is, therefore, to prevent the transition from initial and experimental smoking to regular smoking. Regular smoking is defined as smoking at least one cigarette per week. 


\begin{tabular}{|c|c|c|c|c|c|}
\hline factor & phase & receiver & message & channel & source \\
\hline \multirow[t]{2}{*}{ Reception } & Altention & $\begin{array}{l}\text { motivation } \\
\text { selectivity }\end{array}$ & $\begin{array}{l}\text { attractive } \\
\text { appealing }\end{array}$ & $\begin{array}{l}\text { video-peerled } \\
\text { schools }\end{array}$ & $\begin{array}{l}\text { peer leaders } \\
\text { adolescents }\end{array}$ \\
\hline & Comprehension & $\begin{array}{l}\text { education } \\
\text { level }\end{array}$ & $\begin{array}{l}\text { active learning } \\
\text { clear conclusions } \\
\text { repetition } \\
\text { pretesting }\end{array}$ & $\begin{array}{l}\text { achivities } \\
\text { manuals } \\
\text { video } \\
\text { manual } \\
\text { two schools }\end{array}$ & $\begin{array}{l}\text { adolescents } \\
\text { cartoons } \\
\text { instructors } \\
\text { cartoons } \\
\text { teachers } \\
\text { students }\end{array}$ \\
\hline \multirow[t]{3}{*}{$\begin{array}{l}\text { Encoding } \\
\text { (intention) }\end{array}$} & Attitude & time gap & $\begin{array}{l}\text { direct effects } \\
\text { discrepancy } \\
\text { alternatives }\end{array}$ & $\begin{array}{l}\text { tests } \\
\text { real situations } \\
\text { on wideo } \\
\text { activities }\end{array}$ & $\begin{array}{l}\text { expents } \\
\text { peers } \\
\text { adolescents }\end{array}$ \\
\hline & $\begin{array}{l}\text { Social } \\
\text { Influences }\end{array}$ & peer pressure & $\begin{array}{l}\text { show pressures } \\
\text { raise resistance }\end{array}$ & video & peers \\
\hline & $\begin{array}{l}\text { Self } \\
\text { Efficacy }\end{array}$ & assertiveness & $\begin{array}{l}\text { self confidence } \\
\text { refusal skills } \\
\text { alternatives }\end{array}$ & $\begin{array}{l}\text { rolle plays } \\
\text { modeling skills } \\
\text { on video }\end{array}$ & $\begin{array}{l}\text { adolescents } \\
\text { peers }\end{array}$ \\
\hline \multirow[t]{2}{*}{ Behavior } & Change & $\begin{array}{l}\text { skills } \\
\text { responsibility }\end{array}$ & $\begin{array}{l}\text { skills training } \\
\text { making own choices }\end{array}$ & role plays & $\begin{array}{l}\text { peers } \\
\text { individual }\end{array}$ \\
\hline & Maintenance & $\begin{array}{l}\text { commitment } \\
\text { feedback } \\
\text { repetition }\end{array}$ & $\begin{array}{l}\text { raise commitment } \\
\text { rewards }\end{array}$ & $\begin{array}{l}\text { public poster } \\
\text { poster, button }\end{array}$ & $\begin{array}{l}\text { individual } \\
\text { researchers }\end{array}$ \\
\hline
\end{tabular}

Figure 4.3: the program matrix adapted for smoking prevention

\subsubsection{Program development: behavioral change}

In structuring program development, a program matrix has been developed in which many issues of the information-behavioral-model are dealt with. The matrix is an adapted version of McGuire's matrix (McGuire, 1985). Other 
applications are described by Green \& McAlister (1984), Kok \& Siero (1985) and Siero et al. (1989). In discussing the development of the program we will follow the program matrix as a guideline (see also figure 4.3).

To enhance reception of the message it is important that the message is attractive, easy to understand and easy to implement. Using the school as a place of intervention will increase the chance of exposure. To prevent implementation failure (a poor execution or non-use of the program), we contacted teachers and school directors to analyze the factors that might cause an inadequate or non-use of the program. They indicated that a program had to be easy to apply and should have a clear structure without requiring special time-consuming training sessions. In order to realize these wishes and the above-mentioned theoretical notions we developed a peer-led program on video. This method contained several advantages. First, the teacher only needed to follow a short training, as his main task consisted of coordinating the lessons, assisting the students, and stimulating them to participate. The teacher did not have to spend much time in discovering how to use and prepare the lessons. Second, by using adolescents, who introduced the lessons on video, the program was made attractive to students and improved their comprehension. Third, using activities improved active participation. Finally, evaluation of the program was facilitated as all experimental schools used the program in the same way.

Structure and content of the lessons were explained on video by youngsters The program was delivered to several second grade classes (between 20 and 30 students) of secondary schools in five weekly sessions of forty-five minute each. Structure and content can be summarized as follows: a. introduction of the theme in a class on video ( 7 minutes), b. activities in small groups, peer-led (15 minutes), c. return to one group, and continuation of the lesson on video (8 minutes), d. activities in small groups, peer-led (15 minutes), e. (sometimes) home-activities.

The video consisted of an introduction by two adolescents, real-life situations played by adolescents, interviews, and an introduction for the activities by two older adolescents. The activities, focusing on the theme of the lesson, were realized in groups of four or five students and were led by a peer leader. Students, peer leaders and teachers had their own manuals, summarizing content (by cartoons), activities, and instructions. Peer leaders and teachers received a one hour training consisting of following the first lesson, discussion on problems, and instructions.

As in the Netherlands working with peer leaders is quite uncommon, we decided to adapt the peer-system to the Dutch school situation. The peer leaders did not present information about the program, but served as a chairman of the small activity groups. They summarized the activities, stimulated the group to 
work, and presented the outcomes of group work. Two weeks before the program started the teacher told the class that it would be working on a smoking prevention project for the next five weeks, and that sometimes they had to work in small groups. Mostly groups were constructed first, and the group chose their own peer leader who had to be a non-smoker. If necessary teachers could select a peer leader as well.

Active participation of students was stimulated. Instead of providing information, students were encouraged to discover information (active learning). Thus, students may discover gaps in their knowledge which will make them more receptive to new information (Flay et al., 1983). The message was formulated explicitly and the main aspects were summarized in cartoons in the manual, and during the last lesson. The main channels were the video, the manuals and a non-smoking poster of the program. Important sources were the adolescents on the video (the introducers and those playing the real-life situations), the cartoons, the teacher, and the peer leaders. A pretest of the program in two classes resulted in a few revisions.

The matrix can be applied to each of the five lessons of the program, although each lesson had a different theme. The first lesson gave a general introduction discussing shortly the consequences of smoking, and direct and indirect peer pressure. During the activities students discussed reasons for (non)smoking, and possible ways of refusing cigarettes. The second lesson focused mainly on the short-term effects of smoking. Some short-term effects like trembling and temperature of the hands, heart-rate, and the amount of tar were demonstrated by tests on video. Other effects, such as the costs of smoking, were discussed on video in interviews and in short scenes played by adolescents. The activities concentrated on students' knowledge on these effects and on passive smoking. The third lesson discussed peer pressure and the activities were aimed at recognizing and handling direct pressure. Several methods of skills training were modeled on video, and were practiced afterwards during activities by role-plays in small groups in order to enhance self-efficacy and the acquisition of refusal skills. The fourth lesson analyzed indirect pressure from advertisements and adults. The activities focused on interpreting advertisements and on alternative behaviors for realizing positive outcomes of smoking, and were intended to increase recognition and self-efficacy towards indirect pressure and towards the alternatives for smoking. The last lesson provided a summary. The activities centered on skills training, decision making, and on commitment by students to non-smoking behavior. Individuals" own responsibilities towards their behavior were discussed. To increase commitment, non-smoking adolescents are asked to conclude a nonsmoking contract (anonymous commitment), and to write their name on a 
non-smoking poster that could be clearly seen in the school, and consequently by other students. As a reward for their non-smoking non-smokers could receive a non-smoking poster and a non-smoking button.

Actual development of the program took one year and included the following aspects: script-writing, production, screening the players for the video-film, pretesting and adapting the program, and contacting schools for participation (De Vries \& Dijkstra, 1989). The screen-test also served to control whether the scenes written for the video corresponded with real-life situations of adolescents. The program was pretested in one vocational and one high school class. The pretest resulted in some revisions.

\subsubsection{Questionnaire}

Students were asked to evaluate the program on a five point scale $(-2=$ negative evaluation; $+2=$ positive evaluation). Every lesson and every activity was evaluated. Moreover, general questions on the lessons, the video's, watching video's, the home activities, the activities during the lessons, the manual, working in groups, having a peer leader, the assistance by the peer leader, and the assistance by the teacher were formulated as well. The results of this program evaluation will focus on the general questions, and on separate group interviews with peer leaders and teachers after the end of the program.

\subsubsection{Program implementation}

The program was implemented in November 1986 in four vocational and five high schools. Three vocational and three high schools served as a control group. The pretest was conducted in September 1986 and three posttests were realized in May and September 1987, and June 1988.

\subsection{RESULTS}

Students rated the video, the activities and the peer-led approach positively (see table 4.1). The manuals with the cartoons were also positively rated. The group discussions revealed that the students liked the alternation of the video with the activities, which prevented loss of attention. Students rated the activities posi- 
tively because of their content, and because of the possibility to bring out their own experiences. Most students and teachers liked the peer-led approach. Peer leaders and teachers indicated that their training was clear, not time-consuming and sufficient. The teachers of the vocational schools reported that they sometimes had to help the peer leaders with organizing their groups. High school teachers hardly mentioned any problems with the peer leaders. Actually the success of the peer-led approach was surprising, because this method is hardly used at Dutch schools. It also appeared that some details may need refinement. For instance, sometimes high school students indicated that the introduction given on video by two adolescents was too simple or childish and somewhat unnatural.

We furthermore analyzed which factors were most influential in determining the evaluation of the program. Six general items on the evaluations were summed to form one scale on program evaluation (using video's, watching video's, activities, manual, working in groups, having a peer leader; $\alpha=.81$ ). Results from a stepwise multiple regression analysis indicate that the evaluation of the program was best predicted by students' evaluation of the assistance by their teacher accounting for $25.6 \%$ of the variance $(p<.001)$. Other significant

Table 4.1: evaluation of the program: general results and differences due to positive or

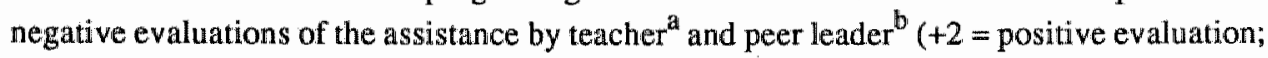
-2 = negative evaluation; $N=837$ )

\begin{tabular}{llllll}
\hline item & $\begin{array}{l}\text { total } \\
\text { population }\end{array}$ & $\begin{array}{l}\text { Pos. } \\
\text { Teacher }\end{array}$ & $\begin{array}{l}\text { Neg } \\
\text { Teacher }\end{array}$ & $\begin{array}{l}\text { Pos. } \\
\text { P-leader }\end{array}$ & $\begin{array}{l}\text { Neg* } \\
\text { P-leader }\end{array}$ \\
\hline program & 0.77 & 1.11 & $0.25^{* *}$ & 0.85 & $0.71^{*}$ \\
lessons on video & 0.72 & 0.99 & $0.32^{* *}$ & 0.80 & $0.66^{*}$ \\
watching the video"s & 0.93 & 1.27 & $0.43^{* *}$ & 1.04 & $0.85^{*}$ \\
home activities & 0.75 & 0.99 & $0.39^{* *}$ & 0.84 & $0.67^{* *}$ \\
activities during lessons & 0.80 & 1.08 & $0.40^{* *}$ & 0.90 & $0.72^{* *}$ \\
manual & 0.67 & 0.97 & $0.23^{* *}$ & 0.85 & $0.52^{* *}$ \\
working in groups & 1.27 & 1.50 & $0.93^{* *}$ & 1.55 & $1.03^{* *}$ \\
having a peer leader & 0.84 & 1.14 & $0.40^{* *}$ & 1.16 & $0.58^{* *}$ \\
assistance by peer leader & 0.53 & & & & \\
assistance by teacher & 0.81 & & & & \\
\hline
\end{tabular}

a controlling for assistance by peer leader: all differences significant, $p<.001 ;{ }^{b}$ controlling for assistance by teacher; ${ }^{+} p<.10 ;{ }^{*} p<.05 ; * * p<.01$ 
predictors were: assistance by peer leader adding $4.3 \%$ ( $p<.001)$, smoking status adding $0.6 \%(\mathrm{p}<.02)$, and type of school adding $0.5 \%(\mathrm{p}<.05)$ of the variance. Together these variables explained $30.9 \%$ of the variance of the program ratings. Age and gender did not have a significant unique contribution on the general program ratings.

Similar results were found for predicting the evaluations of the activities. Assistance by teacher explained $18.4 \%$ (p.<001). Contributions by other predictors were small: assistance by peer leader added $1.8 \%(\mathrm{p}<.001)$, type of school added $0.5 \%$ ( $p<.03)$, age added $0.8 \%$ ( $p<.006)$, while smoking status added $0.6 \%(\mathrm{p}<.02)$.

As assistance by teacher was the most powerful predictor for the evaluation of the program, more detailed information was obtained by comparing students who evaluated the teacher positively $(\mathrm{N}=500)$ with students who evaluated the teacher negatively $(\mathrm{N}=337)$. For statistical reasons we decided to analyze differences by a covariance analysis controlling for students' rating of the peer leader as this variable was the second most important predictor for the overall program ratings (inclusion of other covariates did not render important differences). Table 4.1 shows that the two groups differed on all items, indicating the most positive ratings by students who evaluated the teacher positively. If two groups were formed based on a positive evaluation $(\mathrm{N}=379)$ and a neutral or negative evaluation of the peer leader (now controlling for the evaluation of the teacher) similar results were found (see table 4.1).

The target group of the program was vocational school students as they were at high risk of becoming a smoker. Educational levels of vocational and high school students differ in that high school students are motivated more to process information cognitively while vocational students are encouraged to engage in all kinds of activities. We therefore expected that the program would be evaluated better by vocational $(\mathrm{N}=312)$ than by high school students $(\mathrm{N}=525)$. A covariance analysis (controlling for the students' evaluation of the teacher and the peer leader, and smoking status) indicated that vocational school students were more positive than high school students in their ratings of: the program, its lessons on video, watching the video's, the activities during the lessons, and the manual. Working in groups was evaluated most positively by high school students (see table 4.2). This may be because high school students hardly work in groups, while vocational school students do.

We also expected that regular smokers $(N=68)$ would evaluate the program more negatively than non-smokers $(\mathrm{N}=769)$, as the program favors non-smoking. Although the two groups did not differ significantly in their evaluations of the teacher and the peer leader, the results are controlled for students ratings of the teacher and the peer leader to control for slight effects (see table 4.2). 
Table 42: Differences in evaluations of the program between vocational and high school students, and smokers and non-smokers (controlling for assistance by teacher and peer leader)

\begin{tabular}{lllll}
\hline item & $\begin{array}{l}\text { vocational } \\
\text { school }\end{array}$ & $\begin{array}{l}\text { high } \\
\text { school }\end{array}$ & $\begin{array}{l}\text { Non } \\
\text { Smoker }\end{array}$ & Smoker \\
\hline program & 1.01 & $0.63^{* *}$ & 0.78 & 0.63 \\
lesssong on video & 0.83 & $0.66^{* *}$ & 0.74 & 0.57 \\
watching the video's & 1.07 & $0.85^{* *}$ & 0.95 & $0.70^{*}$ \\
home activities & 0.78 & 0.73 & 0.77 & $0.57^{+}$ \\
activities during lessons & 0.89 & $0.75^{* *}$ & 0.82 & $0.58^{* *}$ \\
manual & 0.74 & $0.63^{*}$ & 0.71 & $0.26^{* *}$ \\
working in groups & 1.15 & $1.34^{* *}$ & 1.29 & $1.01^{* *}$ \\
having a peer leader & 0.88 & 0.82 & 0.87 & $0.54^{*}$ \\
\hline
\end{tabular}

$+p<.10 ; * p<.05 * * * 0.01$

Smokers were less positive about the evaluations of the activities during the lessons, the manual, working in groups and having a peer leader, while similar trends were found for their evaluations on watching the video, and the home-activities.

Girls evaluated their peer leaders more positively. Covariance analysis (controlling for the evaluation of teacher and peer leader) showed one significant difference indicating that girls liked working in groups more (adjusted means: girls $=1.40$, boys $=1.16 ; \mathrm{p}<.001$ ), and a trend indicating that boys liked watching the video's slightly better (adjusted means: girls $=.85$, boys $=1.01$; $\mathrm{p}<.06$ ). There were no significant differences among 13 and 14 years old students.

The program had a preventive impact on regular smoking. One year after the pretest (10 months after the program) regular smoking increased by $4.8 \%$ in the experimental group, compared to $7.4 \%$ in the control group $(\mathrm{p}<.05)$. Furthermore, the program was very successful for vocational school students. Regular smoking increased by $6.7 \%$ in the experimental group, while it increased by $15.9 \%$ in the control group ( $\mathrm{p}<.005$ ). For high school students the program had a significant impact on experimental smoking: less experimental (42\%) than control group never smokers $(52 \%)$ started to experiment with smoking. The results of the effects of the program are discussed elsewhere in more detail in chapter 5 . 


\subsection{CONCLUSIONS AND DISCUSSION}

The $\mathrm{ABC}$ health promotion framework distinguishes three important phases in a health promotion strategy: Analysis of health problems, Behavioral interventions, and Continued prevention. Using a health promotion framework may enhance the likelihood of a clear analysis of the important issues of each phase. It enhances the discovery of topics that need more attention or specific analyses, and the usage of relevant theories and results. The framework is strongly influenced by models developed by Green et al. (1980) and Kok (1988). Within the $\mathrm{ABC}$ framework, much attention is paid to the second phase on behavioral change by information processing on which a specific model has been formulated in which many social psychological theories and findings have been integrated. This model distinguishes four factors: providing information, reception, encoding, and behavioral impact of information.

Based on this model a program matrix has been developed that has been used for the construction of the Dutch smoking prevention program. Advantages of using this matrix are that it enhances use of theories, and that it can serve as a checklist to study if important issues have been forgotten. This resulted in a video-peerled approach for students aged 13 and 14. Although the program matrix has been developed for health education interventions, it may be applicable for the planning and evaluation of other health promoting activities as well, such as the study of the diffusion of programs.

The smoking prevention program was evaluated as attractive by students and teachers. Because of the alternation of video's and activities it prevented boredom. The video-led nature of the program increased chances of implementation, because teachers did not have to follow time-consuming training sessions. This made it also possible to implement the program during for instance mathematics, biology, history or a combination of these different lessons. By using activities adolescents could integrate information within their life-style.

The most important factor determining students' program ratings was their evaluation of the assistance by their teacher. This finding was unexpected, because the program was constructed in such a way to make it teacher-independent. Although we stressed that teachers needed to be encouraging and stimulating, we did not expect such a great impact of the teachers. Several explanations for this high correlation are conceivable. First, the teachers may have differed (in reality or in the perception of the students) with regard to their stimulative role. Apart from stimulating students, the teacher is probably also an important source for students to assess the significance and importance of a program. If teachers do participate in the program, but also show (perhaps 
unintended) signs indicating skepticism, this is likely to influence students" perception of the program. Second, when students did not like the program, they may have attributed the cause to teachers as they are usually responsible for the quality of lessons. Third, it is also possible that students who liked the program better also rated the teacher or peer leader more positively. More in depth studies are needed to analyze this process, and the impact of different program ratings on behavioral change.

Students with a positive evaluation of their teacher liked the program significantly better than students with neutral or negative evaluations of the teacher. Similar results were found if students were divided by their score on the evaluation of their peer leader. The target group for the program was vocational school students as they are at higher risk of becoming a smoker. The expectancy that vocational students would rate the program more positively than high school students was supported, just as the expectancy that smokers would appraise the program more negatively than non-smokers. Girls liked working in groups more than boys. No differences were found between 13 and 14 year old students. Moreover, the program had a preventive impact on the experimental group in general, and on vocational school students in particular.

An attractive and effective program, however, does not guarantee successful prevention of smoking. Schools often have different and conflicting priorities. Health education should therefore become an important subject within the curriculum, which is not the case in the Netherlands. Even then one may wonder if smoking prevention can be really effective. Smoking prevention is credible if it takes place within a society that holds a clear stand on health and health promotion. However, it probably has less impact in a society stimulating health but at the same time also actively promoting health toxic advertisements. Adolescents will have a difficult question to solve: why smoking prevention; if smoking is really that bad, why aren't cigarettes and certainly cigarette advertisements forbidden? One implication should be a health promotional view on health, in which health education activities are integrated with consistent healthy policies and legislation.

\section{Acknowledgements}

This study was supported by a grant of the Dutch Cancer Foundation. We are grateful to Larry Green for his insightful comments on an earlier version of this paper. We would also like to thank Ingeborg Hoekstra for her help in preparing this paper. 


\section{REFERENCES}

Ajzen, I. \& Madden, J.T. (1986) Prediction of goal-directed behavior; attitudes, intentions, and perceived behavioral control. Journal of Experimental Social Psychology, 22, 453-474.

Bandura, A. (1986) Social Foundations of thought and action: a sacial cognitive theory. New York: Prentice-Hall.

Basch, E. (1984) Research on disseminating and implementing health education programs in schools. Journal of School Health, 54, 57-66.

Basch, E. (1987) Focus group interview: an underutilized research technique for improving theory and practice in health education. Health Education Quarterly, 14, 411-448.

Best, J.A., Thomson, S.J., Santi, S.M., Smith, E.A., Brown, K.S. (1988) Preventing cigarette smoking among school children. Ammal Review of Public Health, 9, 161-201.

Botvin, G.J. (1986) Substance abuse prevention research: Recent developments and future directions. Journal of School Health, 9, 369-374.

Conger, J.J. (1977) Adolescence and youth: psychological development in a changing world. New York: Harper \& Row.

De Leeuw, E. (1988) The sane revolution, health promotion." backgrounds, scope, prospects. Maastricht: Van Gorcum.

De Vries, H. (1989) Towards primary cancer prevention: the Dutch ABC framework. European Journal for Cancer and Clinical Oncology, (in press).

De Vries, H., Dijkstra, M. \& Kuhlman, P. (1988) Self-efficacy: the third factor besides attitude and subjective norm as a predictor of behavioural intentions. Health Education Research, $3,273-282$.

De Vries, H. \& Dijkstra, M. (1989) Non-smoking: your choice, a Dutch smoking prevention programme-A case study. In C. James, J. Balding \& D. Harris (Eds.), World Yearbook of Education 1989: Health Education (pp. 20-31). London: Kogan Page.

De Vries, H. Dijkstra, M. \& Kok, G.J. Results of a video smoking prevention program in Dutch schools (in preparation).

De Vries, H. \& Kok, G.J. (1986) From determinants of smoking behaviour to the implications for a prevention programme. Health Education Research, 1, 85-94.

Evans, R.I., Rozelle, R.M., Mittelmark, M.B., Hansen, W.B., Bane, A.L. \& Havis, J. (1978) Deterring the onset of smoking in children: knowledge of immediate physiological effects and coping with peer pressure, media pressure and parent modeling. Journal of Applied Social Psychology, 8, 126-135.

Fishbein, M. \& Ajzen, I. (1975) Belief, attitude, intention and behavior: an introduction to theory and research. Reading, Mass.: Addison Wesley.

Flay, B.R., D*Avernas, J.R., Best, J.A., Kersell, M.W., Ryan, K.B. (1983) Cigarette smoking: why young people do it and ways of preventing it. In P.J. Mc Grath \& P. Firestone (Eds.), Pediatric and adolescent behavioral medicine (pp. 132-183). New York: Springer.

Friedman, L.S. Lichtenstein, E. \& Biglan, A. (1985) Smoking onset among teens: an empirical analysis of initial situations. Addictive Behaviors, 10, 1-13.

Green, L.W., Kreuter, M.W., Deeds, S.G. \& Partridge, K.B. (1980) Healtheducation planning; a diagnostic approach. Palo Alto: Mayfield Publishing Company.

Green, L.W. \& Lewis, F.M. (1986) Measurement and evaluation in health education and health promotion. Palo Alto: Mayfield Publishing Company. 
Green, L.W. \& Mc.Alister, A.L. (1984) Macro-interwention to support health behavior: some theoretical perspectives and practical reflections. Health Education Quarterly, 11, 322 . 339.

Hirschman, R.S., Leventhal, H. \& Glynn, K. (1984) The development of smoking behavior: conceptualization and supportive crosis-sectional survey data. Journal of Applied Social Psychology, 14, 184-206.

Janis, 1.L. \& Mann, L. (1977) Decision making: a psychological analysis of conflict, choice commitment. New York: Free Press.

Kiesler, C.A. (1971) The psychology of commitment: Experiments linking behavior to beliefs. New York: Academic Press.

Kok, G.J. (1988) Health motivation healtheducation from a socialpsychological point of view. In S. Maes, C.D. Spielberger, P.B. Defares and I.G. Sarason (Eds.) Topics in Health Psychology (pp. 295-300). New York: Wiley \& Sons Ltd.

Kok, G.J. \& Siero, S. (1985) Tin recycling: awareness, comprehension, attitude, intention and behavior. Journal of Economic Psychology, $6,157-173$.

McCaul, K.D. \& Glasgow, R. (1985) Preventing Adolescent smoking: what have we learned about treatment construct validity? Health Psychology, 4, 361-387.

McGuire, W.J. (1985) Attitudes and attitude change. In G. Lindzey \& E. Aronson (Eds.), Handbook of Social Psychology, Volume II (pp. 233-246). New York. Lawrence Erlbaum Associates.

Parcel, G.S., Erikson, M.P., Lovato, C.Y., Gottlieb, N.H., Brink, S.G. \& Green, L.W. (1989) The diffusion of school-based tobacco-use prevention programs: project description and baseline data. Health Education Research, 4, 111-124.

Petty, R.E. \& Cacioppo, J.T. (1986) The elaboration likelihood model of persuasion. In L. Berkowitz (Ed.), Advances in Experimental Social Psychology, Vol. 19. London: Academic Press.

Rogers, E.M. (1983) Diffusion of innovations. New York, The Free Press.

Siero, S., Boon, M., Kok, G.J. \& Siero, F. (1989) Modification of driving behavior in a large transport organization: a field experiment. Journal of Applied Psychology, 74, 417-423.

Urberg, K. \& Robbins, R. (1984) Perceived vulnerability in adolescents to the health consequences of cigarette smoking. Preventive Smoking, 13, 367-376. 


\section{Results of a video smoking prevention program in Dutch schools}

Hein De Vries, Margo Dijkstra, \& Gerjo Kok

\section{ABSTRACT}

A peer-led smoking prevention program was presented on video to 8 th grade Dutch students. The major goal was to prevent or to delay the transition to regular smoking. A control group received no special smoking prevention education. The results of a 10 month follow-up (posttest 2) suggest that the program successfully delayed experimental and regular smoking. Special risk analyses show that experimental smoking was delayed in low risk students (high school students, and students experiencing negative norms about smoking), while regular smoking was delayed in high risk students (vocational school students, and students experiencing neutral and positive norms about smoking). Implications for evaluation research and program are discussed. 


\section{$5.1 \quad$ INTRODUCTION}

Some decades ago research indicated that smoking is harmful for health. One of the reactions was to develop smoking cessation programs for smokers. However, cessation of smoking is difficult and only partly successful. Preventive activities aimed at non-smoking children probably constitute a more successful approach to the smoking problem (Leventhal \& Cleary, 1980). Since the development of a smoking prevention program by Evans and colleagues (Evans et al., 1978) many other successful programs have been developed (see for an overview: Best et al., 1988), and some researchers already distinguish different "generations" of programs (Cleary et al. 1986; Flay, 1985).

The Dutch Smoking Prevention Project (DSPP) started in 1984. The development of the program has been based on the $A B C$ health promotion framework. The ABC framework distinguishes three important phases: A. Analysis of health problems, B. Behavioral interventions, C. Continued prevention (De Vries, 1989). Each phase needs attention before we can move to the next, and should be planned and evaluated carefully.

Relevant issues for the Analysis phase are: the severity of the health problem, its relation with different behaviors, the preventability of these behaviors, and the relevant target groups. For the second phase, Behavioral change, we need to know: the determinants of unhealthful behavior, theories on realizing behavioral change, the type of intervention (e.g., a health education approach for a well defined target group, a community approach, or a large health promotion approach), and the development of small scale interventions. To realize Continuation, the third phase, diffusion of successful programs is necessary. Hence, we need diffusion strategies, health promoting policies (e.g. legislative measures stimulating health and providing opportunities for the population to behave healthful), and an intersectoral approach as health concerns several sectors. "This latter approach is also described as a health promotion approach (Perry, 1986; De Leeuw, 1988; Green \& Lewis, 1986).

Before developing a prevention program, the Dutch Smoking Prevention Project started with a problem analysis. Dutch figures show that smoking is related to 18,000 deaths each year (Dutch Foundation on Smoking and Health, 1986). A study on the determinants of initial and regular smoking in 10-15 year old students indicated the relevant determinants, and showed that smoking increased rapidly between age 13 and 14. This category became the target group for intervention (see for more information: De Vries \& Kok, 1986). The results of this study were used for the development of the program. Actual program development was structured by using a program matrix (see also: De Vries \& 
Dijkstra, 1989; De Vries et al. (in preparation)). This program matrix leans heavily on the matrix developed by MoGuire (1985), although other social psychological theories on behavior and behavioral change have been integrated as well (Ajzen \& Madden, 1986; Bandura, 1986; De Vries et al., 1988; Fishbein \& Ajzen, 1975; Janis \& Mann, 1977; Kiesler, 1971; Kok \& Siero, 1985; Petty \& Cacioppo, 1986; Rogers, 1983). The program matrix distinguishes four important factors for behavioral change: providing information, reception of information, encoding information, and behavioral change. The impact of information is determined by receiver, message, channel and source variables. These communication or information variables are important to enhance reception, encoding and behavioral change. Each of these phases may need different operationalizations of these variables (e.g. an adolescent as a source to attract attention, a doctor to enhance encoding on physical effects of smoking). Furthermore, encoding the message should lead to a positive intention towards the behavior. The intention is determined by a person's attitude, social influences and self-efficacy expectations (Ajzen \& Madden, 1986; De Vries et al. 1988). Finally, behavioral change is dependent on several factors, such as adequate skills (also including the alternatives a person has), and on whether performance of behavior is possible and not hindered by barriers. Chances of behavioral maintenance will be enhanced if the message is repeated, if the behavioral outcome or feedback is positive, and if the person feels committed to the behavior (Janis \& Mann, 1977; Kiesler, 1971). The adaptation of the matrix for the smoking prevention program is summarized in figure 5.1 .

As a result, a peer-led program on video has been developed for 13 and 14 year old adolescents ( 2 nd grade of secondary schools). Preventing experimental smoking is probably hard to realize, and may be unwise and counterproductive as many adolescents experiment with new behavior (Conger, 1977). Many youngsters try smoking $(90 \%)$, but this does not necessarily lead to regular smoking although the chances of becoming a regular smoker will increase if the behavior is repeated several times and if the time-interval between smoking cigarettes is short (Hirschman et al., 1984). Therefore, the goal of the Dutch program was to prevent or to delay the transition from never or experimental smoking to (regular) smoking. Regular smoking is defined as smoking at least one cigarette per week.

In this paper we will present the results of the program. With regard to behavior we expected that fewer treatment than control group students would: 1. transfer from non-smoking to experimental and regular smoking; 2 . transfer from experimental to regular smoking. We furthermore expected that: 3 . more experimental than control group smokers would reduce or quit smoking, as we also anticipated an impact of the program on smokers. Moreover, special 


\begin{tabular}{|c|c|c|c|c|c|}
\hline factor & phase & receiver & message & channel & source \\
\hline \multirow[t]{2}{*}{ Reception } & Attention & $\begin{array}{l}\text { motivation } \\
\text { selectivity }\end{array}$ & $\begin{array}{l}\text { attractive } \\
\text { appealling }\end{array}$ & $\begin{array}{l}\text { video-peerled } \\
\text { schools }\end{array}$ & $\begin{array}{l}\text { peer leaders } \\
\text { adolescents }\end{array}$ \\
\hline & Comprehension & $\begin{array}{l}\text { education } \\
\text { level }\end{array}$ & $\begin{array}{l}\text { active learning } \\
\text { dear conclusions } \\
\text { repetition } \\
\text { pretesting }\end{array}$ & $\begin{array}{l}\text { activities } \\
\text { manuals } \\
\text { wideo } \\
\text { manual } \\
\text { two schools }\end{array}$ & $\begin{array}{l}\text { adolescents } \\
\text { cartoons } \\
\text { instructors } \\
\text { cartoons } \\
\text { teachers } \\
\text { students }\end{array}$ \\
\hline \multirow[t]{3}{*}{$\begin{array}{l}\text { Encoding } \\
\text { (intention) }\end{array}$} & Attitude & time gap & $\begin{array}{l}\text { direct effects } \\
\text { discrepancy } \\
\text { altematives }\end{array}$ & $\begin{array}{l}\text { tests } \\
\text { real situations } \\
\text { on video } \\
\text { activities }\end{array}$ & $\begin{array}{l}\text { experts } \\
\text { peers } \\
\text { adolescents }\end{array}$ \\
\hline & $\begin{array}{l}\text { Social } \\
\text { Influences }\end{array}$ & peer pressure & $\begin{array}{l}\text { show pressures } \\
\text { raise resistance }\end{array}$ & video & peers \\
\hline & $\begin{array}{l}\text { Self } \\
\text { Efficacy }\end{array}$ & assertiveness & $\begin{array}{l}\text { self confidence } \\
\text { refusal skills } \\
\text { alternatives }\end{array}$ & $\begin{array}{l}\text { role plays } \\
\text { modeling skills } \\
\text { on video }\end{array}$ & $\begin{array}{l}\text { adolescents } \\
\text { peers }\end{array}$ \\
\hline \multirow[t]{2}{*}{ Behavior } & Change & $\begin{array}{l}\text { skills } \\
\text { responsibility }\end{array}$ & $\begin{array}{l}\text { skills training } \\
\text { making own choices }\end{array}$ & nole plays & $\begin{array}{l}\text { peers } \\
\text { individual }\end{array}$ \\
\hline & Mainlenance & $\begin{array}{l}\text { commitment } \\
\text { feedback } \\
\text { repetition }\end{array}$ & $\begin{array}{l}\text { raise commitment } \\
\text { rewards }\end{array}$ & $\begin{array}{l}\text { public poster } \\
\text { poster,button }\end{array}$ & $\begin{array}{l}\text { individual } \\
\text { researchers }\end{array}$ \\
\hline
\end{tabular}

Figure 5.1: the program matrix adapted for smoking prevention

subgroup analyses of high-risk students will seek to enhance insight into the nature of a program's impact. Best et al. (1984) and Flay et al. (1985) found that program effects may vary as a function of smoking exposure risk and of social influence risk. In our study pretest social norms have been used to analyze the impact of social influence risk. Furthermore, effects will be analyzed separately for two different types of schools, vocational and high schools, as their edu- 
cational levels differ. Moreover, as smoking is more prevalent in vocational schools, students of these schools are at higher risk of experiencing direct and indirect social influences.

\subsection{METHOD}

\subsubsection{The Program}

The program consisted of five lessons, each of 45 minutes, given in weekly sessions during the second grade of the secondary school. It has a so-called video-peer-led nature. Structure and content, explained on video by adolescents, can be summarized as follows: a. introduction of the theme by adolescents on video, b. peer-led activities in small groups, c. continuation of the lesson and presentation of real-life situations by adolescents on video, d. peerled activities in small groups, and sometimes e. home activities. The peer-led activities were realized in small groups consisting of four or five students. Students had formed their own groups and chosen their peer leader before the program started. Peer leaders and teachers received a special one-hour training consisting of following the first lesson. The teacher's task was to coordinate the lessons, to stimulate students and to assist the peer leaders in case problems arose. Students, peer leaders and teachers had their own manuals, summarizing the activities and instructions. The first lesson gave a general introduction. The second lesson focused on short-term effects of smoking, which were also shown on video. The third lesson dealt with peer pressure. Indirect pressure from adults and advertisements formed the central theme in the fourth lesson. The last. lesson gave a summary of the program.

\subsubsection{Design and Sampling}

Fifteen schools were matched on pretest smoking, on type of school (vocational vs. high school), on size (large vs. small) and on urban versus rural, and then assigned randomly within pairs to the experimental or control condition. Four vocational and five high schools received the program while the comparison schools, three vocational and three high schools, received no special smoking education. 


\subsubsection{Questionnaire and measures}

The pretest was in September 1986 (T1), the program implementation took place during November and December, while two follow-ups were conducted in June (T2) and in September 1987 (T3). Formative evaluation was assessed at the end of the program by questionnaires, and by group interviews with peer leaders and teachers separately (for more details on the program and program ratings see: De Vries \& Dijkstra, 1989; De Vries et al., in preparation). In order to enhance self-report validity we followed the so-called bogus pipe-line procedure (Evans et al., 1978).

During the pretest the students watched a video, which demonstrated how cigarette smoking can be verified by carbon-monoxide measurements. Then they completed a questionnaire, after which one third were selected randomly to participate in carbon-monoxide tests. During the posttest the video was not shown again, but students were told that the CO-test would follow the questionnaires. After completion of the questionnaires one third again were randomly asked to participate in the CO-test. Besides behavior, the questionnaires measured attitudes, subjective norms, social pressures, perceived smoking behavior of others, self-efficacy, intention, and amount of cigarettes smoked per month and per week.

\subsubsection{Risk categories}

On the basis of the pretest, subjects were assigned to one of the four behavioral categories indicating smoking risk: 1 . never smoker: never smoked one (puff of a) cigarette; 2 . experimental smoker: smokes occasionally but not every week; 3. quitter: has smoked, but has stopped smoking; 4. regular smoker: smokes at least one cigarette per week.

In the Netherlands vocational and high schools constitute two main types of schools, the former preparing students for specific professions, the latter preparing students for continued specialized education (sometimes university). For an educational base-line level the prevention program focused on vocational schools. Moreover, high schools are mostly characterized by low smoking prevalence and have students of higher social economical backgrounds. To assess the impact of schooltype risk, program effects will be discussed separately for vocational $(\mathrm{N}=557)$ and high schools $(\mathrm{N}=968)$.

To analyze the impact of social influence risk, students were divided in three groups based on pretest scores on the perceived social norms of smoking by others. The measured norms were those of the mother, father, brother, sister, 
relatives, friends, smokers, non-smokers, smoking friends, non-smoking friends, cigarette-advertisements, teacher, and the doctor (see also De Vries \& Kok, 1986). Scores of 14 questions on normative beliefs $(+3 /-3)$ were multiplied by the corresponding 14 questions on students' motivations to comply $(0 /+3)$. The products $(\Sigma$ nb.mc) were summed up (Chronbach's $\alpha=.85)$. Three groups were formed: 1 . Negative Social Norm $(N=692)$ : scores varying between -126 and $-32 ; 2$. Neutral Social Norm $(N=786)$ : scores between -31 and $0 ; 3$. Positive Social Norm $(\mathrm{N}=47)$ : scores varying between 1 and 63 .

\subsubsection{Analysis}

As baseline levels of non-smokers may be different between the experimental and the control group, Cook \& Campbell (1979) suggest covariance analyses for interval data to correct posttest scores by pretest scores. In our study the data for analyzing the overall behavioral effect have a nominal level $(0=$ never, experimental, and ex-smokers; 1 = regular smokers). However, by using the Mantel-Haenzel approach, a chi-square method to analyze data on nominal level that is similar with logistical regression analysis for $2 \times 2$ designs, it is possible to control the posttest scores for the pretest scores (Kleinbaum et al., 1980). As clear hypotheses have been formulated, one-tailed tests have been used.

Trends $(\mathrm{p}<.10)$ will also be discussed, because a general significant impact of the program in the experimental group can be the result of several trends that do not have to be significant, but may explain the overall effect. An effect of a program on smoking in the treatment group may be composed as follows: fewer Never Smokers became Regular Smokers $(p<.07)$, fewer Experimental Smokers became Regular Smokers ( $p<.03)$, More Smokers have Quit $(p<.08)$. As many tests are necessary to analyze the nature of behavioral effects, this may enhance type I errors: the conclusion that a result is significant while it may be significant by chance. Therefore, interpretation of these results should be done with caution.

In sum, overall effects are analyzed first, followed by more detailed analysis showing the nature of the behavioral effects, and the program"s impact on never smokers and smokers.

To maximize numbers of subjects and minimize possible attrition artifacts, the procedure of Johnson et al. (1986) was followed. All subjects, who participated at any posttest survey who could be matched with pretest data, were included. This resulted in overlapping but not identical data sets for the analysis of $\mathrm{T} 2(\mathrm{~N}=1623)$ and $\mathrm{T} 3(\mathrm{~N}=1525)$ outcomes. 


\subsection{RESULTS}

Attrition from pretest to posttest 2 was $14.3 \%(\mathrm{~N}=255)$ and did not differ in proportion between the experimental and the control group. Of 255 "dropouts" $60.4 \%$ was male, $35.7 \%$ was female and $3.9 \%$ did not mention their gender. The dropouts were slightly older than students of the reduced sample (mean for dropouts: 13.8 years; mean for reduced sample: 13.5 years; $t(316.55)=6.35$, $\mathrm{p}<.001)$. The amount of cigarettes smoked weekly and monthly was more in the attrition group than in the reduced sample (weekly: mean for dropouts: 7.5 cigarettes; mean for reduced sample: 2.5 cigarettes; $t(276.86)=3.58, \mathrm{p}<.001$ ) (monthly: mean for dropouts: 25.9 cigarettes; mean for reduced sample: 9.4 cigarettes; $\mathrm{t}(273.90)=2.94, \mathrm{p}<.005)$. Of vocational school students $18.4 \%$ dropped out, of high school students $11.8 \%$ dropped out $\left(\mathrm{X}^{2}(1)=15.34\right.$, $\mathrm{p}<.001)$. More pretest smokers than pretest non-smokers dropped out (13\% non-smokers dropped out vs. $27.4 \%$ regular smokers, $X^{2}(1)=25.76, p<.001$ ) Dropouts in both groups, however, did not differ with regard to their smoking behavior. Compared with the reduced sample, dropouts had more smoking friends (best male friend: $28.6 \%$ vs $16.5 \%, \mathrm{X}^{2}(1)=21.73, \mathrm{p}<.001$ ) (best female friend: $26.7 \%$ vs. $\left.12.9 \%, \mathrm{X}^{2}(1)=32.59, \mathrm{p}<.001\right)$. The students in the attrition group had a more positive attitude, social norm and intention to smoke, compared with the reduced sample. The dropouts were less positive than the reduced sample about their self-efficacy to refuse cigarettes in different situations (see table 5:1).

There were no significant differences between the experimental and control group with respect to the distributions of age and gender at the three tests.

Table 5.1: Differences between dropouts and reduced sample in attitude, social norm, self-efficacy and intention towards smoking

\begin{tabular}{lll}
\hline & dropouts & reduced sample \\
\hline attitude & -27.93 & $-42.75^{*}$ \\
social norm & -22.01 & $-30.74^{*}$ \\
self -efficacy & -14.19 & $-20.63^{*}$ \\
intention & 9.87 & $12.80^{*}$ \\
\hline
\end{tabular}

$* \mathrm{p}<.001$ 
Table 5.2: Percentages of Smokers in experimental and control groups at T1, T2, T3, the \% increase $(1), \mathrm{X}^{2}, \mathrm{p}$-levels, and the number of subjects $(\mathrm{N})$

\begin{tabular}{|c|c|c|c|c|c|c|c|c|c|c|c|c|c|}
\hline group & & $\mathrm{TI}$ & $\mathrm{T} 2$ & I & $x^{2}$ & $\mathrm{p}<$ & $\mathbf{N}$ & $\mathrm{T} 1$ & $\mathrm{~T} 3$ & 1 & $x^{2}$ & $p<$ & $N$ \\
\hline \multirow[t]{2}{*}{ Total } & $\exp$ & $8.7 \%$ & $10.8 \%$ & $2.1 \%$ & .75 & .20 & $(989)$ & $8.4 \%$ & $13.2 \%$ & $4.8 \%$ & 2.46 & .06 & $(926)$ \\
\hline & con & $7.3 \%$ & $10.7 \%$ & $3.4 \%$ & & & $(634)$ & $7.3 \%$ & $14.7 \%$ & $7.4 \%$ & & & (599) \\
\hline High & $\exp$ & $4.2 \%$ & $5.8 \%$ & $1.6 \%$ & .00 & .49 & $(622)$ & $3.6 \%$ & $7.2 \%$ & $3,6 \%$ & .49 & .25 & $(584)$ \\
\hline selhool & con & $3.0 \%$ & $5.2 \%$ & $2.2 \%$ & & & $(404)$ & $2.9 \%$ & $5.5 \%$ & $2.6 \%$ & & & $(384)$ \\
\hline Vocat. & $\exp$ & $16.3 \%$ & $19.3 \%$ & $3.0 \%$ & .72 & .20 & $(367)$ & 16.79 & $23.4 \%$ & $6.7 \%$ & 7.55 & .003 & $(342)$ \\
\hline school & con & $14.8 \%$ & $20.4 \%$ & $5.6 \%$ & & & $(230)$ & $15.3 \%$ & $31.2 \%$ & $15.9 \%$ & & & (215) \\
\hline Lusoc. & $\exp$ & $1.6 \%$ & $2.1 \%$ & $0.5 \%$ & .01 & .47 & $(428)$ & $1.7 \%$ & $4.3 \%$ & $2.6 \%$ & .32 & .29 & (414) \\
\hline risk & con & $1.0 \%$ & $1.4 \%$ & $0.4 \%$ & & & $(289)$ & $1.1 \%$ & $2.9 \%$ & $1.8 \%$ & & & $(278)$ \\
\hline M.soc. & $\exp$ & $12.7 \%$ & $16.4 \%$ & $3.7 \%$ & .66 & .21 & (535) & $13.1 \%$ & $20.4 \%$ & $7.3 \%$ & 2.71 & .05 & $(490)$ \\
\hline risk & con & $10.4 \%$ & $16.4 \%$ & $6.0 \%$ & & & $(318)$ & $10.5 \%$ & $22.6 \%$ & $12.1 \%$ & & & (296) \\
\hline H.soc. & $\exp$ & 42.3 & $38.5 \%$ & $-3.8 \%$ & .12 & .37 & (26) & $31.8 \%$ & $18.2 \%$ & $-13.6 \%$ & 2.40 & .07 & $(22)$ \\
\hline risk & con & 37.0 & $44.4 \%$ & $7.4 \%$ & & & (27) & $40.0 \%$ & $52.0 \%$ & $12.0 \%$ & & & (25) \\
\hline
\end{tabular}

\subsubsection{General behavioral effects}

At T2 regular smoking increased by $2.1 \%$ in the experimental group, while it increased by $3.4 \%$ in the control group (see table 5.2 ). These differences were not statistically significant. However, more treatment than control group smokers had stopped smoking (13.6\% vs. $\left.2.3 \%, \mathrm{X}^{2}(1)=4.20, \mathrm{p}<.02\right)$. At T3 regular smoking had increased in the treatment group by $4.8 \%$, from $8.4 \%$ to $13.2 \%$, while it increased in the control group by $7.4 \%$, from $7.3 \%$ to $14.7 \%$; this difference almost reached significance $\left(\mathrm{X}^{2}(1)=2.46, \mathrm{p}<.06\right)$. Closer examination of the data based on pretest smokers experience risk indicated that fewer treatment than control group Never Smokers had become Experimental smokers $\left(47.8 \%\right.$ vs. $\left.53.3 \%, \mathrm{X}^{2}(1)=2.05, \mathrm{p}<.08\right)$, and Regular Smokers $(1.9 \%$ vs. $\left.4.9 \%, \mathrm{X}^{2}(1)=2.70, \mathrm{p}<.06\right)$. In addition, fewer treatment Quitters started again with experimental smoking $\left(60.2 \%\right.$ vs. $\left.67.7 \%, \mathrm{X}^{2}(1)=2.89, \mathrm{p}<.07\right)$. Finally, 
more treatment than control group Smokers had reduced or quit smoking $\left(17.9 \%\right.$ vs. $\left.6.8 \%, X^{2}(1)=2.91, p<.05\right)$, mainly because of more quitters in the treatment group $\left(12.3 \%\right.$ v8. $\left.4.7 \%, \mathrm{X}^{2}(1)=1.86, \mathrm{p}<.09\right)$.

\subsubsection{Program effects as a function of type of school}

Separate analysis for high school students (and who are at low risk) showed that at T2 the program did not have an impact on smoking (see also figure 5.2). At T3 there still were no significant differences regarding regular smoking between the two groups. However, the program had a significant effect on experimental smoking: fewer treatment than control group Never Smokers had become Experimental Smokers at T3 $\left(41.7 \%\right.$ vs. $\left.52.1 \%, \mathrm{X}^{2}(1)=5.41 ; \mathrm{p}<.01\right)$. Although there was no overall effect on regular smoking, there was one trend favoring an impact of the program, and consequently another trend indicating an opposite effect of the program. More treatment Smokers had reduced or quit smoking $\left(28.6 \%\right.$ vs. $\left.0 \%, \mathrm{X}^{2}(1)=2.22, \mathrm{p}<.07\right)$. However, more treatment than control group Experimental Smokers had become Regular Smokers (10.8\% vs. $\left.5.5 \%, X^{2}(1)=2.87, \mathrm{p}<.09\right)$.

Among vocational school students there was no significant program impact on regular smoking at $\mathrm{T} 2$. However, at $\mathrm{T} 3$ the program had significant preventive effects on regular smoking that increased by $6.7 \%$, from $16.7 \%$ to $23.4 \%$, in the treatment group, compared to $15.9 \%$, from $15.3 \%$ to $31.2 \%$, in the control group $\left(\mathrm{X}^{2}(1)=7.55, \mathrm{p}<.003\right)$. A closer examination revealed that fewer treatment than control group Non-smokers started to smoke regularly (10.9\% vs. $\left.20.3 \%, \mathrm{X}^{2}(1)=7.98, \mathrm{p}<.003\right)$, because fewer Never Smokers had become Smokers ( $4.9 \%$ vs. $\left.15.8 \%, \mathrm{X}^{2}(1)=2.58, \mathrm{p}<.06\right)$, and because fewer Experimentall Smokers had become Smokers $\left(20.9 \%\right.$ vs. $\left.37.3 \%, \mathrm{X}^{2}(1)=6.19, \mathrm{p}<.01\right)$.

\subsubsection{Program effects as a function of social norm risk}

Among low social norm risk students (those experiencing a negative norm on smoking) the program did not have a significant impact on smoking at T2 (see also figure 5.3). The program did have a significant impact on the transition to experimental smoking: less treatment than control group Never Smokers became Experimental Smokers $\left(42.5 \%\right.$ vs. $\left.52.6 \%, \mathrm{X}^{2}(1)=4.51, \mathrm{p}<.02\right)$. The effect on experimental smoking was still apparent at T3. Less treatment than control group Never Smokers had become Experimental Smokers at T3 (41.9\% vs. 


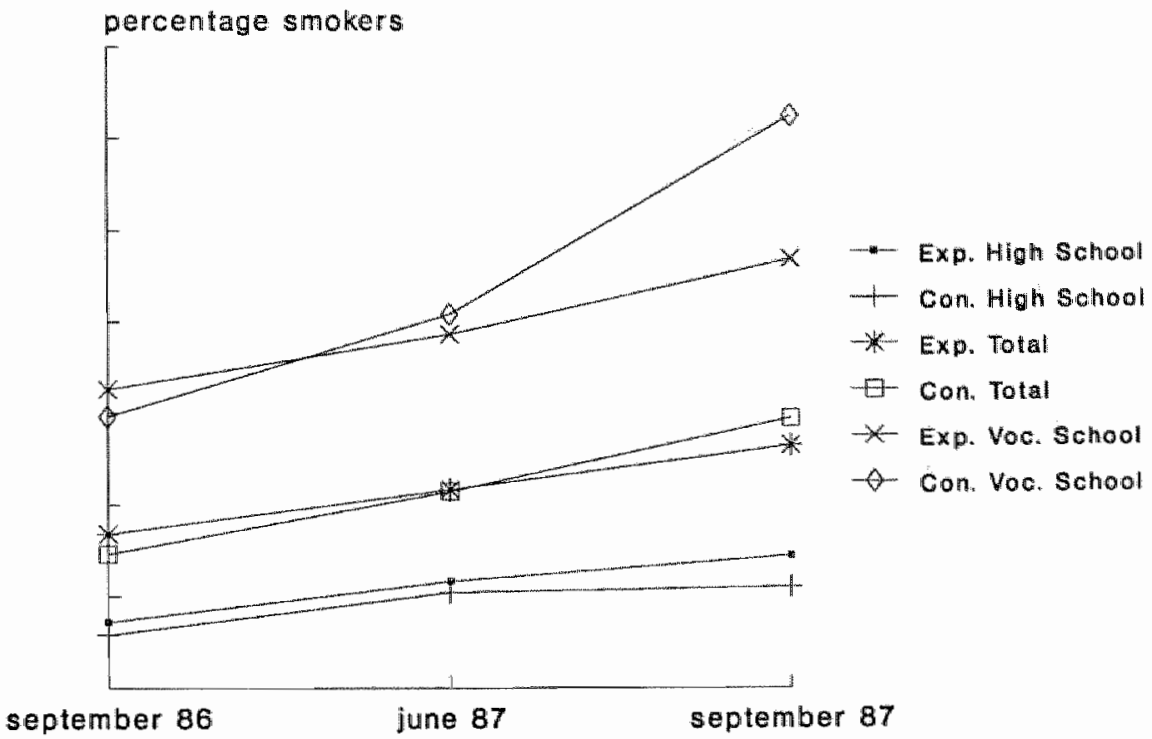

Figure 5.2: Smoking incidence in the total population, vocational school students, and high school students

$\left.52.2 \%, \mathrm{X}^{2}(1)=5.41, \mathrm{p}<.01\right)$. There was also a trend showing that $3.3 \%$ of the control group Never Smokers started to smoke regularly compared to 0\% in the treatment group $\left(\mathrm{X}^{2}(1)=2.22, \mathrm{p}<.07\right)$.

Among intermediate social norm risk students (those experiencing a neutral norm on smoking) the program did not have a significant impact on smoking at $\mathrm{T} 2$, although more treatment than control group Smokers quit smoking $(13.6 \%$ vs. $\left.0 \%, \mathrm{X}^{2}(1)=3.18, \mathrm{p}<.04\right)$. At T3 smoking increased by $7.3 \%$, from $13.1 \%$ to $20.4 \%$, in the experimental group, while it increased by $12.1 \%$, from $10.5 \%$ to $22.6 \%$, in the control group $\left(\mathrm{X}^{2}(1)=2.71, \mathrm{p}<.05\right)$. This effect was mainly caused because less treatment than control group Non-smokers became Smokers at $\mathrm{T} 3\left(10.6 \%\right.$ vs. $\left.14.3 \%, \mathrm{X}^{2}(1)=2.40, \mathrm{p}<.07\right)$. The impact on quitting had disappeared at $\mathrm{T} 3$.

Although smoking decreased in the treatment group at T2 while it increased in the control group, these differences were not significant in high social risk students. At T3 the results show that smoking had decreased by $13.6 \%$, from $31.8 \%$ to $18.2 \%$, in the treatment group while it increased by $12.0 \%$, from $40 \%$ to $50 \%$, in the control group $\left(X^{2}(1)=2.40, p<.07\right)$. This effect was the result of fewer treatment than control group Non-Smokers who had become Smokers 


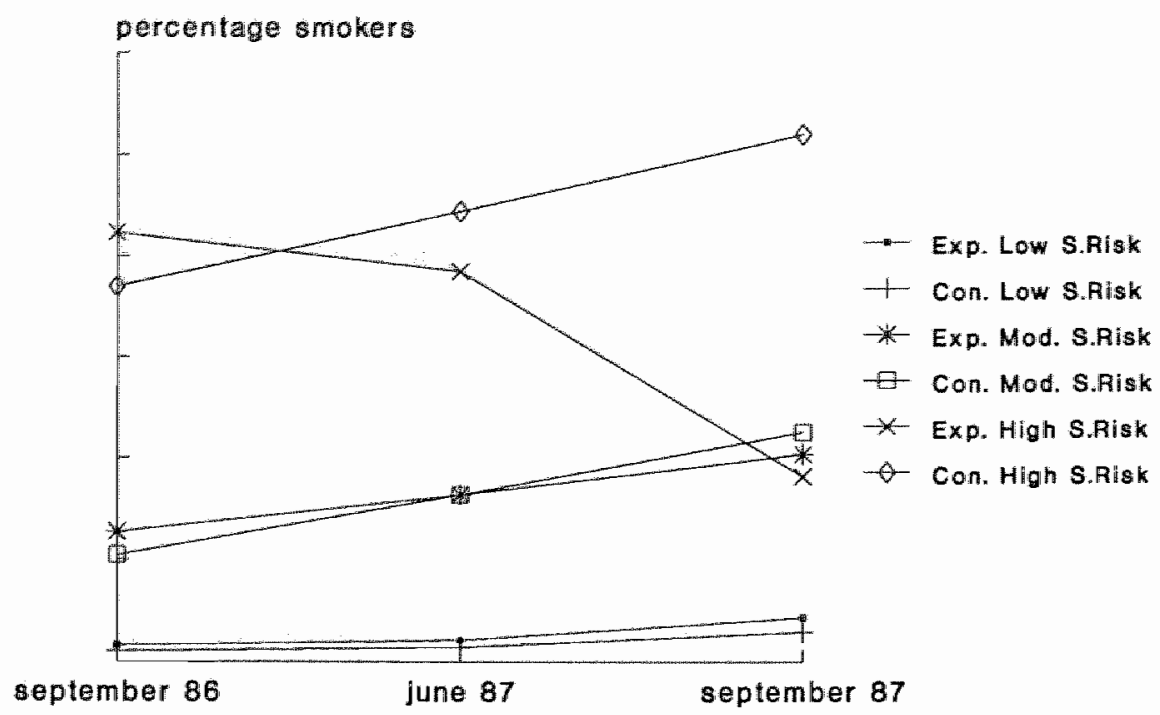

Figure 5.3: Smoking incidence in social norm risk groups

( $0 \%$ vs. $20 \%, \mathrm{X}^{2}(1)=1.48, \mathrm{p}<.12$ ), and more treatment than control group Smokers who had reduced smoking to the experimental level ( 3 vs. 0 persons, Fisher's test, $\mathrm{p}<.06)$.

\section{$5.4 \quad$ CONCLUSIONS AND DISCUSSION}

At posttest 1 (T2) there were no differences in smoking rates in general nor among specific risk groups. However, more treatment than control group smokers had stopped smoking at T2; this effect being most prominent for students at intermediate social norm risk. At T3 more differences emerged. Fewer treatment than control group never smokers became experimental smokers, or regular smokers. Moreover, fewer treatment experimental smokers became regular smokers, fewer ex-smokers started to experiment again with smoking, and more treatment smokers reduced or quit smoking. An overview of program impact on the transitions is given in table 5.3.

The overall effects are understood most clearly by looking at the results for the risk groups separately. These risk analysis suggest a clear pattern: experimental smoking is delayed in low-risk groups (never smokers, high school 
students, adolescents with negative social norms on smoking), while regular smoking is delayed in high-risk groups (experimental smokers, vocational school students, adolescents with neutral and positive social norms). The data suggest that the program had the right impact on the right groups. However, as it is possible that the program only delayed smoking onset, the results of a longer follow-up study are needed to obtain more information on this issue.

The results also showed a striking trend for high school experimental smokers. In this group more treatment than control group adolescents became regular smokers. In-depth analyses showed that these students also experienced negative norms about smoking. One explanation is that, for these students, the combination of negative norms and negative information may have caused reactance leading to smoking.

There are several explanations for the fact that the program had less impact on high school students. First, as smoking incidence is low in high schools, stressing the need of resisting pressure may have been irrelevant and counterproductive reducing the credibility of the message. Second, the program may have been less effective in preventing regular smoking in high school students, because its baseline educational level was directed towards vocational schools. Third, Petty \& Cacioppo (1986) have suggested that behavioral change can be the result of processing information cognitively or affectively. It is conceivable that high school student have a strong need to process information cognitively

Table 5.3: Program effects at T3 $(+=$ trend; $++=$ significant program effect; $-=$ reverse trend)

social pressure

impact in transitions

total High. Voc.

low

moderate high

preventive impact ${ }^{1}$ :

Non-smokers to Regular

Never to Experimental Smoking.

Never to Regular Smoking

Experimental to Regular

Ex to Regular Smoking

Regular to Quitting or reduction

$\begin{array}{llllll}+ & & ++ & & ++ & ++ \\ + & ++ & & ++ & & \\ + & & + & + & & \\ + & & ++ & & & \\ + & + & & & & +\end{array}$

\footnotetext{
${ }^{1}$ Non-smokers to Regular refers to the general impact of the program on regular smoking, while the others descriptions refer to more refined transitions.
} 
before behavioral change or maintenance can be induced. This implies that smoking prevention programs should be adapted to the cognitive needs of the targetgroup. Fourth, it is possible that the impact of the program on high school students will only become manifest after a longer period than one year. Finally, it is possible that assessing opinions about smoking and the measurement of carbon monoxide, in combination with a relatively low smoking prevalence, may have had a sufficient preventive impact on high school treatment and control group students.

This explanation may also be valid to explain why the increase in smoking after one year in the control group was less large than the national increase of $12 \%$ between ages 13 and 14 . It is conceivable that the assessment procedure may have had a preventive impact on the control group. A second study is underway to study this effect, dividing treatment and control groups in two subgroups, one with and one without CO-tests.

The data stress the need of a more refined analysis to check whether the determinants of behavior actually have been changed in general and in different groups at risk (Flay et al., 1983; McCaul \& Glasgow, 1985). However, analyzing these patterns was beyond the scope of this paper.

As the program had a small impact on smokers, this may increase the value of the program, because its use is not strictly limited to non-smokers. Hence, previous smoking experience does not preclude prevention of future smoking (Flay et al., 1985), although special programs for addicted smokers may enhance chances of successful quitting.

In this study effects were analyzed for different risk groups. Therefore, individuals have been used as a unit of analysis. Although the use of schools or classrooms can be recommended on statistical grounds (Flay et al., 1983), it often implies inclusion of many schools or loosing power because of a small number of observations with the danger of overlooking significant results. We also believe that too much emphasis on this issue may endanger (innovative) prevention research, simply because research will become too expensive. As a "compromise" between statistical and practical considerations, inclusion of several schools with sufficient classrooms can be recommended (see also Janicki \& Braverman, 1986).

Several implications can be formulated. As in high risk groups many students smoke at age 13, prevention should start at an earlier age. Therefore, prevention at vocational schools should start in the first grade of this type of school. A finer differentiation within schools seems difficult as, for instance, selecting only high social norm risk groups in high schools will be hard to realize. 
Although the program had a preventive impact on moderate and high social influence risk students, it is clear that these students will continue to experience great pressure to smoke. To enhance effectiveness, we strongly suggest that smoking prevention designed at these groups be accompanied by programs addressing their social environment, for instance a program motivating parents to quit. In this context a health promotion approach is certainly recommended, as in this approach health promotion activities are targeted towards the general population. Moreover, this study also shows that the so-called "drop-outs" are often smokers. It is clear that a health promotion approach will also be important for this group that leaves school at an early age.

\section{Acknowledgements}

This study was supported by a grant of the Dutch Cancer Foundation. We are grateful to Larry Green for his thoughtful comments on an earlier version. We want to thank Harm Hospers for his computer assistance, and Frans Tan for his help with the Mantel-Haenzel approach and his critical review of this paper.

\section{REFERENCES}

Ajzen, I. \& Madden, J.T. (1986) Prediction of goal-directed behavior: attitudes, intentions, and perceived behavioral control. Journal of Experimental Social Psychology, 22, 453-474.

Bandura, A. (1986) Social Foundations of thought and action: a social cognitive theory. New York: Prentice-Hall.

Best, J.A., Flay, B.R., Towson, S.M.J., Ryan, K.B., Perry, C.L., Brown, K.S., Kersell, M.W. \& D'Avernas, J. (1984) Smoking prevention and the concept of risk. Journal of Applied Social Psychology, 14, $257-273$.

Best, J.A., Thomson, S.J., Santi, S.M., Smith, E.A. \& Brown, K.S. (1988) Preventing cigarette smoking among school children. Annual Review of Public Health, 9, 161-201.

Cleary, P.D., Hitchcock, J.L., Semmer, N., Flinchbaugh, L. J \& Pinney, J. (1986) Smoking Behavior and Policy. Discussion Paper Series. Cambridge: Institute for the Study of Smoking Behavior and Policy, Harvand University.

Conger, J.J. (1977) Adolescence and youth: psychological development in a changing world. New York: Harper \& Row.

Cook, T.D. \& Campbell, D.T. (1979) Quasi-Experimentation: Design \& Analysis Issues for Field Settings. Boston: Houghton Mifflin Company.

De Leeuw, E. (1988) The sane revolution, health promotion: backgrounds, scope, prospects, Maastricht: Van Gorcum.

De Vries, H. (1989) Towards primary cancer prevention: the Dutch ABC framework. European Journal for Cancer and Clinical Oncology, (in press). 
De Vries, H, Dijkstra, M. \& Kuhlman, P. (1988) Self-efficacy: the third factor besides attitude and subjective nom as a predictor of behavioral intentions. Health Education Research. $3,273-282$.

De Vries, H. \& Dijkstral, M. (1989) Non-smoking: your choice, a Dutch smoking prevention programme-A case study. In C. James, J. Balding \& D. Harris (Eds.), World Yearbook of Education 1989. Heallh Education (pp. 20-31). London: Kogan Page.

De Vries, H., Dijkstra, M., Borgers., R. \& Kok, G.J. A program matrix to strengthen program development and program ratings by users: application to the development of a peer-led smoking prevention program on video (in preparation).

De Vries, H \& Kok, G.J. (1986) From determinants of smoking behaviour to the implications for a prevention programme. Health Education Research, 1, 85-94.

Dutch Foundation on Smoking and Health (1986) Annwal report. The Hague.

Evans, R.I., Rozelle, R.M., Mittelmark, M.B., Hansen, W.B., Bane, A.L. \& Havis, J. (1978) Deterring the onset of smoking in children: knowledge ofimmediate physiological effects and coping with peer pressure, media pressure and parent modeling. Journal of Applied Social Psychology, 8, 126-135.

Fishbein, M. \& Ajzen, I. (1975) Belief, attitude, intention and behavior: an introduction to theory and research. Reading, Mass.: Addison Wesley.

Flay, B.R. (1985) Psychosocial approaches to smoking prevention: a review of findings. Health Psychology, 4, 449-488.

Flay, B.R., D'Awernas, J.R., Best, J.A., Kersell, M.W., Ryan, K.B. (1983)Cigarette smoking: why young people do it and ways of preventing it. In P.J. Mc Grath \& P. Firestone (Eds.), Pediatric and adolescent behavioral medicine (pp. 132-183). New York: Springer.

Flay, B.R., Ryan, K.B., Best, J.A., Brown, K.S., Kersell, M.W." d'A vernas, J.R. \& Zanna, M.P. (1985) Are social-psychological smoking prevention programs effective? The Waterloo Study. Journal of Behavioral Medicine, 8, 37-59.

Green, L.W. \& Lewis, F.M. (1986) Measurement and evalwation in health education and health promotion. Palo Alto: Mayfield Publishing Company.

Hirschman, R.S., Leventhal, H. \& Glynn, K. (1984) The development of smoking behavior: conceptualization and supportive cross-sectional survey data. Joumal of Applied Social Psychology, 14, 184-206.

Janicki, T. \& Braverman, M.T. (1986) The development and evaluation of school snoking prevention programs. Advances in Health Education and Promotion, 1, 307-340.

Janis, I.L. \& Mann, L. (1977) Decision making: a psychological analysis of conflict, choice and commitment. New York: Free Press.

Joknson, C.A., Hansen, W.B., Collins, L.M. \& Graham, W. (1986) High-school smoking prevention: results of a three-year longitudinal study. Journal of Behavioral Medicine, 9 , 439-452.

Kiesler, C.A. (1971) The psychology of commitment: Experiments linking behavior to beliefs. New York: Academic Press.

Kleinbaum, D.G. Kupper L.L. \& Morgensterm, H. (1980) Epidemialogic research, principles and quantitative methods. California: Belmont.

Kok, G.J. \& Siero, S. (1985) Tin recycling: awareness, comprehension, attitude, intention and behavior. Journal of Economic Psychology, 6, 157-173.

Leventhal, H. \& Cleary, P.D. (1980) The smoking problem: a review of the research and theory in behavioral risk modification. Psychological Bulletin, $88,370-405$. 
Mc Caul, K.D. \& Glasgow, R. (1985) Preventing Adolescent smoking: what have we learned about treatment construct validity? Health Psychology, 4, 361-387.

McGuire, W.J. (1985) Attitudes and attitude change. In G. Lindzey E. Aronson (Eds.), Handbook of Social Psychology, Volume I, (pp. 233-246). New York: Lawrence Erlbaum. Associates.

Perry, C.L. (1986) Community-wide health promotion and drug abuse prevention. Journal of School Health, 56, 359-363.

Petty, R.E. \& Cacioppo, J.T. (1986). The elaboration likelihood model of persuasion. In L. Berkowitz (Ed.), Advances in experimental Social Psychology, Vol. 19, London: Academic Press.

Rogers, R. (1983). Cognitive and physiological processes in fear appeals and attitude change: a revised theory of protection motivation. In: J.T. Cacioppo \& R.E. Petty (Eds.), Social Psychophysiology - A source book (pp. 153-176). New York: Guilfond Press. 


\section{Discussion and conclusions}

This chapter will first summarize and review the major findings of the Dutch smoking prevention project. Next, the focus will be on new developments that may be important for future research about smoking prevention. Furthermore, it will outline some of the methodological problems of smoking prevention research. Finally, some suggestions for future research are formulated.

6.1 WHAT DO WE KNOW;

\section{A SUMMARY OF THE MAJOR FINDINGS}

\subsubsection{The determinants study}

The study on the determinants of smoking in Dutch adolescents provided detailed information on the differences in beliefs about smoking between Dutch non-smoking and smoking adolescents aged 10 to 15 . In general, the results showed that non-smokers more often associated smoking with health, personal and social disadvantages, while the smokers minimized the probabilities of these consequences. Smokers were less negative towards conformity in general and towards smoking in particular, and perceived several positive outcomes of smoking. It was striking that the non-smokers were not convinced of these positive consequences: they associated smoking with the opposite effects. However, it was hypothesized that this discrepancy between smokers and nonsmokers could make non-smokers susceptible to direct and indirect persuasion (via modeling by smokers). It is also conceivable that smokers may initiate a redefining of beliefs about these advantages in non-smokers. Support for this assumption was found in the fact that older non-smokers were more convinced of possible advantages than younger adolescents (De Vries \& Kok, 1988). The 
discrepancy may furthermore constitute an interesting challenge to non-smokers to start smoking in order to discover which party is right with respect to these outcomes.

The study thus yielded detailed information about the consequences on which the two groups differed, and about the beliefs that have to be reinforced in non-smoking adolescents to increase chances for an enduring non-smoking attitude. The study also provided insight into the arguments that smokers may use in their process of direct or indirect persuasion.

Smoking adolescents experienced more pressure to smoke than nonsmokers. Peer pressure had a strong impact in both smokers and non-smokers. The latter group experienced the strongest pressure from cigarette industries and their advertisements. The influence of (peer) pressure, however, was smaller than we had expected. Possible explanations are that pressures can be exerted directly and indirectly, and that adolescents do not always recognize pressure. Another explanation is that adolescents, in search of independence, are not likely to admit that they are being influenced by others.

Regular smoking was more clearly associated with long-term health disadvantages, long-term personal disadvantages, and social disadvantages. Initial smoking was more clearly connected with short-term health hazards, short-term personal disadvantages, and with short-term personal advantages. Although initial smoking was not strongly associated with addiction (in contrast with regular smoking), the clear relation between initial smoking and regular smoking needs attention in a smoking prevention program.

Both smokers and non-smokers were fairly positive about their intentions to smoke in discos and cafes, at parties, and with friends. This highlights the social function of smoking. Initial smokers had, compared with non-smokers, less negative intentions towards both regular and initial smoking in general and towards smoking in specific situations. These situations indicate conditions in which non-smokers may be at a higher risk of becoming a smoker.

Finally, the results of both the pilot study and the study on the determinants suggested that the impact of social influence would also have to be assessed by measuring the perceived behavior of others and the direct pressures they may exert. Moreover, the amount of control or self-efficacy non-smokers perceive towards realizing their behavior needs to be assessed as well.

In sum, the results suggested that a Dutch smoking prevention program has to: a. reinforce the non-smoking attitude of non-smokers, b. discuss the discrepancy and the resulting challenge with regard to the positive consequences perceived by smokers, c. raise adolescents' awareness of both forms of pressure 
and increase resistance towards these pressures, $d$. enhance assertiveness and refusal skills, e. discuss situations in which non-smokers may be at higher risk and the dangers of initial smoking.

\subsubsection{The impact of self-efficacy}

The goal of the second study was to combine Bandura's $(1977,1986)$ concept of self-efficacy with the two concepts of attitude and subjective norms from the theory of Fishbein \& Ajzen (1975), and to assess whether self-efficacy expectations provided a contribution to the prediction of intention and behavior. The results supported this hypothesis. Attitudes and subjective norms were significant predictors of the intention, but self-efficacy expectations added significantly to the prediction of behavior. Self-efficacy expectations also had a direct effect on behavior (after controlling for the intention). It was assumed that self-efficacy probably reflected actual control to a high degree.

Furthermore, non-smoking adolescents appeared to have higher self-efficacy expectations towards non-smoking than smoking adolescents, although they did not differ on all items.

From a longitudinal point of view it is interesting to know which factors would predict future behavior. Results of the control group of the smoking prevention program study indicated the following pattern (De Vries et al., 1989). Self-efficacy expectations of the pretest (September 1986) constituted the best predictor $(\mathrm{r}=.49, \mathrm{p}<.001)$ of the behavioral intention one year later (September 1987), explaining $24 \%$ of the variance. The pretest attitude scores also had a high correlation with the behavioral intention one year later $(r=.44$, $p<.001)$, and added another $5 \%(p<.001)$ to the explained variance. Pretest subjective norms also correlated significantly with the intention $(r=.37$; $\mathrm{p}<.001)$, but added only $1 \%(\mathrm{p}<.007)$. With respect to the prediction of behavior one year later, pretest behavioral intention was the strongest predictor $(r=.64)$, and explained $41 \%$ of the variance ( $p<.001$ ). Pretest self-efficacy was the second predictor $(r=.50, p<.001)$, but added only $2 \%(\mathrm{p}<.001)$. Together, the two pretest variables explained $42 \%$ of the behavior one year later.

In chapters 1 and 3 it was indicated that behavior can best be predicted by using the ASE-model assessing attitudes, self-efficacy, and the impact of social influences. With respect to the prediction of behavior, knowledge is always regarded as a necessary but not sufficient factor. As knowledge beliefs are beliefs about the consequences of a particular behavior, they may be a different and unique sub-factor within the attitude (Flay et al., 1983; McCaul \& Glasgow, 1985). Furthermore, with regard to smoking it is possible that social impact is 
not only predicted by social norms but also by the amount of direct pressure (see e.g. Evans et al., 1978), or by modeling influences or perceived behavior of others (Bandura, 1986, Friedman et al., 1985).

To test these assumptions, a stepwise regression analysis was conducted to assess the predictive value of the above factors. With regard to the pretest ( $N=$ 1583), it was found that behavioral intentions were best predicted by self-efficacy, explaining $41 \%$ of the variance, followed by significant contributions $(\mathrm{p}<.001)$ of the attitude $(10.7 \%)$, perceived behavior $(5.7 \%)$, and subjective norms $(1.0 \%)$. Together these factors explained $58.2 \%$ of the total variance. Smoking behavior was best predicted by self-efficacy, explaining $37.9 \%$, followed by perceived behavior $(12.4 \%)$, attitude $(3.7 \%)$, and pressure $(0.6 \%)$. Together, these variables explained $54.5 \%$ of the variance (to assess the impact of the ASE factors, pretest intention is not included in this and the next analysis).

Furthermore, we assessed which pretest ASE factors predicted behavior one year later at $\mathrm{T} 3$ in the control group $(\mathbb{N}=1357)$. Smoking behavior one year later was best predicted by perceived behavior $(26.2 \%)$, self-efficacy $(11.2 \%)$, attitude (3.1\%), and pressure (1.3\%). Together, these variables explained $41.8 \%$ of the variance.

In sum, the significance of self-efficacy expectations with regard to the prediction of smoking behavior is stressed by both cross-sectional and longitudinal studies. The significant contributions of perceived behavior and pressure suggest that these factors need to be included in the model as well. The impact of subjective norms for the prediction of future behavior seems to disappear with the inclusion of the other social influence factors. Knowledge beliefs did not contribute significantly. More research, however, with different populations and other behaviors will be necessary to provide more detailed information on the impact of self-efficacy, perceived behavior, and pressure. One can also conclude that the ASE model shows many similarities with Green's description of predisposing, enabling, and reinforcing factors (Green et al., 1980).

\subsubsection{The development of the program}

For the development of the program a revised version of McGuire's matrix (1985) was used. This program matrix pays attention to the impact of four types of information variables: receiver, message, channel, and source variables. These variables are important in enhancing reception and encoding of the message, and behavioral change and maintenance. 
A peer-led program on video was developed for adolescents aged 13 and 14 . The program consisted of five lessons and focused on reinforcement of the non-smoking attitude, increasing resistance towards direct and indirect pressures to smoke, and enhancement of self-efficacy by recognition of patterns of pressure by increasing resistance skills through role-playing and focusing on altematives for realizing the positive outcomes of smoking by other behaviors. The ultimate goal was the prevention (or delay) of regular smoking.

Group discussions and program ratings showed that teachers, peer leaders, and students liked the program. The alternation of the video with the activities was positively evaluated, as were the manuals, the cartoons, and the peer-led system. Some high school students, however, indicated that they would not mind a more intellectually stimulating program.

Program ratings by the students were best predicted by students" evaluation of the assistance by their teacher, accounting for almost $26 \%$ of the variance. Other significant predictors were the assistance by the peer leader, the smoking status, and the type of school. Students rating their teacher positively, also liked the program much better. Similar results were found for the prediction of the evaluations of the activities. The target group of vocational school students liked the program significantly better than students of the high schools.

An unexpected result was that the assistance by the teacher was the most predictive factor in students' evaluation of the program. One of the goals of the Dutch smoking prevention project was to develop a program that did not require the teacher to invest much time or provide much assistance. However, we did stress in the training and the manual that the teachers' role was to stimulate and to encourage students.

Several explanations for this finding can be formulated, which are not mutually exclusive. First, teachers may have differed with regard to their stimulative role. Apart from this role, the teacher was probably also an impor tant source for students in assessing the significance of the program. If teachers showed (perhaps unintended) signs indicating skepticism, or lack of involvement (e.g by reading a book while students were involved in the activities), this is likely to have influenced students. Second, if students did not like the program, they may have put the responsibility for this on their teachers, as they are usually responsible for the quality of lessons. Third, it is conceivable that students who liked the program better also rated the teacher or peer leader more positively. 


\subsubsection{Behavioral effects of the program}

Fifteen schools participated in the project. After these schools gave their consent for participation, they were matched on pretest smoking, on type of school, on size, and on urban versus rural, and then randomly assigned to the experimental or control group. Four vocational and five high schools received the program, while the comparison schools, three vocational and three high schools, received no additional smoking education.

The pretest was taken in september 1986 (T1), and the implementation of the program took place during October and December 1986, while two follow-ups were conducted in June (T2) and in September (T3) 1987.

On the basis of the pretest, subjects were assigned to one of four behavioral categories: 1. Never Smoker, 2. Experimental Smoker, 3. Quitter, 4. Regular Smoker (smoking at least one cigarette per week).

Attrition from pretest to posttest 2 was $14.3 \%$. The experimental and the control group did not differ with respect to the percentage of attrition (14.3\%) from pretest to posttest 2 , nor did they differ with respect in the proportion of non-smokers and smokers that dropped out. The proportion of smokers, however, was significantly higher in the drop-out group, a result comparable with those of other smoking prevention projects (see e.g. Best et al., 1988). The experimental and control groups did not differ with respect to age and sex at the three tests.

Six months after the conclusion of the program (posttest 1), no significant behavioral differences were found between the experimental and the control groups. However, at posttest 2 (T3) there was a significant difference in the increase of smoking. Smoking increased by $4.8 \%$, from $8.4 \%$ to $13.2 \%$, in the experimental group, while it increased by $7.4 \%$, from $7.3 \%$ to $14.7 \%$, in the control group. The general increase in the control group was lower than what could be expected on the basis of national findings (see also chapter 1), where an expected increase has been shown of around $9 \%$ in 1986, 14\% in 1987, and $11 \%$ in 1988 . One explanation is that the pre- and posttests combined with CO measurements may have had a preventive impact in the control group, resulting in a slightly lower increase than expected. Another explanation might be the influence of regional differences. However, the determinants study found no large differences between smoking prevalence in our geographical research area, the southern part of the province Limburg, and the Netherlands in general (De Vries \& Kok; 1986).

Separate analyses for high school and vocational school students indicated the following patterns. For both types of school the program had no significant preventive impact at T2. At T3 fewer high school students in the treatment 
condition had moved from never smoking to experimental smoking (41.7\%) compared to the control group (52.1\%). No significant difference was found for regular smoking. Among vocational school students there was a significant program impact on regular smoking at T3. Smoking had increased by $6.7 \%$, from $16.7 \%$ to $23.4 \%$, in the treatment group, while it rose by $15.9 \%$, from $15.3 \%$ to $31.2 \%$, in the control group.

Program effects were also analyzed as a function of social norm risk. This risk could vary from low (when students experienced a negative norm on smoking), via moderate, to high (when students perceived positive norms on smoking). No differences between experimental and control groups were found at the first posttest. At the second posttest the following patterns emerged. In the low risk treatment group significantly fewer non-smokers had started smoking than in the control group: $42.5 \%$ versus $52.6 \%$. The impact of the program on regular smoking was most evident in the intermediate and high social norm risk groups. In the intermediate group smoking increased by $7.3 \%$ in the treatment group while it increased by $12.1 \%$ in the control group. In the high risk group regular smoking decreased by $13.6 \%$, from $31.8 \%$ to $18.2 \%$, while it increased by $12 \%$, from $40 \%$ to $52 \%$, in the control group.

One can conclude that program impact emerged one year after the pretest (10 months after the program). The program had a preventive impact on regular smoking in general, and on high risk students (vocational students, and students with moderate or high social norm risk) in particular. The program also had a preventive impact on experimental smoking for never smokers in general, and for never smokers who are at low risk in particular. Another finding was that the program also enhanced reduction of smoking and quitting.

One reverse trend was observed as well, indicating that more treatment high school experimental smokers with negative social norms had become regular smokers. An explanation may be that the combination of negative social norms with a smoking prevention program may have caused reactance in these students.

There are several explanations for the fact that the program had less impact on high school students. First, it may be that stressing the need for resisting peer pressure was relatively irrelevant for this group, where smoking prevalence is not very high. Second, the educational level of the program may have led to a reduced credibility of the program in some high school non-smoking students. Third, apart from the educational level of the program, it is also conceivable that high school students need more opportunities to process information cognitively. Petty \& Cacioppo (1986) stress that some people may have a higher need for cognition (see also 6.2.3). As cognitive processing of information is highly stressed in Dutch high schools it is conceivable that these students are in need 
of a more cognitive approach. Fourth, the measurement of carbon monoxide may have had a preventive impact. In combination with a relatively low smoking prevalence this may have been a strong and sufficient intervention. Finally, it is possible that the impact of the program will only become manifest after a longer period than one year. Arguments supporting the first three explanations were mentioned during the group interviews with high school peer leaders and teachers. Some mentioned that the smoking problem was not really relevant, as hardly any of their peers smoked. Others mentioned that they would prefer a more intellectually challenging program.

The results strongly suggest that it is important to address different subgroups through different programs. Although the program was effective for high social influence risk students, these students will still encounter great pressure to smoke. It is conceivable that the encouraging results of the program will soon disappear if these students do not have sufficient social support for their non-smoking. Therefore, booster sessions for these high risk groups seem essential. Moreover, in order to obtain satisfactory long-term results, smoking prevention should also address the social environment of this group. One way to do this is to involve parents in smoking interventions as well, and to motivate them to quit smoking, for instance by a community approach. Another method, which does not preclude the former, is to develop more structural devices by which smoking is made less attractive. These structural devices may also provide a method of giving social support to smokers who may be considering to stop, but as yet have too little support.

As smoking prevalence is already high in vocational school students at age 13, smoking prevention should start at an earlier age, for instance at age 12 (grade one of secondary school).

Recommendations for high school students seem less clear. As the program was addressed to vocational schools, it seems reasonable to develop a social influence program, but this time targeted at the second grades or third grades of high schools, as smoking prevalence in high schools is lower than in vocational schools. However, as cognitive information processing is also stressed strongly in high schools it is possible that a more general approach, not only focusing on smoking, would have good preventive prospects as well. This program should enhance cognitive processing of information on smoking. However, when focusing on the mechanisms relevant for smoking, pupils will also realize that smoking behavior may be embedded in a larger context, together with more general themes such as decision making, problem solving etc. Therefore, such a program should also incorporate more general mechanisms of problem solving besides a training on refusal skills. 
Finally, it is important to analyze the nature of the behavioral effects (Flay et al., 1983; McCaul \& Glasgow, 1985). At this moment it is not quite clear whether the results were due to increased knowledge, attitude, or self-efficacy expectations. Analyses of these patterns were beyond the scope of this dissertation, and have not yet been completed.

\subsection{IMPORTANT DEVELOPMENTS IN SMOKING PREVENTION AND HEALTH EDUCATION}

Although the results of the smoking prevention program are promising, it is clear that a substantial proportion of the non-smokers do start to smoke. Moreover, smoking prevention programs in the U.S. have shown promising but limited results as well (Best et al., 1988). One can look at this phenomenon from several points of view. In focusing on these items we will again follow the path suggested by the planning models that have been used to develop the project.

The following questions will be considered in more detail: are the target groups well chosen; are the theories about smoking onset right in stressing the impact of peer pressure; which methodology is necessary for developing interventions; will education alone be sufficient to assure a major and long-term reduction of smoking in society; how can we enhance diffusion of successful programs; and what are the methodological problems of smoking prevention?

\subsubsection{The target group}

The results of the program strongly suggest that it is important to make different programs for different age categories. As smoking prevalence is high in vocational school students, smoking prevention should start at age 12. Smoking prevention is necessary for high school students from age 13. Although smoking prevalence in high schools is much lower than in vocational schools, some students take up smoking at age 13, and smoking prevention programs need to be developed for these groups.

Furthermore, the figures on smoking provided by the Dutch Foundation on Smoking and Health, which were presented in chapter 1, suggest a clear increase in smoking after age 16. The increase in smoking after this age may be artificial, as smoking after age 14 was assessed in a family situation. This means that adolescents were sometimes asked about smoking behavior when parents 


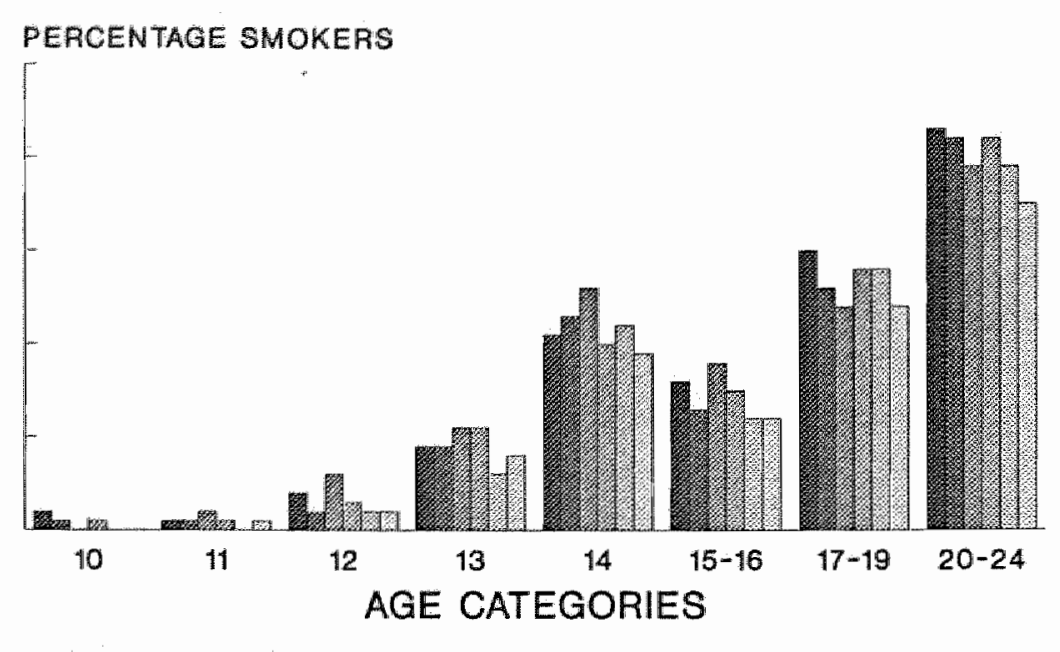

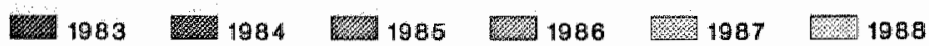

Figure 6.1: Smoking incidence in the Netherlands during 1983 to 1988 . From age 15 smoking assessments are made by means of family interviews in stead of street interviews (Dutch Foundation on Smoking and Health, 1988).

were present, or that parents were asked to report on the smoking behavior of their children. It is clear that this will result in a low reported prevalence, as can also be concluded from the "drop" in smoking prevalence after age 14 (see figure 6.1). Therefore, better and more valid methods are needed to assess smoking behavior. However, figure 6.1 also shows that smoking rises to almost $40 \%$ at age 20 . This suggests that smoking prevention activities need to be directed towards older adolescents as well. Before developing campaigns, however, it is important to assess which groups take up smoking at an older age, and what their motives are. High school students may delay their smoking onset, but may become heavy smokers later. The increase in smoking, however, may also involve both vocational and high school students.

As smoking prevention programs will not be effective for all adolescents, it is necessary to develop smoking cessation programs for smoking students. Because smoking onset occurs rapidly in vocational school students, cessation programs are needed for smoking students at age 14 or 15 .

Successful quitting seems to be related to more negative attitudes on smoking, to more direct and indirect social pressure by peers and parents enhancing non-smoking, to higher self-efficacy expectations about non-smoking, to fewer stressful events in life, and to a shorter smoking history (De Vries, 1989). It is 
not yet clear which factors are most important in predicting successful quitting for experimental and regular smokers, although some attempts to study this issue have been made (see for instance Krohn et al., 1985). More research is necessary to analyze the predictive factors of smoking cessation in adolescence. Stages of smoking cessation in adults such as those formulated by Prochaska and DiClemente (1982), discriminating between pre-contemplation, contemplation, action, maintenance, and relapse, may be applicable to regular adolescent smokers as well. Stages in the cessation process of experimental smoking may be different, and may correspond with the stages describing smoking onset which have been formulated by Leventhal \& Cleary (1980) and Flay et al. (1983). Successful adult smoking cessation methods suggest that the focus should be on increasing self-efficacy, and re-attribution training (Försterling, 1985; Schwartz, 1987). For instance, attribution training can stimulate adolescent smokers' beliefs that they can control their smoking behavior. However, we do not yet know which method will support or enhance self-initiated cessation in adolescence. A topic for further research is whether cessation programs should be incorporated within smoking prevention interventions, whether they should stand alone and be targeted towards specific populations who are at risk (for ins ance, dropouts), or whether they should also focus on the inclusion of social networks by, for instance, developing cessation interventions for smoking parents as well.

In sum, different smoking prevention programs for different types of schools and different age groups are recommended, more research is necessary to study smoking onset of older adolescents, and smoking cessation programs for adolescents are necessary.

\subsubsection{The impact of peers}

The major theme of social influence approaches is the impact of peer pressure on smoking onset. The resulting prevention method is to increase resistance and to enhance refusal skills. However, other theories on smoking onset have been developed as well. As they offer additional explanations to the onset of smoking besides the social influence approach and may enhance future research on smoking prevention they will be briefly described below.

The best known group of other explanations are referred to as the cognitive behavioral approach (Flay, 1985), as the life skills approach or as problem solving theories (Botvin, 1986). A distinguishing feature of this approach compared to the social influence approach is the emphasis on the acquisition of generic personal and social skills. Its theoretical roots are also based in social 
learning theory (Bandura, 1977), and in the problem behavior theory of Jessor and Jessor (1977). Substance abuse in general is conceptuallized as a socially learned, purposive, and functional behavior resulting from the interplay between social and personal factors. Substance abuse is learned through modeling and reinforcement, and is influenced by personal factors such as cognitions, attitudes, and beliefs. The primary distinguishing feature of this approach is that they typically include two or more of the following components: 1. general problem-solving and decision-making skills (e.g. brainstorming), 2. general cognitive skills for resisting interpersonal influences, 3. skills for increasing self-control and self-esteem, 4 . coping strategies for relieving stress, 5 . general interpersonal skills (e.g. initiating social interactions), 6. general assertive skills (e.g. saying no). The intention of programs using this prevention strategy is to teach relatively general skills for coping with life that will have a broad application.

In addition to this approach, Hirschi (1969) stresses the importance of the need for deviant behavior in adolescents to compensate for other needs which are not satisfied (e.g. school performance, attention). To compensate for this shortage some adolescents may start to smoke. Therefore, general coping skills are needed for this group. If these skills are not sufficiently developed, students look for other ways to cope with stress, such as smoking.

Smoking is also regarded as a functional behavior according to the self-perception theory. This theory states that people try to make positive impressions on others in order to obtain approval and to avoid disapproval (Bem, 1972). Koelen (1988) found that smoking adolescents go to a bar or disco more frequently, drink alcohol, listen to pop-music and wear trendy clothes more often than non-smokers. Non-smokers practice sports, wear sportswear, like going to school and do well at school more often than smokers. Intenders often had an intermediate position. Smoking, in Koelen's opinion, should be understood in the context of a larger process of adolescents who are striving to create positive opinions and obtain positive outcomes from their peer group. One way to impress the smoking peer group is to become a smoker oneself. If an adolescent assumes that he can derive satisfaction from characteristics of a particular group, he will be inclined to behave according to the groups' lifestyle. The resulting recommendations are that health education should address youngsters in their own lifestyles.

Recently, interesting results have been documented by Mosbach \& Leventhal (in press), partly supporting the need for a life skills approach for "hotshots", and at the same time providing support for the impact of self-presentation theory: adolescents will affiliate with others who are similar to themselves in attitudes and behavior. They found high smoking rates in two groups: "the 
jocks" (mostly male, macho self-confident and excitement seeking students), and the "hot-shots" (mostly female, moderately high self-esteem, successful). The authors suggested that the jocks smoke not because of a lack of skills, but because they are motivated to smoke because of the excitement. They seem unconcerned about the health implications. For hot-shots smoking was a conflicted activity: although they smoked and were frequent users of other substances, they were also strong believers that smoking is harmful, and it is suggested that they may start to smoke out of dissatisfaction, frustration, and anxiety about performance. Mosbach \& Leventhal (in press) suggest that smoking intervention programs need to address the specific social and emotional needs of individuals. For the jocks it is suggested to decrease smoking motivation by depicting smoking as a weak and infantile rather than a precocious or adult form of self-regulation. Hot-shots might benefit from the life skills approach.

Research on the life skills approach has shown promising results (Botvin \& Eng, 1982; Schinke et al., 1985), although Tobler (1986) concludes that the most promising results are for special risk groups, such as students having school problems.

In conclusion, the above-mentioned theories have in common that smoking is conceptualized as functional and purposive behavior to improve life conditions. While the problem solving theory seems to focus more on the impact of stress, the self-presentation theory seems to stress more the positive function of smoking. The strategy suggested by problem solving theory is to provide adolescents with sufficient means to cope with life. Although a clear approach has not been formulated by the self-presentation theory, a related strategy seems conceivable, such as providing adolescents with skills for seeking excitement by other means than smoking.

However, one may wonder whether the above theories have a significantly different explanation for smoking. The social influence approach stresses the impact of conformity to peer pressure. Conformity may be the result of compliance (acceptance of behavior because of external pressure), but also of acceptance (acceptation of the values and behavior of others) as a result of perceived or expected positive outcomes, such as approval from peers and belonging to a group. Although both processes are recognized, the social influence approach seems to pay most attention to the impact of direct pressure. In this sense self-perception theory does not give a new explanation, but stresses the impact of modeling influences from peers with respect to a variety of behaviors, and thus of conformity as a result of acceptance. The concept of peer pressure has been placed in a larger context. In this sense the Dutch program cannot be called 
a pure social influence approach, as it also adresses the impact of indirect pressure, the meaning of smoking, and how positive outcomes of smoking can be realized by other behaviors.

The problem solving theory suggests a new theoretical explanation and approach by stating that smoking may be the effect of conformity or stress which can be caused by a variety of factors. The resulting strategy is therefore to focus on improving skills to resist peer pressure on the one hand, and on improving self-esteem and on providing skills to cope with stress on the other hand.

In addition, as the methods for problem solving also involve the training of general skills, this method probably involves more "cognitive work" than the social influence approach. It is therefore assumed that the problem solving approach can also be used to develop a cognitive approach for high school adolescents.

In sum, the problem solving approach may have interesting features for students who show poor school performance, or who have "self-actualization" problems. In addition, this approach may also be used to develop a cognitive program for high school adolescents. More research is necessary to analyze for which groups a social influence approach or a problem solving approach will be most successful.

\subsubsection{Information processing}

In the above section it is suggested that two different approaches to smoking prevention can be formulated. The two approaches do not discuss the didactic means that can or should be utilized in programs for enhancing behavioral change. We will therefore briefly discuss the Elaboration Likelihood Model by Petty \& Cacioppo, which states that attitudinal change can be realized by two different ways: a cognitive route and a more peripheral route. This line of reasoning was expanded in chapters 3 and 4 to behavioral change in general, by including beliefs regarding subjective norms and self-efficacy.

However, the application of the theory to health education seems complicated, as it is not clear how a target group will react to the cues of the message. It is therefore not clear how a strictly cognitive or peripheral message can be developed. We therefore briefly summarize the theory and will focus on its handicaps below.

According to the theory, the extensive cognitive processing of the information will be characterized by the great attention given to arguments relevant for a persons" attitude, subjective norms, and self-efficacy expectations. This is 
called the cognitive route. Behavioral change can also occur by the peripheral route, by which change is caused by peripheral cues. In this case, a person will process a message using more simple decision rules and will focus only on, for instance, some attitude and self-efficacy beliefs. Less elaboration of all consequences of a behavior takes place, while more attention is paid to simple cues, such as the impact of attractive sources and nice materials. These cues were called affective cues in chapters 3 and 4 , as it is assumed that their impact comes from an emotional change within the receiver.

The probability of using a particular route is dependent on factors within and outside the individual. Individual or internal factors that enhance cognitive processing are internal ability factors (e.g. education level, intelligence), and internal motivational factors (e.g. a person's need for coherent cognitive structures, level of involvement with the issue, amount of responsibility or commitment to the subject). These variables can be conceptualized as the receiver variables described by McGuire (1985): the characteristics of the target group that determine behavioral change. The external factors, which also determine the possibilities of scrutinized screening of the arguments, are diverse as well. They include both message variables (e.g. the clarity of the message, the amount of repetition), channel variables (a short television commercial or a poster often does not provide much information), and source variables (e.g. if a source is perceived as incompetent and unreliable, the information will be disregarded and no cognitive processing of information will take place).

One conclusion can be that health education should consider the characteristics of the target group for program development. If the target group is not really motivated for the subject, the chances of extensive cognitive processing of information by this group will be rather low. In such a case campaigns utilizing a more affective approach may be more successful. However, Petty \& Cacioppo (1986) also state that chances of long-term behavioral change will be higher if it is induced by the cognitive route. This may suggest a two-step approach: first it is necessary to construct a message using peripheral cues, resulting in short-term behavioral change and enhanced motivation, followed by a more cognitive approach to assure enduring long-term changes. Sucli an approach may enhance the impact of health education in groups who have a low involvement with the issue (De Vries, 1988).

However, the first handicap of the theory is that it is difficult to assess which factors determine elaboration likelihood. Although Petty \& Cacioppo (1986) refer to motivation and ability as the factors determining elaboration likelihood, it is clear that motivation and ability may be caused by a wariety of individual factors that may be difficult to assess, and that may have different directions 
(e.g. what to conclude for a target group with a high need for cognitive structures, but a low level of involvement?). More research will be necessary to solve this problem.

A second handicap is that it is difficult to assess what the effect of variables in the message on the target group will be. Will cartoons serve as a peripheral cue or enhance argument processing? Petty \& Cacioppo argue that variables in the message may serve different roles, depending on the persuasion context (see Petty \& Cacioppo (1986), postulate 3). They give an example of such a situation: a highly prestigious source (e.g. a professor) may serve as a simple positive peripheral cue for a low elaboration likelihood audience. In contrast, high elaboration likelihood subjects may process this source's information as arguments (see e.g. Verplanken (1989) for more details).

In sum, the Elaboration Likelihood Model suggests that behavioral change can be the result of two different strategies. The utilization of a two-step approach may be advisable in enhancing motivation by a peripheral method first, followed by a more cognitive approach. However, the application of the theory is hindered by the fact that it is as yet unclear how for instance a strictly peripheral message should be developed, and how the target group will interpret this message.

\subsubsection{Smoking prevention: health education or health promotion}

The previous section discussed ways which could be utilized to enhance the impact of education. In this section we will discuss whether health education in schools is a sufficient means of enhancing health and smoking prevention.

Smoking prevention activities usually involve interventions at schools. The rationale for choosing schools is quite evident: it is the place where adolescents can be reached easily. However, smoking prevention programs often have a limited amount of impact time: the program usually runs a limited amount of weeks within one school year, and is sometimes followed by booster sessions. It is nonetheless evident that to obtain long-term effects, smoking prevention needs to receive more attention, for instance by embedding successful programs in a more comprehensive approach towards health (International Union Against Cancer, 1990). Moreover, certain groups, such as drop-outs and those who start smoking at a later age, are harder to reach by health education in schools.

During the last decade it has been strongly suggested that a health education approach will not have optimal effects if it is not embedded in an larger approach also incorporating more structural measures. Therefore, a health promotion approach has been advocated (see e.g. De Leeuw, 1988; Green \& 
Lewis, 1986; Milio, 1986; Perry, 1986; World Health Organization, 1986). In such an approach, an individual's health is related not only to individual factors, but also to other factors, such as economical and structural ones. We will not try to discuss the different definitions of health promotion (see e.g. De Leeuw, 1988 for an overview). However, the conceptualization of health in a broader context implies that other preventive activities for promoting health are also necessary. We will therefore briefly discuss some essential ellements of a health promotion approach.

With regard to health promotion four different relevant dimensions can be distinguished: education, legislation, type of behavior, and receiver. The first two refer to methods that can be utilized within the health promotion approach, the last two refer to the target behavior and the target group.

Health education is a frequently used tool in motivating people to change their behavior. The second method is legislation, by which certain behaviors can be prohibited or promoted by encouraging the realization of healthful behavior by structural measures and means. Examples of prohibitive or discouraging legal measures are the prohibition of driving when too much allcohol has been consumed, and price policies to increase the cost of alcohol consumption. An example of promotive structural measures is the realization of smokefree areas to promote non-smoking. The realization of both approaches involves complex planning and attuning of different organizations.

The utilization of both educational and legislative methods will enhance the impact of health promotion. Therefore, a health promotion approach is characterized by containing both methods. This combination of both methods is apparent when means to realize healthful behavior are supported by legislative actions, and promoted by educational campaigns. Moreover, combining both methods is supposed to have a synergistic effect (De Leeuw, 1988).

Furthermore, a choice has to be made whether to focus on one or on more behaviors. Health promotion may focus on one behavior (e.g. smoking), but often tries to focus on several behaviors that are detrimental to health. This usually results in a more general lifestyle approach.

The choice of the target group is the fourth dimension of interest. The rationale for focusing on one specific target group is usually a combination of different motives. It may be that a specific target group is more easily reached by a separate message (e.g. motivating pregnant women to quit smoking). The most distinct reasons probably refer to availability of time and financial resources. In community programs more general and larger populations are addressed to, such as a workplace or city. The rationale for involving a larger population is that unhealthful behavior is not restricted to a single sub-population. It is embedded in a larger framework of community norms and social 
support systems that regulate the occurrence of these behaviors. Therefore, an orientation towards a community focus and organization may help to ameliorate health problems (Perry, 1986). Examples of health promotion community programs are the North Karelia project (Puska et al., 1983), the Stanford Community Program (Farquhar et al, 1983), the Fargo-Moorhead Heart Health Program (Murray, 1986), and the STAR project (Pentz et al., 1986).

A health promotion approach utilizes both education and legislative means, and focuses on a variety of behaviors and target groups. Therefore, an intersectoral approach is necessary. Consequently, the realization of a health promotion approach becomes increasingly complex as much planning and cooperation with many sectors are needed (see e.g. Green (1986) for a discussion on large scale campaigns).

De Leeuw (1988) indicates that a health promotion approach should contain the following features. Health promotion should be: 1 . integral, meaning that all methods of intervention need to be in harmony; 2 . intersectoral, meaning that many sectors (e.g. societal, educational, economical, and governmental sectors) need to be involved; 3 . comprehensive, meaning that a lifestyle approach is recommended; 4 , action oriented, meaning that both individuals and groups need to be able to improve their health. Although De Leeuw's reference to the action oriented definition may have political consequences that are not agreed on by every person or group in society, it is a clear statement that health is a complex process resulting from many factors, and that health promotion should not focus on health education alone.

Although it seems clear that, in essence, a health promotion approach has the best chances of producing the greatest impact on health, its realization is more complex. First, if many target groups, behaviors, and methods are involved, attuning all activities will become difficult, and effective interventions may be hard to realize due to complex planning. Therefore, sufficient time for a careful planning of all activities is essential. Second, if many target groups and behaviors are involved it may become difficult to analyze and evaluate carefully the determinants of behavior and the results of interventions. Moreover, other determinants referring to factors outside the control of individuals need much attention as well.

In sum, health education and smoking prevention programs at schools constitute valid methods of improving health, and will be more easily realized than a health promotion approach. However, although much more planning, time and resources will be required, the impact of smoking prevention programs will increase if they become integrated within a larger health promotion approach. 


\subsubsection{Diffusion}

Results show that smoking prevention studies can be effective in preventing (or delaying) smoking onset. However, the impact of these programs will remain limited if these programs are not diffused and adopted by secondary schools. Unfortunately, diffusion of programs beyond the demonstration sites is often slow (Best et al., 1988; Parcel et al., 1989). Therefore, diffusion of successful programs needs more attention. Diffusion theory has been discussed in great extend by Rogers (1983), and elaborated by, for instance, Bandura (1986), Basch (1984), Best et al. (1988), Green (1986). These theories have been combined by Parcel and colleagues to study, in a recently started project, the process of diffusion of smoking prevention programs in Texas (Parcel et al., 1989). We will therefore briefly discuss some of the issues raised by theories on diffusion without pretending to be complete, as diffusion research is a growing and complex field.

Diffusion can be described as the process by which an innovation is communicated through certain channels over time among the members of a social system. These members can be individuals or organizations (e.g. schools, workplaces), and can be characterized as innovators, early adopters, early majority, late majority, or laggards, based on their (observed or expected) readiness to adopt the innovation (Rogers, 1983). Whether an innovation is perceived as needed and acceptable depends on the characteristics of the innovation, such as its relative advantage over existing practices, its compatibility with existing values, the degree of complexity, the trialability, and the degree of observability of the effects to others. Furthermore, adoption or rejection depends on the consequences of the innovation. Consequences can be classified as: desirable versus undesirable, direct versus indirect, and anticipated versus unanticipated. Other factors such as expectations, perceived availability of resources, willingness to make changes in the status quo, support and reinforcement, and self-efficacy have also been identified as factors that influence adoption of an innovation (Parcel et al., 1989).

The diffusion process can be characterised by several phases (Basch, 1984; Best et al., 1988; Green \& McAlister, 1984; Parcel et al., 1989; Rogers, 1983) starting with attention for the innovation, followed by motivation to use the innovation, and leading to adoption of the innovation and long-term utilization of the innovation (maintenance). Many studies distinguish dissemination (efforts by agencies to implement a program), adoption (the process by which initial commitment is made by potential users of the innovation), implementation (utilization of an innovation), and maintenance (long-term use of the program) as important phases in the diffusion process. 
Moreover, social learning theory can also offer a framework for designing interventions to influence diffusion in all four phases of the diffusion process (Bandura, 1986; Parcel et al., 1989). Modeling can inform potential adopters about the relative benefits and outcomes of an innovation, and can provide reinforcement for adoption.

The notions above indicate that a theoretical framework exists for studying the process of innovations. As many similarities exist with the process described by McGuire (1985), it is possible that the program matrix (see Chapter 3) can be utilized for studying diffusion as well, in order to enhance insight into, for instance, the characteristics of the target groups (receiver variables), or channel variables. With regard to the latter, the "dual-link" model proposed by Bandura (1986) is interesting, as it indicates that influential persons pick up new ideas from the media and pass them on to their followers through personal influence.

We will now focus our attention on the Dutch situation. With regard to the diffusion of the Dutch smoking prevention program, three main types of groups can be distinguished that are important in the process of adoption of smoking prevention programs: schools, public health services (Health education services, and the Dutch Foundation on Smoking and Health), and the government. This implies that it may be wise to analyze possible determinants of adoption of the program in these groups. Until now very limited information is available, and it is mostly based on general impressions on the barriers for adoption.

Health education is not mandatory for most Dutch secondary schools. Therefore, smoking prevention needs to be put on the agenda. As some schools have already asked for the smoking prevention program, there are probably early innovators who could provide an important modeling role for later adopters. However, due to the lack of financial resources of the research project, the health education departments and the schools, dissemination of the project was not feasible (an exception was made for one department, where the program was disseminated by health educators, since one of the goals was to assess the possibilities of use under "normal field conditions"; the results have been very encouraging, although no behavioral results are available yet). In other schools motivation to pay attention may be lower, due to a lack of interest for smoking prevention, lack of knowledge on the existence of a program, and competing activities. These schools will probably need to receive support from innovative schools, local health education departments, the Dutch Foundation on Smoking and Health, and the government.

As the Dutch Foundation on Smoking and Health focuses mainly on mass media campaigns, also as a result of their limited financial resources, one of the greatest problems may be to indicate to them the relative advantage of the 
smoking prevention project. Moreover, as they have not been involved in the development, their commitment to the program may not be very high. Some local health departments have shown considerable interest in being involved in disseminating the program, which has not been feasible due to lack of financial resources. However, as many departments have their own programs, and have not been involved in the development of our program, problems of relative advantage, complexity, and commitment will probably appear as well..

Similar problems may arise for the government, although smoking prevention is an important issue on their agenda. The governments "Nota 2000" formulates the goal of reducing smoking to $20 \%$ (Nota 2000, 1986). Since activities by the Dutch Foundation on Smoking and Health have not prevented an increase in smoking prevalence to $40 \%$ for adolescents aged $20-24$, realization of these goals needs to receive far more attention in order to make these goals feasible and credible. Therefore, it is recommended to include health education and smoking prevention in the curriculum of secondary schools and to provide financial resources for enhancing diffusion and implementation of successful smoking prevention programs on a larger scale.

In conclusion, theories on diffusion have been developed and can be utilized to study the process of implementation and adoption of the Dutch smoking prevention program. As many determinants of successful adoption are not yet known, research on these determinants is essential. In this sense, a study recently started by Parcel and colleagues, on the diffusion of smoking prevention programs in Texas, may provide a useful example. Moreover, it is recommended that the government should take a more active role in reinforcing smoking prevention research in order to enhance the credibility and feasibility of their goal of a reduction in smoking prevalence for the year 2000 .

\subsection{METHODOLOGICAL ISSUES}

Flays' (1985) review describes several methodological problems of smoking prevention research, such as: few schools per condition, validation of smoking behavior, no acknowledgment of pretest differences and inadequate reporting of data, no randomization, construct validity, attrition, testing by treatment interactions and Hawthorne effects. In discussing our project we will focus on these issues below.

The experimental and control groups consisted of nine and six schools respectively. Therefore, chances of confounding the programs" impact with 
schools or classrooms is unlikely. Lately, the use of schools or classrooms as units of analysis, in stead of individuals, has been strongly advocated (see e.g. Best et al., 1988), because program implementation is on the level of schools or classrooms. The main reason for advocating the school or classroom as an unit of analysis is that students behave differently in groups (classrooms) than alone. Yet, effect evaluations often utilize students' individual outcomes. However, at the start of the project, registration occurred only on an individual basis, as one of the goals of the study was to analyze the effects for different risk groups. Therefore, individuals have been used as the unit of analysis. Although the use of schools or classrooms can be recommended on statistical grounds, it also has some drawbacks. First, it often implies the inclusion of many schools or losing power because of the small number of observations. Second, too much emphasis on utilizing schools or classrooms as a unit of analysis may jeopardize innovative prevention research because of the increased costs of large sample sizes. Third, the cognitive appraisal of program information is probably also dependent on other factors than classroom association. Students also associate with other peer groups outside schools, and interact with their parents as well. In conclusion, if we want to address questions about the relationship between classroom and school characteristics and the variation in smoking onset, more research is necessary to analyze to what extend students' smoking responses are dependent on other students within the classroom or school.

Valid reports of smoking behavior have been encouraged in this study by demonstration of a video on measuring the amount of carbon monoxide during the pretest, and actual assessment in one third of the sample at each pretest and the two posttests. During these assessments, $\mathrm{CO}$ levels indicating use of cigarettes were very rare in non-smokers: sometimes one person at a test.

In analyzing the effects of the program, pretest scores were taken into account. However, another problem in this kind of research is that careful analysis of the nature of the effects requires many tests. This increases the chance of experiment-wise errors or type I errors: the likelihood that the conclusion of a significant effect was made erroneously. Therefore, the discussion of the nature of the effects of the Dutch program should take this chance into account.

Complete randomization is difficult to obtain in smoking prevention research (Flay, 1985). In our study, randomization has not been realized completely, because one of the goals was to assess the impact of the program for different types of schools. Therefore, the 15 schools were matched on the type of school. Furthermore, schools were matched on the level of urbanization, on size, and on pretest smoking. 
McCaul \& Glasgow (1985) conclude in their review that little is known about the construct validity of smoking prevention programs. They describe three reasons why assessing construct validity may be important. First, research on the construct validity will improve theory testing and development. The validity of the theoretical models can best be assessed by evaluating whether successful treatments are influencing the theoretically relevant intervening variables and whether these variables are associated with treatment outcome. Second, for generalization purposes it may be wise to know which components are the most powerful as program users do not always adopt the program in its entirety. Third, an understanding of construct validity may lead to more efficient and less costly programs. It is therefore essential to determine how the effects of programs are obtained by assessing the effects of prevention programs on process measures, such as attitudes, self-efficacy scores, and intentions.

The problem of attrition has been encountered by many smoking prevention programs (Flay et al., 1983). Attrition can be a threat to internal validity if it is differential across conditions (Flay, 1985). Fortunately, this was not the case in our study. However, external validity (the extent of generalization of the results) is always threatened. It is unclear, for instance, whether the program worked or will work for drop-outs.

The students will perceive the program and the data collection activities as related. Therefore, testing by treatment interactions are possible, and the direction of such interactions is unknown: some students may react by giving a too positive impression on, for instance, their smoking attitudes, while others may do the opposite. Moreover, testing by treatment interactions may also differ for each posttest. Finally, Hawthorne effects are possible as well, as treatment students received more attention than controls.

Although the existence of these methodological problems indicates that the results have to be viewed with a certain degree of caution, we support the conclusion of Cleary et al. (1986) that smoking prevention programs will probably always be confronted with many problems, such as high drop-out rates, which are often hard to overcome. This may result in an overly critical view of the results of smoking prevention research. On the other hand, as the follow-ups are mostly limited to only one or two years, modesty is required with respect to the overall impact of smoking prevention programs for adolescents in the long run as we cannot expect a large and enduring impact of such programs for many years. To enhance the impact of smoking prevention programs, several suggestions for future research are discussed below. 


\subsection{IMPLICATIONS FOR SMOKING PREVENTION}

The study on the determinants provided detailed information on differences between smokers and non-smokers. However, the nature of this study was cross-sectional. More detailed information on the process of smoking onset has to be obtained by longitudinal studies. The concept of social influence should be considered by assessing subjective norms, indirect pressure, and direct pressure. Moreover, future studies on the determinants should also take into account other theoretical perspectives on smoking which pay more attention to the role of the environmental context in the process of smoking onset.

As program ratings were best predicted by the assistance of the teacher and the peer leader, it is recommended to study the impact of program provider variables more thoroughly.

More research is needed to address methodological issues, such as the relationship between classroom and school characteristics and the variation in smoking onset, long-term follow-up, and tracking individuals over time (including the drop-outs).

Little is known about the construct validity of smoking prevention programs. Therefore, it is essential to determine how the effects of programs are obtained. The effects of prevention components have to be tested on process measures, such as attitudes, self-efficacy scores, and intentions.

The application of the Elaboration Likelihood Model to health education is hindered because it is insufficiently known how persons will interpret aspects within a message as a cue or as an argument. Therefore, more research on these aspects and the applicability of the model for health education is needed.

Special programs need to be developed for different subgroups. For high schools it is recommended to compare the results of a revised social influence approach with those of a more general problem solving method that has a stronger cognitive approach. For students at a high risk it is suggested to involve the social environment, as otherwise prevention programs will not have enduring results. Cessation programs for smoking adolescents need to be developed as well, starting at age 14 or 15 for vocational school students. Smoking prevention programs should address adolescents for a longer period than one or two years. Therefore, smoking prevention needs to be embedded in a health promotion context. It would be interesting to assess the impact of a smoking education program both without and within a health promotion context.

As diffusion of successful programs is essential for effective health education and promotion, diffusion studies are required to obtain more information about this process, and about methods of influencing it. 
It is strongly recommended that the Dutch government take a far more active role in enhancing smoking prevention to make the goal of a reduction of smoking prevalence to $20 \%$ in the year 2000 feasible and credible. Suggested means are, for instance, the inclusion of health education and smoking prevention in the curriculum of secondary schools, the promotion of community programs, legislative means, and, last but not least, the enhancement of a health promotion approach.

In conclusion, it is feasible to address smoking prevention utilizing a framework which stresses careful planning and evaluation. As smoking prevention is a complex area, the next challenge is to address the more complicated issues described above.

\section{REFERENCES}

Bandura, A. (1977) Self-efficacy: toward a unifying theory of behavior change. Psychological Review, 84, 191-215.

Bandura, A. (1986) Social Foundations of thought and action: a social cognitive theory. New York: Prentice-Hall.

Basch, E. (1984) Research on disseminating and implementing health education programs in schools. Journal of School Health, 54, 57-66.

Bem, D.J. (1972) Self-perception theory. In: L. Berkowitz (Ed.), Advances in Experimental Social Psychology, Vol 6 (pp. 2-57) New York: Academic Press.

Best, J.A., Thomson, S.J., Santi, S.M., Smith, E.A., Brown, K.S., (1988) Preventing cigarette smoking among school children. Annual Review of Public Health, 9, 161-201.

Botvin, G.J. (1986) Substance abuse prevention research: Recent developments and future directions. Journal of School Health, 9, 369-374.

Botvin, G.J. \& Eng, A. (1982) The efficacy of a multicomponent approach to the prevertion of cigarette smoking. Preventive Medicine, 11, 199-211.

Cleary, P.D., Hitchcock, J.L., Semmer, N., Flinchbaugh, L.J. \& Pinney, J. (1986) Smoking Behavior and Pollicy. Discussion Paper Series. Cambridge: Institute for the Study of Smoking Behavior and Policy, Harvard University.

De Leeuw, E. (1988) The sane revolution, health promotion: backgrounds, scope, prospects, Maastricht: Van Gorcum.

De Vries, H. (1988) Theorieën over voorlichting en gedragsverandering. In R.W.Meertens \& J. von Grumbkow (Eds), Sociale Psychologie [Theories about education and behavioral change; In: Social Psychology] (pp. 161-176), Groningen: Wolters-Noordhoff.

De Vries, H. (1989) Who are the successful quitters? Paper prepared for the International Union Against Cancer for the International Workshop on children and tobacco in industrialized countries, Toronto, Canada. Geneva: UICC. 
De Vries, H., Dijkstra, M. \& Kok, G.J. (1989) Self-efficacy as a determinant of the onset of smoking and interventions to prevent smoking in adolescents. Paper presented at the First European Congress of Psychology, July 1989, Amsterdam, Netherlands.

De Vries, H. \& Kok, G.J. (1986) From determinants of smoking behaviour to the implications for a prevention programme. Health Education Research, 1, 85-94.

De Vries, H. \& Kok, G.J. (1988) Prevention of Smoking in children. In D. Tamir (Ed.), Health education in schools (pp. 217-235). London: Freund Publishing House Ltd.

Evans, R.I., Rozelle, R.M., Mittelmark, M.B., Hansen, W.B., Bane, A.L. \& Havis, J. (1978) Deterring the onset of smoking in children: knowledge of immediate physiological effects and coping with peer pressure, media pressure and parent modeling. Jourmal of Applied Social Psychology, 8, 126-135.

Farquhar, J.W., Fontmann, S.P., Wood, P.D., Haskel, W.L. (1983) Community studies of cardiovascular disease prevention. In N.M. Kaplan \& J. Stamler (Eds.), Prevention of coronary heart disease: practical management of risk factors (pp. 170-181). Philadelphia: W.B.Saunders Co.

Fishbein, M. \& Ajzen, I. (1975) Belief attitude, intention and behavior: an introduction to theory and research. Reading, Mass.: Addison Wesley.

Flay, B.R. (1985) Psychosociall approaches to smoking prevention: a review of findings. Health Psychology, 4, 449-488.

Flay, B.R., D’Avernas, J.R., Best, J.A., Kersell, M.W., Ryan, K.B. (1983) Cigarette smoking: why young people do it and ways of preventing it. In P.J. Mc Grath \& P. Firestone (Eds.), Pediatric and adolescent behavioral medicine (pp. 132-183). New York: Springer.

Friedman, L.S., Lichtenstein, E., Biglan, A. (1985) Smoking onset among teens: an empirical analysis of initial situations. Addictive Behaviors, 10, 1- 13 .

Försterling, F. (1985) Attributional retraining: A review. Psychological Bulletin, 98, 495-512.

Green, L.W. (1986) Prevention and Health Education. In J.M. Last (Ed.), Prevention and health education (pp.1089-1108). Norwalk: Appleton-Century-Crofts.

Green, L.W., Kreuter, M.W., Deeds, S.G. Partridge, K.B. (1980) Health education planning; a diagnostic approach. Palo Alto: Mayfield Publishing Company.

Green, L.W. \& Lewis, F.M. (1986) Measurement and evaluation in health education and health promotion. Pallo Alto: Mayfield Publishing Company.

Green, L.W. \& McAlister, A.L. (1984) Macro-intervention to support health behavior: some theoretical perspectives and practical reflections. Health Education Quarterly, 11, 322339.

Hirschi, T. (1969) Causes of delinquency. Berkely: University of California Press.

International Union against Cancer/Union International Contre Cancer (1990) Amanual on smoking and young people for the industrialized world. A. Charlton, $\mathrm{P}$. Melia, \& C. Moyer (Eds). Geneva: IUCC.

Jessor, R., Jessor, S.L. (1977) Problem behavior and psychosocial development. New York: Academic Press.

Koelen, M.A. (1988) Tales of logic; a self-presentational view on health-related behaviour. Dissertation. Wageningen: Agricultural University.

Krohn, M.D., Skinner, W.F., Massey, J.L., Akers, R.L. (1985) Social learning theory and adolescent cigarette smoking: a longitudinal study. Social Problems, 32, 455-473.

Leventhal, H. \& Cleary, P.D. (1980) The smoking problem: a review of the research and theory in behavioral risk modification. Psychological Bulletin $, 88,370-405$. 
McCaul, K.D. \& Glasgow, R. (1985) Preventing Adolescent smoking: what have we learred about treatment construct validity? Healh Psychology, 4, 361-387.

McGuire, W. (1985) Attitudes and attitude change. In G. Lindzey \& E. Aronson (Eds.), Handbook of Sacial Psychology, Volume I, (pp. 233-246). New York: Lawrence Erlbaum Associates.

Milio, N. (1986) Multisectoral pollicy and health promotion: where to begin? Health PromorionAn International Journal, 12, 129-132.

Mosbach, P. \& Leventhal, H. Peer group identification and smoking: implications for intervention (in preparation).

Murray, D.M. (1986) Dissemination of community health promotion programs: the FargoMoorhead Heart Health Program. Journal of School Health, 56, 375-381.

Nota 2000 (1986) Gezondheid als uilgangspunt; werkorte versie Nota 2000 (Health as staringpoint; abbreviated version of Nota 2000). Den Haag: Staatsuitgeverij.

Parcel, G.S., Erikson, M.P., Lovato, C.Y., Gottlieb, N.H., Brink, S.G. \&. Green, L.W. (1989) The diffusion of school-based tobacco-use prevention programs: project description and baseline data. Health Education Research, 4, 111-124.

Pentz, M.a., Cormack, C., Flay, B.R., Hansen, W.B. \& Johnson, C.A. (1986) Balancing program and research integrity in community drug abuse prevention: project $S T A R$ approach. Journal of School Health, 56, 389-393.

Perry, C.L. (1986) Community-wide health promotion and drug abuse prevention. Journal of School Health, 56, 359-363.

Petty, R.E. \& Cacioppo, J.T. (1986) The elaboration likelihood model of persuasion. In L. Berkowitz (Ed.), Advances in Experimental Social Psychology, Vol. 19, London: Academic Press.

Puska, P., Salonen, J.T., Tuomiletho, J., Ninninen, A., Kottke, T.E. (1983) Evaluating community-based preventive cardiovascular programs: problems and experiences from the North Karelia Project. Journal of Community Health, 9, 49-64.

Prochaska, J.O. \& DiClemente, C.C. (1982) Transtheoretical therapy: Toward a more integrated model of change. Psychotherapy: Theory, Research, and Practice, 19, 276-288.

Rogers, E.M. (1983) Diffusion of innovations. New York: The Free Press.

Schinke, S.P., Gillchrist, L.D., Snow, W.H. (1985) Skills intervention to prevent cigarette smoking among adolescents. American Journal of Public Health, 76, 665-667.

Schwartz, J.L. (1987) Smoking cessation methods: The United States and Canada, 1978-1985. Bethesda, Maryland: Department of health \& human services.

Schinke, S.P., Gilchrist, L.D., Snow, W.H. (1985) Skills interwention to prevent cigarette smoking among adolescents. American Journal of Public Health, 76, 665-667.

Tobler, N.S. (1986) Meta-analysis of 143 adolescents drug prevention programs: Quantitatiwe outcome results of program participants compared to a control or comparison group. The Journal of Drug Issues, 16, 537-567.

Verplanken, B. (1989) Persuasive communications of technological risks; a test of the elabora. tion likelihood model. Dissertation, University of Leiden. Meppel: Krips Repro.

World Health Organization/EURO (1986) Health promotion Concept and Principle In Action A Policy Framework. Copenthagen: World Health Organization. 


\section{Summary}

In this dissertation the development and the evaluation of the Dutch Smoking Prevention Project from 1984 to 1989 is described.

The background of the project is outlined in chapter 1. Two planning models on health education, the PRECEDE model of Green and the applied research model of Kok, are discussed. Both models stress careful planning and evaluation of phases that are important in the process of health education. Several aspects about smoking are discussed, such as smoking prevalence in the Netherlands, and the increase of smoking to $40 \%$ at age $20-24$.

Both the social learning theory and the theory of reasoned action are described briefly as they serve as major theoretical models for this study with respect to the explanation of smoking behavior in adolescents. Furthermore, theories about the development of smoking indicate four phases in the process of smoking onset: preparation, initiation, experimentation, and regular smoking.

The history of smoking prevention and the didactic components of the programs are outlined by first discussing the new approach of Evans on smoking prevention, also referred to as the social influence approach. The innovations made to this approach by other researchers have been described briefly, such as skills training, utilization of peer leaders, active learning, repetition, commitment, and validation of self-reports. The positive behavioral effects of these programs are briefly summarized.

In Chapter 2 a study on the determinants of smoking in Dutch adolescents of 10 to 15 years is described. Non-smokers associated more health, personal, and social disadvantages with smoking than smokers, and were not convinced of the positive outcomes claimed by smokers. It is suggested that this discrepancy, however, may create a challenge in non-smokers to initiate smoking to discover which party is right with respect to these outcomes. Both smokers and nonsmokers experienced peer pressure, although this was more apparent in smoking adolescents. Both groups also perceived pressure by cigarette-industries and advertisements. Moreover, it is suggested that social influences can also be exerted indirectly.

Adolescents connected regular smoking more strongly with long-term hazards. Initial smoking was associated more with short-term disadvantages, 
but also with short-term advantages, such as satisfying curiosity. As initial smoking was not strongly associated with regular smoking, the role of initial smoking needs to receive attention in a smoking prevention program. Both smokers and non-smokers had a stronger intention to smoke in social situations, such as at parties, in discos, and when they are with friends. Therefore, these situations need special attention in a program as they indicate higher risk situations for non-smoking adolescents. Other suggestions for the development of a smoking prevention program have been formulated as well, such as reinforcement of the non-smoking attitude by stressing the short-term consequences of smoking, indicating alternative behaviors for the realization of the positive outcomes, recognition of the different patterns of social influence, and skills training.

In Chapter 3 the impact of self-efficacy as a determinant of smoking behavior is outlined. The assumption that self-efficacy would be a unique factor besides attitudes and subjective norms was confirmed. Moreover, self-efficacy had a direct effect on behavior. This is probably due to the fact that self-efficacy expectations highly reflect the actual skills students have for realizing their (non)smoking behavior. The findings also showed that non-smoking adolescents had higher self-efficacy levels than smoking adolescents.

In Chapter 4 the development of the program and the program ratings by students and teachers are reviewed. An adapted version of health planning models of Kok and Green, the $A B C$ health promotion framework, is formulated. Second, the process of behavioral change and information processing is outlined by discussing the work of McGuire and an adapted version of his matrix. This program matrix has been used for the development of the Dutch smoking prevention project. Furthermore, the development of the peer-led program on video, consisting of five lessons, has been described. The goal of the program was the prevention of regular weekly smoking in adolescents at ages 13 and 14 .

The program ratings obtained by group discussions and questionnaires indicated that teachers, peer leaders and students liked the program, the peer-led approach on video, the manuals, and the activities. Program ratings by students were best predicted by students' evaluation of the assistance by their teacher, the peer leader, the smoking status, and type of school. The target group of vocational school students liked the program significantly better than students of the high school.

In Chapter 5 the behavioral results of the program are discussed. The program did not result in significant differences between the experimental and the control group at posttest 1 , seven months after the program. However, significant differences were found at posttest 2,10 months after the program. The overall results are best understood by looking at the results for the two 
different types of school separately. The program had a preventive impact on regullar smoking for vocational school students: fewer students in the experimental than in the control group started to smoke regularly. The program had a preventive impact on experimental smoking for high school students: fewer students in the experimental group started to experiment with smoking. The results have also been analyzed by assessing the impact of the program in terms of social norm risk. The program had a preventive impact on experimental smoking for students who experienced few pressures to smoke. The program had a preventive impact on regular smoking for students who did experience pressures to smoke.

In Chapter 6 the major outcomes of the studies are reviewed. Moreover, some relatively new and important developments for smoking prevention and health education are outlined. Several conclusions can be drawn. The target group for smoking prevention should become more diversified and has to involve adolescents until age 20 , while smoking cessation activities for smokers are also needed. Smoking prevention programs also have to view the process of smoking within a larger social context. The Elaboration Likelihood Model suggests that a two-step approach may be advisable to enhance behavioral change in less involved persons. However, the application of the theory is hindered, because it is not well known how persons will interpret aspects within a message as a cue or as an argument. Diffusion of successful smoking programs is necessary and has to be stimulated. This is also essentiall to make the goal of the Dutch government on smoking reduction to $20 \%$ credible and feasible. To enhance the implementation of programs, research on the determinants of successful diffusion is needed. Finally, smoking prevention programs will probably have a greater impact when they are included in a larger health promotion framework. 


\section{Samenvatting}

Dit proefschrift beschrijft de ontwikkeling en de evaluatie van het Nederlandse Rookpreventie Projekt (ROP) gedurende de periode 1984 tot 1989.

In Hoofdstuk 1 wordt de achtergrond van het projekt nader toegelicht. Twee planningsmodellen over gezondheidsvoorlichting en -opvoeding (Gvo) worden besproken, te weten het PRECEDE-model van Green en het model voor toegepast onderzoek van Kok. Beide modellen benadrukken een zorgvuldige planning en evaluatie van de fasen die belangrijk zijn voor Gvo. Vervolgens worden verschillende aspekten over roken toegelicht, zoals de rookprevalentie in Nederland en de toename van het rookgedrag tot ongeveer $40 \%$ op 20 tot 24 -jarige leeftijd.

Zowel de sociale leertheorie als de theorie van beredeneerd gedrag worden kort beschreven, aangezien deze de belangrijkste theoretische modellen zijn voor de verklaring van rookgedrag in deze studie. Verder wordt aangegeven dat het ontstaansproces van rookgedrag in individuen kan worden onderverdeeld in vier stadia: de preparatie, de initiatie, de experimentatie, en het reguliere rookgedrag.

In het overzicht over de geschiedenis van de rookpreventie wordt allereerst het werk van Evans besproken. Zijn werk gaf de aanzet voor de ontwikkeling van de zogenaamde sociale invloed benadering voor rookpreventie in de Verenigde Staten. Toevoegingen op deze benadering zijn gemaakt door andere onderzoekers. Deze betreffen het aanieren van vaardigheden aan jongeren om sigaretten te kunnen weigeren, het gebruik van groepsleiders bij het programma (leeftijdsgenoten die een belangrijke rol vervullen tijdens de lessen), aktief leren, herhaling, commitment, en validering van de zelf-rapportages over het rookgedrag. Het blijkt dat deze rookpreventieprogramma's een preventief effekt kunnen hebben op het rookgedrag van adolescenten.

In Hoofdstuk 2 wordt een studie besproken over de determinanten van rookgedrag bij Nederlandse jongeren tussen de 10 en 15 jaar. Niet-rokende jongeren verbinden sterker allerlei gezondheids-, persoonlijke en sociale nadelen aan het roken en zijn niet overtuigd van de positieve effekten die door de rokers worden genoemd. Een veronderstelling is dat deze discrepantie kan bijdragen tot het creëren van een uitdaging voor niet-rokers om het roken toch eens uit te proberen, om zo na te gaan of er inderdaad positieve effekten zijn als 
gevolg van het roken. Zowel rokers als niet-rokers ervaren van hun leeftijdsgenoten druk om te gaan roken, hoewell deze druk sterker wordt ervaren bij de rokers. Beide groepen ervaren druk van de sigaretten-industrie en -reklame om te gaan roken. Sociale druk kan zich via twee manieren uiten: direkt en indirekt.

Jongeren koppelen aan het reguliere rookgedrag meer lange termijn nadelen. Het uitproberen (het initiêle roken) wordt meer geassocieerd met korte termijn nadelen, maar ook met korte termijn voordelen, zoals het bevredigen van de nieuwsgierigheid. Een rookpreventie programma moet aandacht besteden aan de rol van het initiële roken, daar jongeren dit niet sterk associëren met het verslaafd raken aan het roken. In sociale situaties, zoals op feestjes, in disco's en bij vrienden, overwegen rokers en niet-rokers meer om te gaan roken. Daar jongeren in deze situaties een groter risiko lopen om roker te worden, moeten deze situaties worden besproken in een rookpreventie programma. Verdere suggesties voor een programma zijn het versterken van de attitude ten aanzien van het niet-roken, door het benadrukken van de korte termijn nadelen, het aangeven van de alternatieven die er zijn om de voordelen van het roken te realiseren door middel van andere gedragingen, het herkenbaar maken van de verschillende soorten sociale druk, en vaardigheidstrainingen om sigaretten te kunnen weigeren.

In Hoofdstuk 3 wordt de rol van persoonlijke effektiviteit als een determinant van rookgedrag besproken. De assumptie, dat persoonlijke effektiviteit een unieke faktor is naast de attitude en de subjectieve norm, wordt ondersteund. Bovendien bleek dat de persoonlijke effektiviteit een direkte invloed had op het gedrag. Dit komt waarschijnlijk doordat persoonlijke effektiviteit in hoge mate overeenkomt met de daadwerkelijke vaardigheden die jongeren hebben ten aanzien van het (niet)roken. Verder blijkt dat niet-rokende jongeren een hogere persoonlijke effektiviteit hebben dan rokende jongeren.

Hoofdstuk 4 beschrijft de ontwikkeling van het programma en de beoordeling ervan door de leerlingen en leerkrachten. Een aangepaste versie van de planningsmodellen van Kok en Green, het ABC-gezondheids-planningsmodel, wordt geformuleerd. Het proces van gedragsverandering wordt aan de hand van het model van McGuire besproken. Verder wordt diens matrix aangepast tot een programma-matrix welke is gebruikt voor de ontwikkeling van het programma. De ontwikkeling van het programma, een videogestuurd programma van vijf lessen, wordt verder besproken. Het doel van dit programma was de preventie van regulier wekelijks rookgedrag bij leerlingen tussen de 13 en 14 jaar.

Het programma is geëvalueerd door groepsdiskussies en vragenlijsten met leerkrachten en leerlingen. Beide groepen gaven een positief oordeel over het programma, het videogestuurde karakter, de werkboeken en de aktiviteiten. De mening over het programma van de leerlingen werd het beste voorspeld door 
hun oordeel over de begeleiding door de leerkracht, de groepsleider, hun rookgedrag, en het schooltype. Leerlingen van het Lbo waren de belangrijkste doelgroep. Deze gaven een positiever oordeel over het programma vergeleken met leerlingen van het Mavo, Havo en Vwo.

In Hoofdstuk 5 worden de effekten van het programma besproken. $\mathrm{Bij}$ de eerste nameting, zeven maanden na het programma, waren er geen signifikante verschillen tussen de experimentele en de controle groep. Deze waren er wel bij de tweede nameting, 10 maanden na het programma. De algemene resultaten zijn het beste te interpreteren door naar de resultaten per schooltype te kijken. Het programma had een preventieve invloed op het reguliere rookgedrag bij Lbo leerlingen: minder Lbo leerlingen gingen wekelijks roken in de experimentele groep vergeleken met de controle groep. Bij leerlingen van het Mavo, Havo, en het Vwo had het programma een preventieve invloed op het experimentele rookgedrag: minder leerlingen in de experimentele groep gingen af en toe roken. Verder had het programma een preventieve invloed op het reguliere rookgedrag bij leerlingen die van hun omgeving veel druk om te roken ervaren. Bij leerlingen die weinig druk ervaren om te roken, had het programma een preventieve invloed op het experimentele rookgedrag.

In Hoofdstuk 6 worden de belangrijkste uitkomsten van de verschillende studies samengevat en besproken. Verder worden belangrijke en relatief nieuwe ontwikkelingen voor rookpreventie en Gvo besproken. Hieruit worden verscheidene konklusies getrokken. Een konklusie is dat de doelgroep voor rookpreventieprogramma's gedifferentieerder moet worden benaderd en moet worden verbreed tot adolescenten van 20 jaar. Bovendien moeten er stopprogramma's komen voor rokende jongeren. Rookpreventie programma's moeten roken ook benaderen vanuit een bredere sociale context. Het "elaboration likelihood" model suggereert dat gedragsverandering voor laag geïnvolveerde personen via een benadering in twee stappen kan plaats vinden. Echter, de toepassing van deze theorie voor Gvo wordt bemoeilijkt doordat het niet voldoende duidelijk is wanneer mensen informatie cognitief of affectief zullen interpreteren. De verspreiding en het gebruik van suksesvolle rookpreventie programma's moet worden gestimuleerd. Dit is bovendien noodzakelijk om de doelen van de Nederlandse regering over het terugbrengen van rookgedrag to $20 \%$ in het jaar 2000 geloofwaardig en haalbaar te maken. Onderzoek naar de determinanten van suksesvolle diffusie is daarom nodig. Tenslotte, de effekten van rookpreventie programma's zullen toenemen als rookpreventie plaatsvindt binnen een zogenaamde "health promotion" benadering. 


\section{Curriculum vitae}

Hein de Vries was born in Thesinge (Ten Boer) on September 15th, 1956. He visited Havo from 1968 to 1973, and Atheneum from 1973 to 1975 . He started studying psychology in 1975 in Groningen. He switched in 1981 from clinical psychology to social psychology, and graduated in 1984. During his study he was research assistant at the Polemological Institute, Traffic Research Centre, and Department of Social Psychology, University of Groningen. In September 1984 he started to work at the University of Limburg, Department of Health Education, on the development of the Dutch smoking prevention project, a project funded by the Dutch Cancer Foundation. Since January 1989 he is project-leader (also funded by the Dutch Cancer Foundation) of the ABC projects on primary cancer prevention at the same department. 